ArgOn national laboratory

\title{
Sensitivity and Representativity Analysis of Past Experiments with Respect to ABTR System
}

Nuclear Engineering Division 


\begin{abstract}
About Argonne National Laboratory
Argonne is a U.S. Department of Energy laboratory managed by UChicago Argonne, LLC under contract DE-AC02-06CH11357. The Laboratory's main facility is outside Chicago, at 9700 South Cass Avenue, Argonne, Illinois 60439. For information about Argonne, see www.anl.gov.
\end{abstract}

\title{
Availability of This Report
}

This report is available, at no cost, at http://www.osti.gov/bridge. It is also available on paper to the U.S. Department of Energy and its contractors, for a processing fee, from:

U.S. Department of Energy

Office of Scientific and Technical Information

P.O. Box 62

Oak Ridge, TN 37831-0062

phone (865) 576-8401

fax (865) 576-5728

reports@adonis.osti.gov

\begin{abstract}
Disclaimer
This report was prepared as an account of work sponsored by an agency of the United States Government. Neither the United States Government nor any agency thereof, nor UChicago Argonne, LLC, nor any of their employees or officers, makes any warranty, express or implied, or assumes any legal liability or responsibility for the accuracy, completeness, or usefulness of any information, apparatus, product, or process disclosed, or represents that its use would not infringe privately owned rights. Reference herein to any specific commercial product, process, or service by trade name, trademark, manufacturer, or otherwise, does not necessarily constitute or imply its endorsement, recommendation, or favoring by the United States Government or any agency thereof. The views and opinions of document authors expressed herein do not necessarily state or reflect those of the United States Government or any agency thereof, Argonne National Laboratory, or UChicago Argonne, LLC.
\end{abstract}




\section{Sensitivity and Representivity Analysis of Past Experiments with Respect to ABTR System}

by

G. Aliberti, G. Palmioti and M. Salvatores

Nuclear Engineering Division, Argonne National Laboratory

August 2007

work sponsored by

U. S. Department of Energy,

Office of Nuclear Energy, Science and Technology

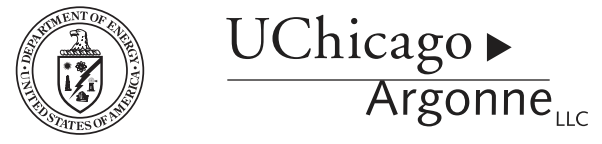





\title{
Sensitivity and Representativity Analysis of Past Experiments with Respect to ABTR System
}

\author{
G. Aliberti, G. Palmiotti, M. Salvatores \\ Nuclear Engineering Division
}

\begin{abstract}
A comprehensive validation analysis has been performed that incorporates representativity of multiple parameters, experiments, reference designs, and adjustment of the nuclear data. The work involves a new representativity study among selected reactor designs and several experiments. Application, using existing experiments, to reference design like the ABTR and the SFR has demonstrated that it is possible to achieve a significant reduction of uncertainty on the main integral parameters of interest for their neutronic design. This is possible when the set of available experiments are relevant (i.e. representative of the reference designs), of good quality (i.e. of reduced uncertainty on experimental results), and consistent (i.e. not providing conflictive information).
\end{abstract}

Results reported in the AFCI series of technical memoranda frequently are preliminary in nature and subject to revision. Consequently, they should not be quoted or referenced without the author's permission. 


\section{Table of Contents}

I. Introduction

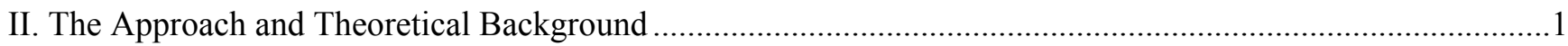

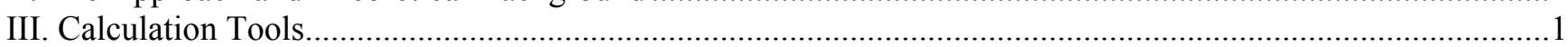

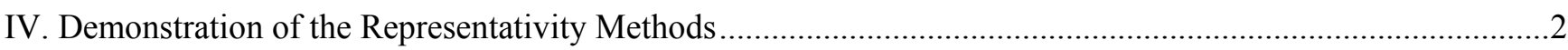

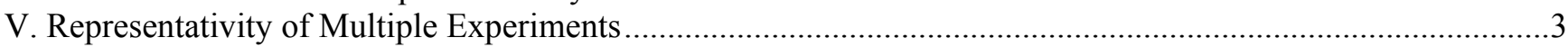

VI. Nuclear Data Validation and Fast Reactor Design Performances Uncertainty Reduction..............................6

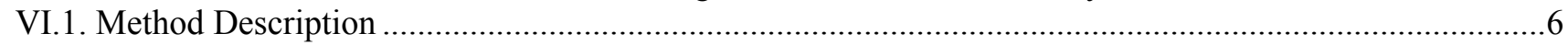

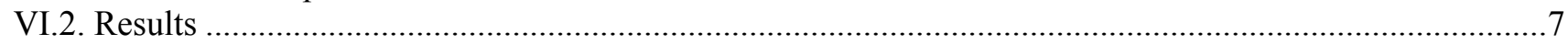

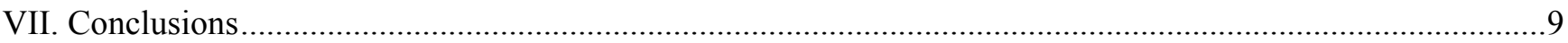

Appendix A. Uncertainty and Target Accuracy Assessment Using the Recent Covariance Data Evaluations .....10

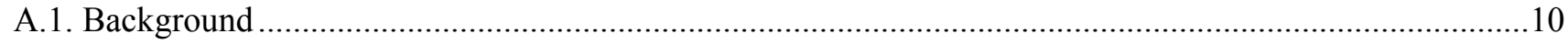

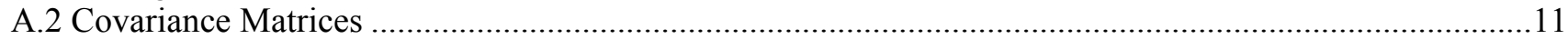

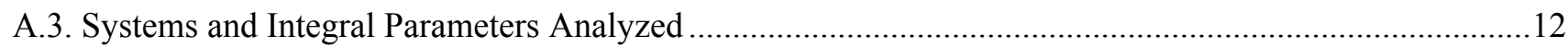

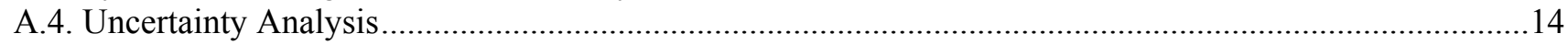

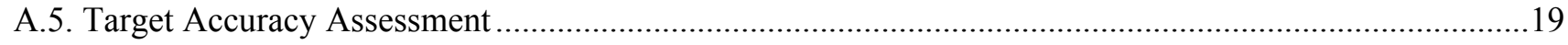

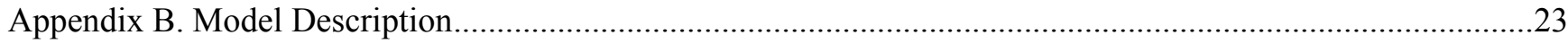

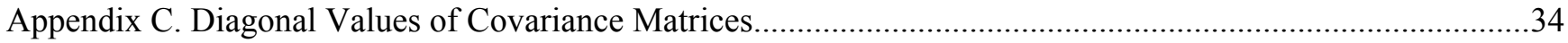

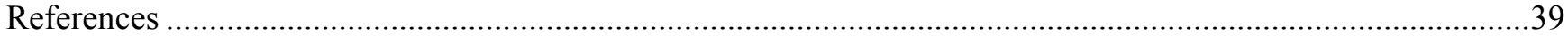




\section{List of Tables}

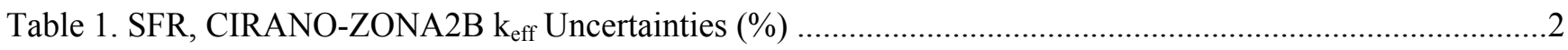

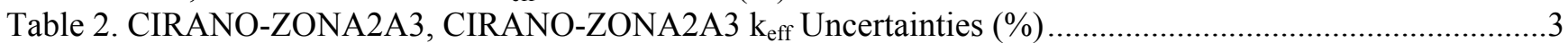

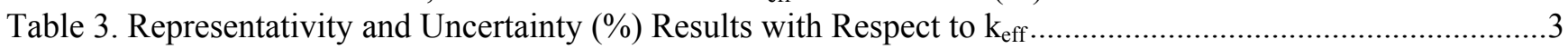

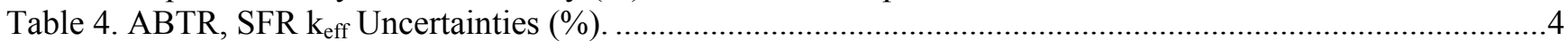

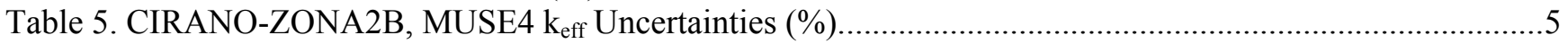

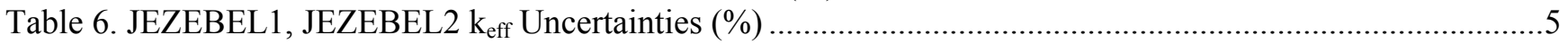

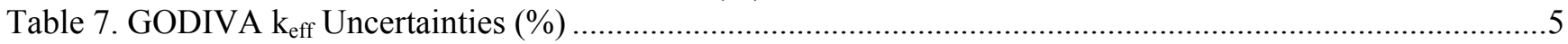

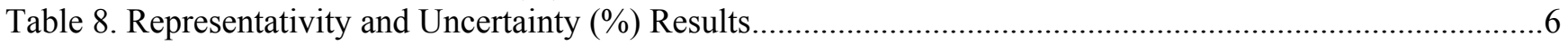

Table 9. C/E and Associated Uncertainties $(\varepsilon)$ Before and After Adjustment ....................................................8

Table 10. Covariance Values Before and After Adjustment for Selected Parameters ${ }^{\text {(a) }}$..................................... 9

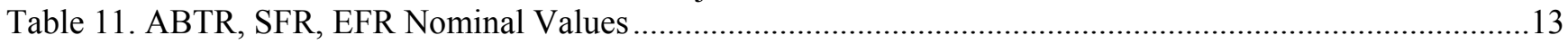

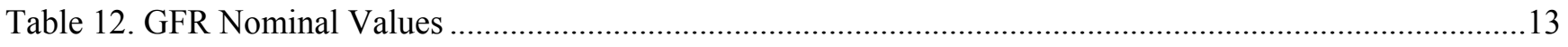

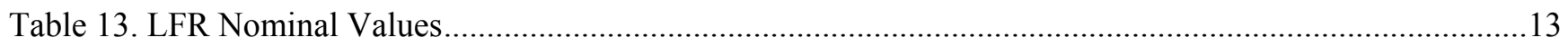

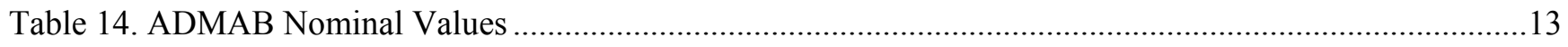

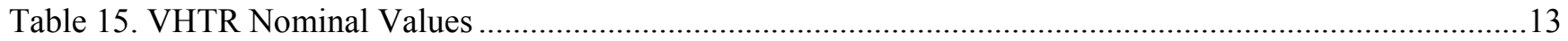

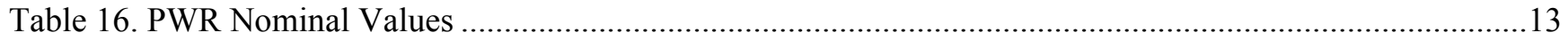

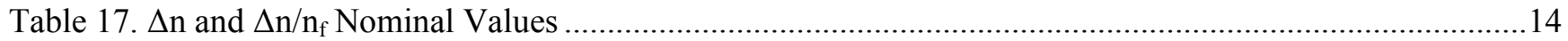

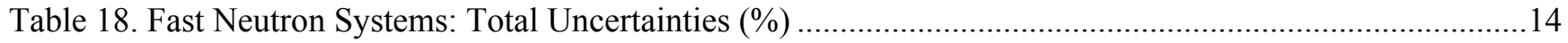

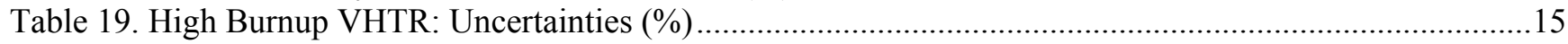

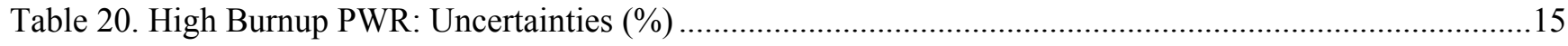

Table 21. $\Delta \rho$ Burnup Uncertainty Breakdown into Components $[\mathrm{pcm}]$.........................................................15

Table 22. Fast Reactor Systems: Uncertainties (\%) due to Pu Isotope Cross-Sections (BOLNA) .......................16

Table 23. Fast Reactor Systems: Uncertainties (\%) due to Selected MA Cross-Sections (BOLNA) ...................16

Table 24. Fast reactor Systems: Uncertainties (\%) due to Inelastic and Capture (BOLNA)..............................16

Table 25. Uncertainty (\%) on Pu Isotope Density at End of Cycle (Case of EFR) .........................................17

Table 26. Uncertainty (\%) on Selected MA Density at End of Cycle (Case of EFR) .......................................17

Table 27. Thermal systems: Uncertainties (\%) due to Selected Isotopes and Reactions (BOLNA) .....................18

Table 28. SFR $\mathrm{k}_{\mathrm{eff}}$ Uncertainties (\%). Energy Breakdown [pcm] for Selected Isotopes/Reactions .......................18

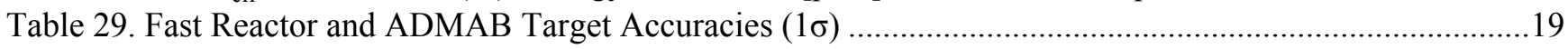

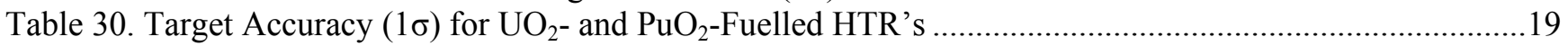

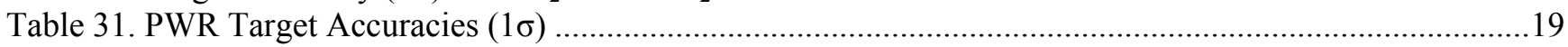

Table 32. Integral Parameter Uncertainties (\%) Using the BOLNA Diagonal Covariance Matrix ......................20

Table 33. Summary Target Accuracies for Fast Reactors ...........................................................................21

Table 34. VHTR: Uncertainty Reduction Requirements Needed to Meet Integral Parameter Target Accuracies.22

Table 35. PWR: Uncertainty Reduction Requirements Needed to Meet Integral Parameter Target Accuracies...22

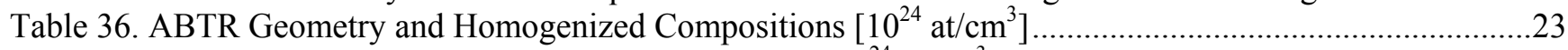

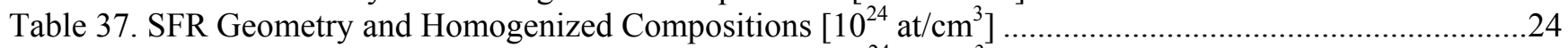

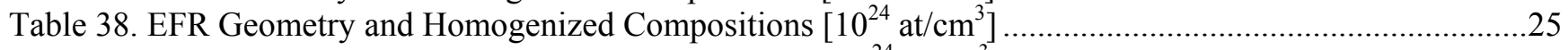

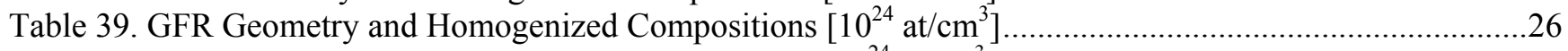

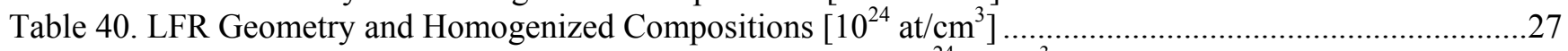

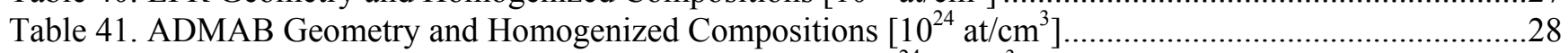

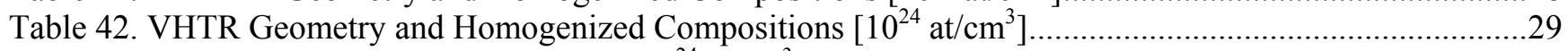

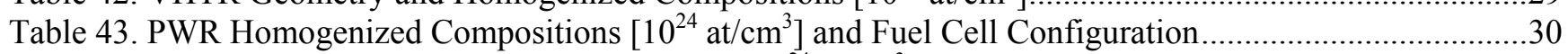

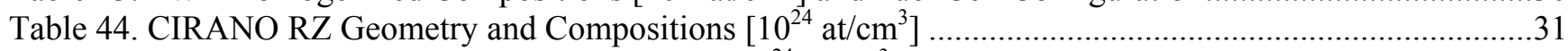

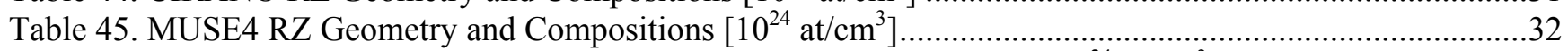

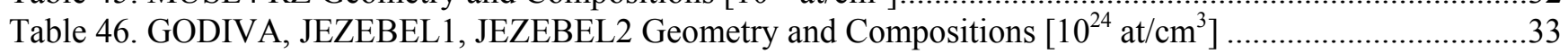

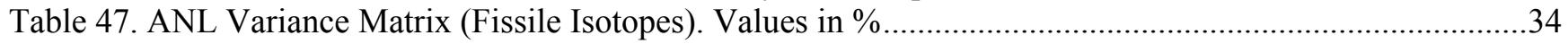

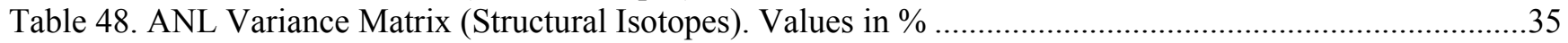

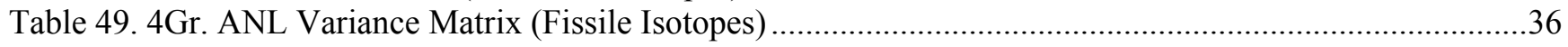

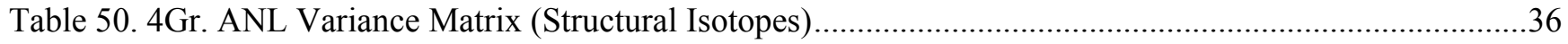

Table 51. BOLNA Variance Matrix (Fissile Isotopes): U235, U238 and Pu239 (with nu-bar corrected) from

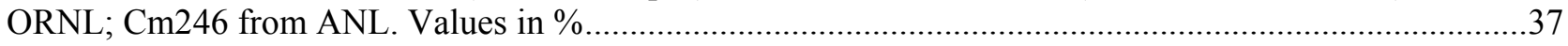


Table 52. BOLNA Variance Matrix (Structural Isotopes): Only Pb204, Pb206, Pb207, Pb208 from NRG; C, B10

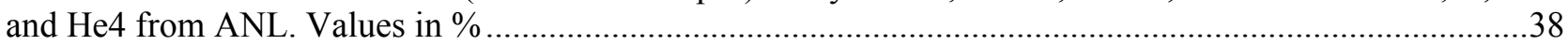




\section{Introduction}

When reliable design target accuracies and nuclear data uncertainties are available, quantitative indications can be defined on priority needs for data uncertainty reductions. Past [1,2] and present $[3,4]$ uncertainty and target accuracy assessment studies (see Appendix A) demonstrated that the nuclear data improvements, needed to meet integral parameter accuracy requirements of specific reactor designs, are often very tight and as consequence difficult to reach even with the most sophisticated measurement techniques. This conclusion suggests to pursue a complementary use of differential and integral experiments in order to meet design target accuracies.

At first, a realistic assessment of the potential role of experimental techniques at existing experimental facilities, could help to streamline and prioritize new differential measurements. This effort should be as far as possible coordinated at an international level. In parallel, the use of integral experiments should be envisaged, to provide complementary information. In fact, a powerful strategy has been developed that allows to reduce current uncertainties on design parameters, using integral experiments as much as possible "representative" of the corresponding integral parameters for the "reference" design.

\section{The Approach and Theoretical Background}

Based on the sensitivity methodology, a representativity factor $r_{R E}$ can be defined to quantify the similarity between a reactor and an experimental configuration $[5,6]$ :

$$
r_{R E}=\frac{\left(S_{I, R}^{T} D_{I, E}\right)}{\left[\left(S_{I, R}^{T} D_{I, R}\right)\left(S_{I, E}^{T} D_{I, E}\right]^{1 / 2}\right.}
$$

where $S_{I, R}$ and $S_{I, E}$ are the sensitivity coefficient vectors of the parameter I under study, for the reactor and the experiment, respectively, and $\mathrm{D}$ is the dispersion matrix containing the nuclear data covariances. The parameter $r_{R E}$ is closer to the optimum value $r_{R E}=1$ as $S_{I, R}$ and $S_{I, E}$ become similar.

The representativity factor can also be used to get an estimate of how the dispersion $\Delta \mathrm{I}_{1}^{2}$ in the calculation of an integral reactor parameter $\mathrm{I}$ is reduced, if an integral experiment $\mathrm{E}$ is performed:

$\Delta \mathrm{I}_{1}^{2}=\Delta \mathrm{I}_{0}^{2}\left(1-\mathrm{r}_{\mathrm{RE}}^{2}\right)$,

Eq. 2

where $\Delta \mathrm{I}_{0}^{2}$ is the original dispersion:

$\Delta \mathrm{I}_{0}^{2}=\mathrm{S}_{\mathrm{I}, \mathrm{R}}^{\mathrm{T}} \mathrm{DS}_{\mathrm{I}, \mathrm{R}}$.

\section{Calculation Tools}

In the present study, all the sensitivity calculations have been performed with the ERANOS code system [7,8], which allows calculating homogeneous and inhomogeneous solutions of the Boltzmann equations, generalized importance functions and performing perturbation and uncertainty analysis. The discrete ordinate module BISTRO [9] has been used to perform flux and generalized importance function calculations. An $\mathrm{S}_{4} \mathrm{P}_{1}$ approximation in RZ geometry has proved accurate enough for this type of calculation.

Cross-section data have been processed with the ECCO code [10]. The nuclear data are from the JEF2.2 [11] and JEF3.0 [12] libraries. For all the investigated reactors, homogenized cross-sections have been calculated, since heterogeneity effects on the cross-sections are rather small in the systems under study. 


\section{Demonstration of the Representativity Methods}

To investigate the performance of the methodology discussed in Section II, a representativity study was first performed between a Sodium-cooled Fast Reactor (SFR), investigated in Ref. 2, and the series of the CIRANO experimental configurations, ZONA2A, ZONA2A3 and ZONA2B [13]. Geometry and compositions are presented in Appendix B. The CIRANO specifications are recently available at ANL in the framework of a DOE/CEA agreement.

The SFR is a burner fast reactor of $840 \mathrm{MW}_{\text {th }}$ power with conversion ratio $\mathrm{CR}=0.25$. The core is loaded with $\mathrm{U}$ TRU-Zr metallic alloy fuel (enrichment: 56\%; Minor Actinides, MA: 10\%), using Na coolant. The system uses stainless-steel reflector.

The CIRANO experimental program was carried out in France in the 1990's in the frame of the studies on Puburners (rather than Pu-breeders) fast reactors, where the traditional fertile blankets are replaced by stainlesssteel reflector. The CIRANO program had three different phases:

- ZONA2A, with MOX fuel zone surrounded by axial and radial $\mathrm{UO}_{2}$ blankets;

- ZONA2A3, with MOX fuel zone surrounded by an axial $\mathrm{UO}_{2}$ blankets and a radial stainless-steel reflector;

- ZONA2B, with MOX fuel zone surrounded by axial and radial stainless-steel reflectors.

The fuel is made of mixed $\mathrm{PuO}_{2}-\mathrm{UO}_{2}$ oxide. The $\mathrm{Pu} /(\mathrm{U}+\mathrm{Pu})$ content is about $25 \%$, with about $77 \% \mathrm{Pu}-239$.

The representativity study were done with respect to the multiplication factor. Sensitivity coefficients were first obtained over a 33 group structure and then collapsed over the 15 macro-groups of the available covariance data. In this demonstrative analysis, the home-made ANL covariance matrix [14] has been used (see Appendix C for the variance data). Cross-sections have been produced with the JEF3.0 data library.

Tables 1 and 2 show the breakdown of the $\mathrm{k}_{\text {eff }}$ uncertainty components by isotope and cross-section type. As expected, the contribution from the MA cross-sections is important for the SFR, while it is practically negligible for the CIRANO configurations.

Table 1. SFR, CIRANO-ZONA2B k $\mathrm{eff}_{\mathrm{f}}$ Uncertainties (\%)

\begin{tabular}{|c|c|c|c|c|c|c|c|c|c|c|c|c|c|c|c|}
\hline \multicolumn{8}{|c|}{ SFR } & \multicolumn{8}{|c|}{ ZONA2B } \\
\hline Isotope & $\sigma_{\text {cap }}$ & $\sigma_{\text {fiss }}$ & $v$ & $\sigma_{\mathrm{el}}$ & $\sigma_{\text {inel }}$ & $\sigma_{\mathrm{n} .2 \mathrm{n}}$ & Total & Isotope & $\sigma_{\text {cap }}$ & $\sigma_{\text {fiss }}$ & $v$ & $\sigma_{\mathrm{el}}$ & $\sigma_{\text {inel }}$ & $\sigma_{\mathrm{n} .2 \mathrm{n}}$ & Total \\
\hline U235 & - & - & - & - & - & - & - & U235 & - & 0.01 & - & - & - & - & 0.01 \\
\hline U238 & 0.07 & 0.05 & 0.04 & 0.01 & 0.09 & 0.01 & 0.13 & U238 & 0.18 & 0.20 & 0.13 & 0.05 & 0.16 & 0.03 & 0.34 \\
\hline Pu238 & 0.03 & 0.22 & 0.05 & - & - & - & 0.22 & Pu239 & 0.18 & 1.02 & 0.29 & 0.01 & 0.01 & - & 1.08 \\
\hline Pu239 & 0.09 & 0.57 & 0.16 & - & 0.02 & - & 0.60 & Pu240 & 0.08 & 0.10 & 0.06 & 0.01 & 0.01 & - & 0.14 \\
\hline Pu240 & 0.20 & 0.23 & 0.14 & 0.01 & 0.03 & - & 0.33 & Pu241 & 0.01 & 0.06 & 0.01 & - & - & - & 0.06 \\
\hline Pu241 & 0.03 & 0.33 & 0.05 & - & - & - & 0.34 & Pu242 & - & 0.01 & - & - & - & - & 0.01 \\
\hline Pu242 & 0.04 & 0.13 & 0.04 & - & 0.01 & - & 0.14 & Am241 & 0.03 & 0.03 & 0.01 & - & - & - & 0.04 \\
\hline Np237 & 0.03 & 0.04 & 0.01 & - & 0.01 & - & 0.06 & Fe56 & 0.05 & - & - & 0.35 & 0.04 & - & 0.35 \\
\hline Am241 & 0.06 & 0.05 & 0.02 & - & 0.01 & - & 0.08 & Cr52 & 0.02 & - & - & 0.11 & 0.01 & 0.10 & 0.15 \\
\hline Am242m & 0.05 & 0.43 & 0.09 & - & 0.02 & - & 0.45 & Ni58 & 0.02 & - & - & 0.07 & - & - & 0.07 \\
\hline Am243 & \begin{tabular}{|l|l|} 
& 0.04 \\
\end{tabular} & 0.04 & 0.02 & - & 0.01 & - & 0.06 & $\mathrm{Na23}$ & 0.01 & - & - & 0.07 & 0.04 & - & 0.08 \\
\hline Cm242 & - & 0.02 & - & - & - & - & 0.03 & 016 & 0.05 & - & - & 0.05 & 0.01 & - & 0.07 \\
\hline $\mathrm{Cm} 243$ & - & 0.01 & - & - & - & - & 0.01 & Si28 & - & - & - & 0.01 & - & - & 0.01 \\
\hline Cm244 & 0.04 & 0.22 & 0.04 & - & 0.01 & - & 0.23 & Total & 0.28 & 1.05 & 0.32 & 0.38 & 0.17 & 0.10 & 1.21 \\
\hline Cm245 & 0.01 & 0.20 & 0.03 & - & - & - & 0.20 & & & & & & & & \\
\hline Cm246 & 0.01 & 0.02 & - & - & - & - & 0.02 & & & & & & & & \\
\hline Fe56 & 0.06 & - & - & 0.25 & 0.29 & - & 0.39 & & & & & & & & \\
\hline Cr52 & 0.01 & - & - & 0.05 & 0.02 & 0.09 & 0.10 & & & & & & & & \\
\hline Zr90 & 0.01 & - & - & 0.03 & 0.03 & - & 0.04 & & & & & & & & \\
\hline $\mathrm{Na23}$ & 0.01 & - & - & 0.03 & 0.25 & - & 0.25 & & & & & & & & \\
\hline B10 & 0.11 & - & - & 0.01 & - & - & 0.12 & & & & & & & & \\
\hline Total & 0.29 & 0.92 & 0.25 & 0.26 & 0.40 & \begin{tabular}{|l|l|}
0.09 \\
\end{tabular} & \begin{tabular}{|l|}
1.10 \\
\end{tabular} & & & & & & & & \\
\hline
\end{tabular}


Table 2. CIRANO-ZONA2A3, CIRANO-ZONA2A3 k $\mathrm{eff}_{\mathrm{ff}}$ Uncertainties (\%)

\begin{tabular}{|c|c|c|c|c|c|c|c|c|c|c|c|c|c|c|c|}
\hline \multicolumn{8}{|c|}{ ZONA2A } & \multicolumn{8}{|c|}{ ZONA2A3 } \\
\hline Isotope & $\sigma_{\text {cap }}$ & $\sigma_{\text {fiss }}$ & $v$ & $\sigma_{\mathrm{el}}$ & $\sigma_{\text {inel }}$ & $\sigma_{\mathrm{n} .2 \mathrm{n}}$ & Total & Isotope & $\sigma_{\text {cap }}$ & $\sigma_{\text {fiss }}$ & $v$ & $\sigma_{\mathrm{el}}$ & $\sigma_{\text {inel }}$ & $\sigma_{\mathrm{n} .2 \mathrm{n}}$ & Total \\
\hline U235 & - & 0.02 & - & - & - & - & \begin{tabular}{|l|}
0.02 \\
\end{tabular} & U235 & - & 0.01 & - & - & - & - & 0.01 \\
\hline U238 & 0.25 & 0.24 & 0.15 & 0.11 & 0.17 & 0.03 & \begin{tabular}{|l|l|}
0.43 \\
\end{tabular} & U238 & 0.21 & 0.22 & 0.14 & 0.08 & 0.16 & 0.03 & 0.39 \\
\hline Pu239 & 0.17 & 1.00 & 0.28 & 0.01 & 0.01 & - & 1.06 & Pu239 & 0.18 & 1.02 & 0.29 & 0.01 & 0.01 & - & 1.08 \\
\hline Pu240 & 0.08 & 0.09 & 0.05 & 0.01 & 0.01 & - & 0.13 & Pu240 & 0.08 & 0.09 & 0.06 & 0.01 & 0.01 & - & 0.14 \\
\hline Pu241 & 0.01 & 0.06 & 0.01 & - & - & - & 0.06 & Pu241 & 0.01 & 0.06 & 0.01 & - & - & - & 0.06 \\
\hline Pu242 & - & 0.01 & - & - & - & - & 0.01 & Pu242 & - & 0.01 & - & - & - & - & 0.01 \\
\hline Am241 & 0.03 & 0.03 & 0.01 & - & - & - & 0.04 & Am241 & 0.03 & 0.03 & 0.01 & - & - & - & 0.04 \\
\hline Fe56 & 0.02 & - & - & 0.12 & 0.04 & - & 0.13 & Fe56 & 0.04 & - & - & 0.24 & 0.04 & - & 0.25 \\
\hline Cr52 & 0.01 & - & - & 0.03 & 0.01 & 0.06 & 0.07 & Cr52 & 0.01 & - & - & 0.07 & 0.01 & 0.08 & 0.11 \\
\hline Ni58 & 0.02 & - & - & 0.02 & 0.01 & - & 0.03 & Ni58 & 0.02 & - & - & 0.05 & 0.01 & - & 0.05 \\
\hline $\mathrm{Na23}$ & 0.01 & - & - & 0.07 & 0.05 & - & 0.09 & $\mathrm{Na23}$ & 0.01 & - & - & 0.07 & 0.04 & - & 0.08 \\
\hline 016 & 0.05 & - & - & 0.09 & 0.01 & - & 0.11 & 016 & 0.05 & - & - & 0.07 & 0.01 & - & 0.09 \\
\hline Total & 0.32 & 1.04 & 0.33 & 0.20 & 0.18 & 0.06 & 1.17 & Total & 0.30 & 1.05 & 0.33 & 0.29 & 0.18 & 0.08 & 1.19 \\
\hline
\end{tabular}

The representativity results are summarized in Table 3 . It can be noticed that the representativity factors obtained for the SFR and each CIRANO configuration vary between 0.622 and 0.652 and are quite far from the optimal value 1 , because of the role played by the minor actinides. The higher representativity factor is obtained for the ZONA2B configuration that, like the SFR, has no blanket. Looking at the obtained reduced uncertainties, it can be concluded that based for instance on the information from the ZONA2B configuration, the total uncertainty on the SFR multiplication factor can be reduced from the initial $1.1 \%$ to $0.87 \%$. Of course, more consistent uncertainty reductions could be obtained if the selected experiments give better representativity factors.

Table 3. Representativity and Uncertainty (\%) Results with Respect to $k_{\text {eff }}$

\begin{tabular}{|c|c|c|c|}
\hline $\begin{array}{r}\text { Reactor }(\mathrm{R}) \rightarrow \\
\text { Experiment }(\mathrm{E}) \rightarrow\end{array}$ & $\begin{array}{c}\text { SFR } \\
\text { ZONA2B } \\
\end{array}$ & $\begin{array}{c}\text { SFR } \\
\text { ZONA2A } \\
\end{array}$ & $\begin{array}{c}\text { SFR } \\
\text { ZONA2A3 } \\
\end{array}$ \\
\hline Absolute Value in R: & 1.052802 & 1.052802 & 1.052802 \\
\hline Absolute Value in E: & 0.990103 & 0.998187 & 0.989193 \\
\hline Total Uncertainty in R: & 1.10 & 1.10 & 1.10 \\
\hline Total Uncertainty in E: & 1.21 & 1.17 & 1.19 \\
\hline Representativity Factor: & 0.652 & 0.622 & 0.643 \\
\hline Reduced Uncertainty in R: & 0.84 & 0.87 & 0.85 \\
\hline
\end{tabular}

\section{Representativity of Multiple Experiments}

A more comprehensive validation analysis has been performed that incorporates representativity of multiple parameters, experiments, reference designs, and adjustment of the nuclear data. The work involves a new representativity study among selected reactor designs and several experiments.

Besides the SFR, the Advanced Burner Test Reactor (ABTR) was chosen as reference reactor in view of the new GNEP initiatives [15]. On the other hand, among the several hundreds integral experiments performed in the USA that are the most relevant to the AFCI and GENIV programs, JEZEBEL (Pu239 and Pu240 configurations) [16], and GODIVA [16] have been selected. In addition, the French MUSE4 [17] and CIRANO, both available at ANL, have been also considered for assessing data and methods impact in configurations without blankets typical of transmuter designs.

A short description of the investigated systems is provided in the following, while geometry and compositions can be found in Appendix B.

- ABTR: $250 \mathrm{MW}_{\text {th }}$ - Na cooled; U-TRU-10Zr fuel; HT9(75\%)-Na(15\%) reflector; enrichment: 17\%, MA: $<1 \%$; 
- MUSE4: subcritical configurations driven by $(\mathrm{d}, \mathrm{t})$ or $(\mathrm{d}, \mathrm{d})$ sources produced at the core center by the GENEPI (Générateur de Neutrons Pulsés Intense) pulsed neutron generator. The fuel is made of mixed $\mathrm{PuO}_{2}-\mathrm{UO}_{2}$ oxide. The $\mathrm{Pu} /(\mathrm{U}+\mathrm{Pu})$ content is about $25 \%$, with about $77 \% \mathrm{Pu}-239$. The core is surrounded by $\mathrm{HT} 9(75 \%)-\mathrm{Na}(25 \%)$ reflector;

- JEZEBEL-1 and 2: bare spheres of Pu metal with different vectors;

- GODIVA: based on the experiments performed by Los Alamos National Laboratory; included with the purpose to determine the critical mass of a bare sphere of highly enriched uranium (HEU: 94 wt.\% U-235).

The final goal of the present study is to provide guidelines for a cross-section adjustment at the first stage based over a 4 energy macro-groups structure. For a more in-depth analysis, the same work could be performed in the future over a finer energy group structure.

To be consistent with this goal, sensitivity and uncertainty coefficients have been produced over a 4 energy group structure, with energy boundaries: $19.6 \mathrm{MeV}, 498 \mathrm{keV}, 67.4 \mathrm{keV}$ and $2.04 \mathrm{keV}$ down to the thermal energy. A dispersion matrix, giving the cross-section uncertainties, had to be developed on the same group structure. This matrix has been derived from the 15-group ANL covariance matrix and presented in Appendix C. Cross-sections are now produced with the JEF2.2 data library.

The representativity study has been performed with respect to the multiplication factor and the void reactivity coefficient. This last parameter has been calculated voiding the entire core or only a central zone, whose volume is arbitrarily fixed to $61500 \mathrm{~cm}^{2}(\mathrm{R}=29.5 \mathrm{~cm} ; \mathrm{H}=22.5 \mathrm{~cm})$ for each investigated system in order to minimize the leakage effects.

Tables 4 to 7 show the breakdown by isotope and cross-section type of the obtained uncertainty coefficients for the multiplication factor of each system under study.

Table 4. ABTR, SFR k $\mathrm{eff}_{\mathrm{f}}$ Uncertainties (\%).

\begin{tabular}{|c|c|c|c|c|c|c|c|c|c|c|c|c|c|c|c|}
\hline \multicolumn{8}{|c|}{ ABTR } & \multicolumn{8}{|c|}{ SFR } \\
\hline Isotope & $\sigma_{\text {cap }}$ & $\sigma_{\text {fiss }}$ & $v$ & $\sigma_{\mathrm{el}}$ & $\sigma_{\text {inel }}$ & $\sigma_{\mathrm{n} .2 \mathrm{n}}$ & Total & Isotope & $\sigma_{\text {cap }}$ & $\sigma_{\text {fiss }}$ & $v$ & $\sigma_{\mathrm{el}}$ & $\sigma_{\text {inel }}$ & $\sigma_{\mathrm{n} .2 \mathrm{n}}$ & Total \\
\hline U235 & - & 0.01 & - & - & - & - & 0.01 & U235 & - & - & - & - & - & - & 0.01 \\
\hline U238 & 0.49 & 0.36 & 0.24 & 0.09 & 0.52 & 0.02 & 0.84 & U238 & 0.12 & 0.08 & 0.06 & 0.01 & 0.19 & 0.01 & 0.25 \\
\hline Pu238 & - & 0.01 & - & - & - & - & 0.01 & Pu238 & 0.05 & 0.30 & 0.07 & - & 0.01 & - & 0.31 \\
\hline Pu239 & 0.27 & 1.63 & 0.46 & 0.02 & 0.03 & - & 1.71 & Pu239 & 0.14 & 0.85 & 0.24 & 0.01 & 0.03 & - & 0.89 \\
\hline Pu240 & 0.06 & 0.07 & 0.04 & - & 0.01 & - & 0.11 & Pu240 & 0.31 & 0.37 & 0.22 & 0.02 & 0.05 & - & 0.54 \\
\hline Pu241 & 0.01 & 0.07 & 0.01 & - & - & - & 0.07 & Pu241 & 0.05 & 0.54 & 0.07 & - & 0.01 & - & 0.54 \\
\hline Pu242 & - & 0.01 & - & - & - & - & 0.01 & Pu242 & 0.06 & 0.19 & 0.06 & 0.01 & 0.02 & - & 0.21 \\
\hline Np237 & 0.01 & 0.01 & - & - & - & - & 0.01 & Np237 & 0.05 & 0.06 & 0.02 & - & 0.02 & - & 0.08 \\
\hline Am241 & 0.01 & 0.01 & - & - & - & - & 0.01 & Am241 & 0.09 & 0.10 & 0.03 & - & 0.02 & - & 0.13 \\
\hline Fe56 & 0.07 & - & - & 0.48 & 0.35 & 0.01 & 0.60 & Am242m & 0.07 & 0.61 & 0.14 & - & 0.03 & 0.01 & 0.63 \\
\hline Cr52 & 0.01 & - & - & 0.09 & 0.04 & - & 0.10 & Am243 & 0.08 & 0.06 & 0.03 & - & 0.08 & - & 0.13 \\
\hline Ni58 & - & - & - & 0.01 & - & - & 0.01 & Cm242 & 0.01 & 0.03 & 0.01 & - & - & - & 0.03 \\
\hline Zr90 & 0.02 & - & - & 0.07 & 0.04 & - & 0.08 & Cm243 & - & 0.01 & - & - & - & - & 0.01 \\
\hline $\mathbf{N a}$ & 0.01 & - & - & 0.06 & 0.16 & - & 0.17 & Cm244 & 0.07 & 0.35 & 0.06 & - & 0.01 & - & 0.36 \\
\hline B10 & 0.04 & - & - & - & - & - & 0.04 & Cm245 & 0.01 & 0.33 & 0.05 & - & - & - & 0.33 \\
\hline Total & 0.57 & 1.67 & 0.52 & 0.51 & 0.65 & 0.02 & 2.02 & Cm246 & - & 0.04 & 0.01 & - & - & - & 0.04 \\
\hline & & & & & & & & Fe56 & 0.10 & - & - & 0.42 & 0.70 & 0.03 & 0.82 \\
\hline & & & & & & & & Cr52 & 0.01 & - & - & 0.08 & 0.07 & - & 0.11 \\
\hline & & & & & & & & Ni58 & - & - & - & 0.01 & - & - & 0.01 \\
\hline & & & & & & & & $\mathbf{N a}$ & 0.01 & - & - & 0.02 & 0.41 & - & 0.41 \\
\hline & & & & & & & & B10 & 0.17 & - & - & 0.01 & - & - & 0.17 \\
\hline & & & & & & & & Total & 0.45 & 1.38 & 0.39 & 0.43 & 0.84 & 0.03 & 1.77 \\
\hline
\end{tabular}


Table 5. CIRANO-ZONA2B, MUSE4 $\mathrm{k}_{\mathrm{eff}}$ Uncertainties (\%).

\begin{tabular}{|c|c|c|c|c|c|c|c|c|c|c|c|c|c|c|c|}
\hline \multicolumn{8}{|c|}{ CIRANO - ZONA2B } & \multicolumn{8}{|c|}{ MUSE4 } \\
\hline Isotope & $\sigma_{\text {cap }}$ & $\sigma_{\text {fiss }}$ & $v$ & $\sigma_{\mathrm{el}}$ & $\sigma_{\text {inel }}$ & $\sigma_{\mathrm{n} .2 \mathrm{n}}$ & Total & Isotope & $\sigma_{\text {cap }}$ & $\sigma_{\text {fiss }}$ & $v$ & $\sigma_{\mathrm{el}}$ & $\sigma_{\text {inel }}$ & $\sigma_{\mathrm{n} .2 \mathrm{n}}$ & Total \\
\hline U235 & - & 0.01 & - & - & - & - & \begin{tabular}{|l|}
0.01 \\
\end{tabular} & U235 & - & 0.01 & - & - & - & 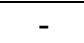 & 0.01 \\
\hline U238 & 0.34 & 0.31 & 0.19 & \begin{tabular}{|l|}
0.06 \\
\end{tabular} & 0.27 & 0.02 & \begin{tabular}{|l|}
0.57 \\
\end{tabular} & U238 & 0.35 & 0.30 & 0.19 & 0.05 & 0.30 & 0.02 & 0.58 \\
\hline Pu239 & 0.28 & 1.53 & 0.43 & 0.02 & 0.03 & 0.01 & 1.62 & Pu238 & - & 0.01 & - & - & - & - & 0.01 \\
\hline Pu240 & 0.13 & 0.16 & 0.09 & 0.01 & 0.01 & - & \begin{tabular}{|l|}
0.23 \\
\end{tabular} & Pu239 & 0.28 & 1.52 & 0.43 & 0.01 & 0.03 & 0.01 & 1.60 \\
\hline Pu241 & 0.01 & 0.10 & 0.01 & - & - & - & 0.10 & Pu240 & 0.13 & 0.16 & 0.09 & 0.01 & 0.01 & - & 0.23 \\
\hline Pu242 & - & 0.01 & - & - & - & - & 0.01 & Pu241 & 0.01 & 0.07 & 0.01 & - & - & - & 0.07 \\
\hline Am241 & 0.04 & \begin{tabular}{|l|}
0.05 \\
\end{tabular} & 0.01 & - & - & - & 0.07 & Pu242 & - & 0.01 & - & - & - & - & 0.01 \\
\hline Fe56 & 0.08 & - & - & 0.65 & 0.05 & 0.01 & \begin{tabular}{|l|}
0.66 \\
\end{tabular} & Am241 & 0.05 & 0.06 & 0.02 & - & 0.01 & - & 0.08 \\
\hline Cr52 & 0.02 & - & - & \begin{tabular}{|l|}
0.17 \\
\end{tabular} & 0.02 & - & \begin{tabular}{|l|l|}
0.17 \\
\end{tabular} & Fe56 & 0.07 & - & - & 0.61 & 0.06 & - & 0.62 \\
\hline Ni58 & 0.03 & - & - & 0.11 & 0.01 & - & 0.11 & Cr52 & 0.02 & - & - & 0.16 & 0.02 & - & 0.17 \\
\hline $\mathbf{N a}$ & 0.01 & - & - & 0.08 & 0.10 & - & 0.13 & Ni58 & 0.03 & - & - & 0.10 & 0.01 & - & 0.10 \\
\hline $\mathbf{O}$ & 0.06 & - & - & 0.06 & 0.01 & - & 0.08 & $\mathbf{N a}$ & 0.01 & - & - & 0.07 & 0.13 & - & 0.15 \\
\hline $\mathbf{S i}$ & - & - & - & 0.01 & - & - & 0.01 & $\mathbf{O}$ & 0.06 & - & - & 0.04 & 0.01 & - & 0.07 \\
\hline B10 & 0.01 & - & - & - & - & - & \begin{tabular}{|l|}
0.01 \\
\end{tabular} & $\mathbf{S i}$ & - & - & - & 0.01 & - & - & 0.01 \\
\hline Total & 0.48 & \begin{tabular}{|l|}
1.58 \\
\end{tabular} & 0.49 & 0.69 & 0.29 & (0.03 & \begin{tabular}{|l|}
1.87 \\
\end{tabular} & $\mathbf{P b}$ & 0.01 & - & - & 0.03 & 0.05 & 0.01 & 0.06 \\
\hline & & & & & & & & Total & 0.48 & 1.56 & 0.48 & 0.65 & 0.34 & 0.02 & 1.85 \\
\hline
\end{tabular}

Table 6. JEZEBEL1, JEZEBEL2 $\mathrm{k}_{\text {eff }}$ Uncertainties (\%)

\begin{tabular}{||c|c|c|c|c|c|c|c||c|c|c|c|c|c|c|c||}
\hline \multicolumn{10}{|c|}{ JEZEBEL1 } & \multicolumn{10}{|c|}{ JEZEBEL2 } \\
\hline Isotope & $\boldsymbol{\sigma}_{\text {cap }}$ & $\boldsymbol{\sigma}_{\text {fiss }}$ & $\boldsymbol{v}$ & $\boldsymbol{\sigma}_{\text {el }}$ & $\boldsymbol{\sigma}_{\text {inel }}$ & $\boldsymbol{\sigma}_{\text {n.2n }}$ & Total & Isotope & $\boldsymbol{\sigma}_{\text {cap }}$ & $\boldsymbol{\sigma}_{\text {fiss }}$ & $\boldsymbol{v}$ & $\boldsymbol{\sigma}_{\text {el }}$ & $\boldsymbol{\sigma}_{\text {inel }}$ & $\boldsymbol{\sigma}_{\text {n.2n }}$ & Total \\
\hline Pu239 & 0.11 & 3.11 & 0.82 & 0.23 & 0.34 & 0.05 & $\mathbf{3 . 2 4}$ & Pu239 & 0.09 & 2.73 & 0.71 & 0.19 & 0.23 & 0.04 & $\mathbf{2 . 8 4}$ \\
\hline Pu240 & 0.01 & 0.12 & 0.06 & 0.03 & 0.02 & - & $\mathbf{0 . 1 4}$ & Pu240 & 0.04 & 0.56 & 0.30 & 0.14 & 0.09 & 0.01 & $\mathbf{0 . 6 6}$ \\
\hline Pu241 & - & 0.03 & - & - & - & - & $\mathbf{0 . 0 3}$ & Pu241 & 0.01 & 0.30 & 0.03 & 0.02 & 0.01 & 0.01 & $\mathbf{0 . 3 0}$ \\
\hline Total & $\mathbf{0 . 1 1}$ & $\mathbf{3 . 1 1}$ & $\mathbf{0 . 8 2}$ & $\mathbf{0 . 2 3}$ & $\mathbf{0 . 3 4}$ & $\mathbf{0 . 0 5}$ & $\mathbf{3 . 2 4}$ & Pu242 & - & 0.02 & - & - & - & - & $\mathbf{0 . 0 2}$ \\
\hline
\end{tabular}

Table 7. GODIVA k $\mathrm{eff}_{\text {Uncertainties (\%) }}$

\begin{tabular}{|c|c|c|c|c|c|c|c|}
\hline \multicolumn{10}{|c|}{ GODIVA } \\
\hline Isotope & $\boldsymbol{\sigma}_{\text {cap }}$ & $\boldsymbol{\sigma}_{\text {fiss }}$ & $\boldsymbol{v}$ & $\boldsymbol{\sigma}_{\text {el }}$ & $\boldsymbol{\sigma}_{\text {inel }}$ & $\boldsymbol{\sigma}_{\text {n.2n }}$ & Total \\
\hline U235 & 0.39 & 2.53 & 0.74 & 0.35 & 0.84 & 0.10 & $\mathbf{2 . 8 1}$ \\
\hline U238 & 0.01 & 0.03 & 0.02 & 0.02 & 0.08 & - & $\mathbf{0 . 0 9}$ \\
\hline Total & $\mathbf{0 . 3 9}$ & $\mathbf{2 . 5 3}$ & $\mathbf{0 . 7 4}$ & $\mathbf{0 . 3 5}$ & $\mathbf{0 . 8 4}$ & $\mathbf{0 . 1 0}$ & $\mathbf{2 . 8 2}$ \\
\hline
\end{tabular}

The representativity factors are presented in Table 8 (absolute values and reduced uncertainties are summarized in the same table). It is observed that CIRANO and MUSE4 show quite good representativity factors with respect to the ABTR reactor, while the similarity with the SFR decreases because of the important role played by the minor actinides. 
Table 8. Representativity and Uncertainty (\%) Results

\begin{tabular}{|c|c|c|c|c|c|c|}
\hline $\begin{array}{l}\mathbf{R}=\rightarrow \\
\mathbf{E}=\rightarrow\end{array}$ & \begin{tabular}{|c|} 
ABTR \\
JEZEBEL1
\end{tabular} & \begin{tabular}{|c|} 
SFR \\
JEZEBEL1
\end{tabular} & \begin{tabular}{|c} 
ABTR \\
JEZEBEL2
\end{tabular} & \begin{tabular}{|c|} 
SFR \\
JEZEBEL2
\end{tabular} & $\begin{array}{c}\text { ABTR } \\
\text { GODIVA }\end{array}$ & $\begin{array}{c}\text { SFR } \\
\text { GODIVA }\end{array}$ \\
\hline Integral Parameter & \multicolumn{2}{|c|}{$\mathbf{k}_{\text {eff }}$} & \multicolumn{2}{|c|}{\begin{tabular}{|l|}
$\mathbf{k}_{\text {eff }}$ \\
\end{tabular}} & \multicolumn{2}{|c|}{$\mathbf{k}_{\text {eff }}$} \\
\hline Absolute Value in R: & 1.036694 & 1.007617 & 1.036694 & 1.007617 & 1.036694 & 1.007617 \\
\hline Absolute Value in E: & 0.947881 & 0.947881 & 0.916852 & 0.916852 & 0.962011 & 0.962011 \\
\hline Total Uncertainty in R: & 2.02 & 1.77 & 2.02 & 1.77 & 2.02 & 1.77 \\
\hline Total Uncertainty in E: & 3.24 & 3.24 & 2.93 & 2.93 & 2.82 & 2.82 \\
\hline Representativity factor: & 0.536 & 0.328 & 0.538 & 0.386 & $-3.161 \mathrm{E}-4$ & $-5.482 \mathrm{E}-4$ \\
\hline Reduced Uncertainty in R: & 1.70 & 1.68 & 1.70 & 1.64 & 2.02 & 1.77 \\
\hline $\begin{aligned} & \mathbf{R}=\rightarrow \\
& \mathbf{E}=\rightarrow \\
&\end{aligned}$ & $\begin{array}{c}\text { ABTR } \\
\text { ZONA2B } \\
\end{array}$ & $\begin{array}{c}\text { SFR } \\
\text { ZONA2B } \\
\end{array}$ & $\begin{array}{c}\text { ABTR } \\
\text { MUSE4 } \\
\end{array}$ & $\begin{array}{c}\text { SFR } \\
\text { MUSE4 } \\
\end{array}$ & & \\
\hline Integral Parameter & \multicolumn{2}{|c|}{$\mathbf{k}_{\text {eff }}$} & \multicolumn{2}{|c|}{$\mathbf{k}_{\text {eff }}$} & & \\
\hline Absolute Value in R: & 1.036694 & 1.007617 & 1.036694 & 1.007617 & & \\
\hline Absolute Value in E: & 0.992808 & 0.992808 & 1.001496 & 1.001496 & & \\
\hline Total Uncertainty in R: & 2.02 & 1.77 & 2.02 & 1.77 & & \\
\hline Total Uncertainty in E: & 1.87 & 1.87 & 1.85 & 1.85 & & \\
\hline Representativity factor: & 0.952 & 0.637 & 0.957 & 0.639 & & \\
\hline Reduced Uncertainty in R: & 0.62 & 1.37 & 0.59 & 1.37 & & \\
\hline Integral Parameter & \multicolumn{2}{|c|}{ Void Core } & \multicolumn{2}{|c|}{ Void Core } & & \\
\hline Absolute Value in R: & $173.7 \mathrm{pcm}$ & $2141 \mathrm{pcm}$ & $173.7 \mathrm{pcm}$ & $2141 \mathrm{pcm}$ & & \\
\hline Absolute Value in E: & $-1194.6 \mathrm{pcm}$ & $-1194.6 \mathrm{pcm}$ & $-1148.3 \mathrm{pcm}$ & $-1148.3 \mathrm{pcm}$ & & \\
\hline Total Uncertainty in R: & 143.67 & 23.31 & 143.67 & 23.31 & & \\
\hline Total Uncertainty in E: & 23.15 & 23.15 & 25.08 & 25.08 & & \\
\hline Representativity factor: & -0.881 & -0.633 & -0.903 & -0.685 & & \\
\hline Reduced Uncertainty in R: & 67.95 & 18.04 & 61.70 & 16.97 & & \\
\hline Integral Parameter & \multicolumn{2}{|c|}{ Void Center Core } & \multicolumn{2}{|c|}{ Void Center Core } & & \\
\hline Absolute Value in R: & $284.3 \mathrm{pcm}$ & $136.9 \mathrm{pcm}$ & $284.3 \mathrm{pcm}$ & $136.9 \mathrm{pcm}$ & & \\
\hline Absolute Value in E: & $184.2 \mathrm{pcm}$ & $184.2 \mathrm{pcm}$ & $133.4 \mathrm{pcm}$ & $133.4 \mathrm{pcm}$ & & \\
\hline Total Uncertainty in R: & 60.23 & 300.51 & 60.23 & 300.51 & & \\
\hline Total Uncertainty in E: & 76.17 & 76.17 & 115.18 & 115.18 & & \\
\hline Representativity factor: & 0.920 & 0.749 & 0.971 & 0.854 & & \\
\hline Reduced Uncertainty in R: & 23.66 & 199.19 & 14.29 & 156.55 & & \\
\hline
\end{tabular}

\section{Nuclear Data Validation and Fast Reactor Design Performances Uncertainty Reduction}

As already discussed in Section V, uncertainty and sensitivity analysis can be used to effectively combine nuclear data covariance information, integral experiments, their "representativity" [18] and their associated experimental uncertainties in order to reduce a priori uncertainties on performance parameters (like $\mathrm{k}_{\mathrm{eff}}$ or reactivity coefficients) that characterize a reference design configuration. Several approaches (usually called "bias factor" methods, see e.g. Refs. 19 to 22) have been attempted. In the present work, a general and consistent method has been defined and an application has been performed to show relevant features of the uncertainty reduction process.

\section{VI.1. Method Description}

Denoting $B_{p}$ the "a priori" nuclear data covariance matrix, $S_{B}$ the sensitivity matrix of the performance parameters $\mathrm{B}\left(\mathrm{B}=1 \ldots \ldots \mathrm{B}_{\mathrm{TOT}}\right)$ to the $\mathrm{J}$ nuclear data, the "a priori" covariance matrix of the performance parameters is given by:

$\mathrm{B}_{\mathrm{B}}=\mathrm{S}_{\mathrm{B}} \mathrm{B}_{\mathrm{p}} \mathrm{S}_{\mathrm{B}}^{\mathrm{T}}$

Eq. 4 
It can be shown that, using a set of $\mathrm{N}$ integral experiments $\mathrm{A}$, characterized by a sensitivity matrix $\mathrm{S}_{\mathrm{A}}$, besides a set of statistically adjusted cross-section data, a new (“a posteriori”) covariance matrix $\widetilde{B}_{p}$ can be obtained (see e.g. Ref. 23):

$$
\widetilde{B}_{\mathrm{p}}=\mathrm{B}_{\mathrm{p}}-\mathrm{B}_{\mathrm{p}} \mathrm{S}_{\mathrm{A}}^{\mathrm{T}}\left(\mathrm{S}_{\mathrm{A}} \mathrm{B}_{\mathrm{p}} \mathrm{S}_{\mathrm{A}}^{\mathrm{T}}+\mathrm{B}_{\mathrm{A}}\right)^{-1} \mathrm{~S}_{\mathrm{A}} \mathrm{B}_{\mathrm{p}}
$$

where $B_{A}$ is the integral experiment uncertainty matrix. In the case of $N$ experiments $(n=1 \ldots N)$ :

$$
\mathrm{B}_{\mathrm{A}}=\left|\begin{array}{llll}
\mathrm{b}_{11} & \mathrm{~b}_{12} & \cdots & \mathrm{b}_{1 \mathrm{~N}} \\
\mathrm{~b}_{21} & \mathrm{~b}_{22} & & \\
\vdots & & \ddots & \\
\mathrm{b}_{\mathrm{N} 1} & & & \mathrm{~b}_{\mathrm{NN}}
\end{array}\right|
$$

$\left(b_{n n}\right.$ are the experimental uncertainties of each experiment $n$ ) and $S_{A}$ is the sensitivity matrix of the $\mathrm{N}$ experiments to the $\mathrm{J}$ nuclear parameters (cross-sections by energy group, isotope, and reaction type):

$$
\mathrm{S}_{\mathrm{A}}=\left|\begin{array}{llll}
\mathrm{s}_{11} & \mathrm{~s}_{12} & \cdots & \mathrm{s}_{1 \mathrm{~J}} \\
\mathrm{~s}_{21} & \mathrm{~s}_{22} & & \\
\vdots & & \ddots & \\
\mathrm{s}_{\mathrm{N} 1} & & & \mathrm{~s}_{\mathrm{NJ}}
\end{array}\right|
$$

This matrix can then be used to define a new ("a posteriori") covariance matrix $\widetilde{B}_{B}$ for the performance parameters:

$$
\begin{aligned}
& \widetilde{B}_{B}=S_{B} \widetilde{B}_{p} S_{B}^{T}=\left\{B_{B}-S_{B} B_{p} S_{A}^{T}\left(S_{A} B_{p} S_{A}^{T}+B_{A}\right)^{-1} S_{A} B_{p} S_{B}^{T}\right\}= \\
& =B_{B}\left\{1-\left(S_{B} B_{p} S_{B}^{T}\right)^{-1}\left(S_{A} B_{p} S_{A}^{T}+B_{A}\right)^{-1}\left(S_{A} B_{p} S_{B}^{T}\right)^{2}\right\}
\end{aligned}
$$

If only one performance parameter B and only one experiment " $\mathrm{n}$ " is considered, and if $\mathrm{B}_{\mathrm{A}}=0$, from Eq. 8 the expression of the "representativity" for only one integral experiment can be derived as defined in Ref. 6 :

$$
r_{n B}=\frac{\left(S_{B} B_{p} S_{n}^{T}\right)}{\left[\left(S_{n} B_{p} S_{n}^{T}\right)\left(S_{B} B_{p} S_{B}^{T}\right)\right]^{1 / 2}}
$$

Then, Eq. 8 can be considered as a generalized expression for the reference parameter uncertainty reduction as given in Ref. 6. This generalized expression accounts for more than one experiment and allows estimating the impact of any new experiment in the reduction of the "a priori" uncertainty of the design performance parameters.

\section{VI.2. Results}

The method described above has been used to evaluate the potential for reduction of "a priori" uncertainties associated to two reference systems, namely the Advanced Burner Test Reactor (ABTR) as introduced in Section $\mathrm{V}$ and the Sodium-cooled Fast Reactor (SFR) burner, as introduced in Section IV, using a series of existing high accuracy integral experiments. "A priori" uncertainties on selected integral parameters $B$ ( $\mathrm{k}_{\text {eff }}$ and the sodium void reactivity coefficient at core center) have been evaluated for both systems, using basic nuclear data uncertainties and correlations consistent with the those defined in Ref. 2. 
A set of 42 integral experiments [24] has been considered. The initial C/E values and experimental uncertainties $\varepsilon$ are given in Table 9. In the same table, the "a posteriori" $\mathrm{C}^{\prime} / \mathrm{E}$ and $\varepsilon^{\prime}$ values (i.e. after the statistical crosssection adjustment), are also shown.

Table 9. $\mathrm{C} / \mathrm{E}$ and Associated Uncertainties $(\varepsilon)$ Before and After Adjustment

\begin{tabular}{|c|c|c|c|c|c|}
\hline Type of Experiment & old $\mathrm{C} / \mathbf{E} \pm \varepsilon$ & new $C / E \pm \varepsilon$ & Type of Experiment & old $\mathbf{C} / \mathbf{E} \pm \boldsymbol{\varepsilon}$ & new $C / E \pm \varepsilon$ \\
\hline $\begin{array}{c}\text { U235/U236 } \\
\text { PROFIL1 }^{\text {(a) }}\end{array}$ & $0.942 \pm 0.020$ & $1.004 \pm 0.011$ & $\begin{array}{c}\text { Cm242 } \\
\text { TRAPU1 }^{(b)}\end{array}$ & $1.020 \pm 0.031$ & $1.037 \pm 0.013$ \\
\hline $\begin{array}{l}\text { U238/Pu239 } \\
\text { PROFIL1 }^{\text {(a) }}\end{array}$ & $0.993 \pm 0.023$ & $1.004 \pm 0.016$ & $\begin{array}{c}\text { Cm243 }^{(b)} \\
\text { TRAPU2 }^{(b)}\end{array}$ & $0.750 \pm 0.031$ & $1.007 \pm 0.031$ \\
\hline $\begin{array}{l}\text { Pu238/Pu239 } \\
\text { PROFIL2 }^{\text {(a) }} \\
\end{array}$ & $0.988 \pm 0.040$ & $0.997 \pm 0.033$ & $\begin{array}{c}\text { Cm244 } \\
\text { TRAPU2 }^{(b)} \\
\end{array}$ & $1.120 \pm 0.023$ & $1.004 \pm 0.02$ \\
\hline $\begin{array}{l}\text { Pu239/Pu238 } \\
\text { PROFIL1 }^{(a)}\end{array}$ & $0.641 \pm 0.150$ & $1.014 \pm 0.148$ & $\begin{array}{c}\text { U238 Fission Rate } \\
\text { MUSE }^{(c)}\end{array}$ & $0.999 \pm 0.020$ & $1.005 \pm 0.018$ \\
\hline $\begin{array}{l}\text { Pu239/Pu240 } \\
\text { PROFIL1 }^{(a)}\end{array}$ & $0.980 \pm 0.030$ & $1.002 \pm 0.02$ & $\begin{array}{c}\text { Np237 Fission Rate } \\
\text { MUSE }^{\text {(c) }}\end{array}$ & $0.962 \pm 0.020$ & $1.001 \pm 0.011$ \\
\hline $\begin{array}{l}\text { Pu240/Pu241 } \\
\text { PROFIL1 }^{\text {(a) }}\end{array}$ & $1.131 \pm 0.022$ & $1.009 \pm 0.017$ & $\begin{array}{c}\text { Pu238 Fission Rate } \\
\text { MUSE }^{\text {(c) }}\end{array}$ & $1.067 \pm 0.033$ & $0.981 \pm 0.028$ \\
\hline $\begin{array}{l}\text { Pu241/Pu242 } \\
\text { PROFIL1 }^{\text {(a) }}\end{array}$ & $1.152 \pm 0.041$ & $1.015 \pm 0.017$ & $\begin{array}{c}\text { Pu239 Fission Rate } \\
\text { MUSE }^{\text {(c) }}\end{array}$ & $0.989 \pm 0.020$ & $1.022 \pm 0.009$ \\
\hline $\begin{array}{l}\text { Pu242/Am243 } \\
\text { PROFIL1 }^{\text {(a) }}\end{array}$ & $1.120 \pm 0.035$ & $0.949 \pm 0.02$ & $\begin{array}{c}\text { Pu240 Fission Rate } \\
\text { MUSE }^{\text {(c) }}\end{array}$ & $1.052 \pm 0.030$ & $0.978 \pm 0.02$ \\
\hline $\begin{array}{c}\text { Pu242/Cm244 } \\
\text { PROFIL1 }^{\text {(a) }}\end{array}$ & $1.164 \pm 0.050$ & $0.961 \pm 0.022$ & $\begin{array}{c}\text { Pu241 Fission Rate } \\
\text { MUSE }^{\text {(c) }}\end{array}$ & $1.011 \pm 0.027$ & $0.986 \pm 0.022$ \\
\hline $\begin{array}{c}\text { Am241/Am242 } \\
\text { PROFIL1 }^{(a)}\end{array}$ & $1.061 \pm 0.020$ & $0.994 \pm 0.014$ & $\begin{array}{c}\text { Pu242 Fission Rate } \\
\text { MUSE }^{\text {(c) }}\end{array}$ & $1.023 \pm 0.030$ & $0.993 \pm 0.029$ \\
\hline $\begin{array}{c}\text { Np237/Pu238 } \\
\text { PROFIL2 }^{\text {(a) }}\end{array}$ & $0.943 \pm 0.036$ & $1.025 \pm 0.029$ & $\begin{array}{c}\text { Am241 Fission Rate } \\
\text { MUSE }^{(c)}\end{array}$ & $1.068 \pm 0.030$ & $0.996 \pm 0.029$ \\
\hline $\begin{array}{c}\text { U236 } \\
\text { TRAPU2 }^{(b)} \\
\end{array}$ & $0.940 \pm 0.010$ & $1.002 \pm 0.009$ & $\begin{array}{c}\text { Am243 Fission Rate } \\
\text { MUSE }^{(c)}\end{array}$ & $1.056 \pm 0.030$ & $0.996 \pm 0.029$ \\
\hline $\begin{array}{c}\text { Np237 }^{(b)} \\
\text { TRAPU2 }^{(b)} \\
\end{array}$ & $0.800 \pm 0.033$ & $1.006 \pm 0.033$ & $\begin{array}{c}\mathbf{k}_{\text {eff }} \\
\text { MUSE }^{(\mathbf{c})}\end{array}$ & $1.000 \pm 0.002$ & $1.002 \pm 0.001$ \\
\hline $\begin{array}{c}\text { Pu238 } \\
\text { TRAPU2 }^{(b)} \\
\end{array}$ & $1.010 \pm 0.010$ & $0.993 \pm 0.007$ & $\begin{array}{c}\mathbf{k}_{\text {eff }} \\
\text { GODIVA }^{(d)} \\
\end{array}$ & $1.000 \pm 0.001$ & $1 \pm 0.001$ \\
\hline $\begin{array}{c}\text { Pu239 } \\
\text { TRAPU2 }^{(b)}\end{array}$ & $1.000 \pm 0.010$ & $0.998 \pm 0.004$ & $\begin{array}{c}\text { Np237 Fission Rate } \\
\text { GODIVA }^{(d)}\end{array}$ & $0.950 \pm 0.016$ & $1.01 \pm 0.009$ \\
\hline $\begin{array}{c}\text { Pu240 }^{(b)} \\
\text { TRAPU2 }^{(b)} \\
\end{array}$ & $0.980 \pm 0.010$ & $1.001 \pm 0.006$ & $\begin{array}{c}\mathbf{k}_{\text {eff }} \\
\text { JEZEBEL9 }^{(e)} \\
\end{array}$ & $1.000 \pm 0.002$ & $0.999 \pm 0.002$ \\
\hline $\begin{array}{c}\text { Pu241 }^{(b)} \\
\text { TRAPU1 }^{(b)}\end{array}$ & $1.050 \pm 0.010$ & $0.994 \pm 0.008$ & $\begin{array}{c}\text { Np237 Fission Rate } \\
\text { JEZEBEL9 }^{(\mathrm{e})}\end{array}$ & $0.949 \pm 0.017$ & $1.01 \pm 0.009$ \\
\hline $\begin{array}{c}\text { Pu242 }^{(b)} \\
\text { TRAPU1 }^{(b}\end{array}$ & $1.110 \pm 0.010$ & $0.984 \pm 0.009$ & $\begin{array}{c}\mathbf{k}_{\text {eff }} \\
\text { JEZEBEL0 }^{(f)} \\
\end{array}$ & $1.000 \pm 0.002$ & $1.001 \pm 0.002$ \\
\hline $\begin{array}{c}\operatorname{Am}_{241} \\
\text { TRAPU2 }^{(b)}\end{array}$ & $0.970 \pm 0.039$ & $1.017 \pm 0.006$ & $\begin{array}{c}\text { Np237 Fission Rate } \\
\text { JEZEBEL0 }^{(f)}\end{array}$ & $0.977 \pm 0.017$ & $0.981 \pm 0.009$ \\
\hline $\begin{array}{c}\text { Am242 }^{(b)} \\
\text { TRAPU2 }^{(b)}\end{array}$ & $1.060 \pm 0.031$ & $0.983 \pm 0.013$ & $\begin{array}{c}\mathbf{k}_{\text {eff }} \\
\text { Np Sphere }^{(\mathrm{g})} \\
\end{array}$ & $0.996 \pm 0.003$ & $1 \pm 0.003$ \\
\hline $\begin{array}{c}\text { Am243 } \\
\text { TRAPU1 }^{(b)} \\
\end{array}$ & $1.080 \pm 0.025$ & $1.019 \pm 0.02$ & \begin{tabular}{|c|}
$\mathbf{k}_{\text {eff }}$ \\
CIRANO $^{(h)}$ \\
\end{tabular} & $1.004 \pm 0.002$ & $0.998 \pm 0.001$ \\
\hline \multicolumn{6}{|c|}{$\begin{array}{l}\text { Isotope A/B atom density ratio at the end of irradiation of a sample of isotope A [24]; } \\
\text { Isotope atom density at the end of irradiation of TRAPU fuel pins with different initial Pu vectors [24]; } \\
\text { Normalized fission rates and } \mathrm{k}_{\text {eff }} \text { in the MUSE critical experiment at MASURCA [17]; } \\
\text { GODIVA: U-235 Sphere [16]; } \\
\text { JEZEBEL9: Pu-239 Sphere [16]; } \\
\text { JEZEBEL0: Pu-239 Sphere with high Pu-240 content [16]; } \\
\text { Np Sphere [16]; } \\
\mathrm{k}_{\text {eff }} \text { of the critical experiment CIRANO (high Pu content) at MASURCA [13]. }\end{array}$} \\
\hline
\end{tabular}


As for the new covariance matrix $\widetilde{B}_{\mathrm{p}}$, Table 10 shows as an example the new and "a priori" uncertainty data, based on Ref. 14, for the fission cross-sections of Pu-239, Pu-240 and Pu-241 in groups 1 and 2 of the 4 energy group scheme chosen for the present study (see Section V). The uncertainty reduction is very significant, in particular in group $1(20 \mathrm{MeV}<\mathrm{E}<0.5 \mathrm{MeV})$. Moreover, a specific feature of the procedure is that new energy and among isotopes correlations are introduced, as a result of the adjustment.

Finally, it is interesting to note that not only the "a posteriori" uncertainties of the integral experiments are reduced (see Table 9), but correlations among experiments that "a priori" are equal to zero are now different from zero, and sometimes very significant and well justified on physics ground. One example is relative to the $\mathrm{Pu}-239$ atom density in the TRAPU2 experiment: "a posteriori" correlation coefficients are observed e.g. with the U-238/Pu-239 and Pu-239/Pu-240 atom ratios in the PROFIL1 experiment (correlation coefficients equal to 0.76 and -0.50 respectively), with the Pu-240 atom density in the TRAPU1 experiment (0.44), with the U-238 fission spectrum index in MUSE (0.12), and with the $\mathrm{k}_{\text {eff }}$ of MUSE and CIRANO ( -0.13 and -0.11 , respectively).

As for the initial $\left(\mathrm{B}_{\mathrm{B}}\right)$ and resulting $\left(\widetilde{\mathrm{B}}_{\mathrm{B}}\right)$ covariance matrix for the integral parameters of the SFR and ABTR reference systems, the reduction of uncertainty e.g. on the $\mathrm{k}_{\mathrm{eff}}$, is quite considerable (from $2.02 \%$ to $0.36 \%$ ) in the case of the ABTR. In the case of the SFR the reduction is smaller (from $1.77 \%$ to $1.13 \%$ ), due to the fact that the chosen integral experiments are not sensitive enough to minor actinides nuclear data, but still significant.

A very general study along these lines is underway.

Table 10. Covariance Values Before and After Adjustment for Selected Parameters ${ }^{\text {(a) }}$

\begin{tabular}{|c|c|c|c|c|c|c|c|c|}
\hline & & & \multicolumn{2}{|c|}{ Pu-239 } & \multicolumn{2}{|c|}{ Pu-240 } & \multicolumn{2}{|c|}{ Pu-241 } \\
\hline & & & $\sigma_{\text {fiss }}^{\text {gr.1 }}$ & $\sigma_{\text {fiss }}^{\text {gr.2 }}$ & $\sigma_{\text {fiss }}^{\text {gr.1 }}$ & $\sigma_{\text {fiss }}^{\text {gr.2 }}$ & $\sigma_{\text {fiss }}^{\text {gr.1 }}$ & $\sigma_{\text {fiss }}^{\text {gr.2 }}$ \\
\hline \multirow{4}{*}{ Pu-239 } & \multirow{2}{*}{$\sigma_{\text {fiss }}^{\text {gr.1 }}$} & before adj. $\rightarrow$ & 0.050 & - & - & - & - & - \\
\hline & & after adj. $\rightarrow$ & 0.007 & -0.853 & -0.191 & 0.025 & -0.093 & 0.021 \\
\hline & \multirow{2}{*}{$\sigma_{\text {fiss }}^{\text {gr.2 }}$} & before adj. $\rightarrow$ & - & 0.050 & - & - & - & - \\
\hline & & after adj. $\rightarrow$ & -0.853 & 0.032 & -0.067 & -0.006 & -0.007 & 0.002 \\
\hline \multirow{4}{*}{ Pu-240 } & \multirow{2}{*}{$\sigma_{\text {fiss }}^{\text {gr.1 }}$} & before adj. $\rightarrow$ & - & 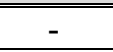 & 0.050 & 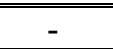 & - & - \\
\hline & & after adj. $\rightarrow$ & -0.191 & -0.067 & 0.023 & -0.127 & -0.407 & 0.109 \\
\hline & \multirow{2}{*}{$\sigma_{\text {fiss }}^{\text {gr.2 }}$} & before adj. $\rightarrow$ & - & - & - & 0.050 & - & - \\
\hline & & after adj. $\rightarrow$ & 0.025 & -0.006 & -0.127 & 0.050 & 0.030 & -0.005 \\
\hline \multirow{4}{*}{ Pu-241 } & \multirow{2}{*}{$\sigma_{\text {fiss }}^{\text {gr.1 }}$} & before adj. $\rightarrow$ & - & - & - & - & 0.150 & - \\
\hline & & after adj. $\rightarrow$ & -0.093 & -0.007 & -0.407 & 0.030 & 0.112 & -0.419 \\
\hline & \multirow{2}{*}{$\sigma_{\text {fiss }}^{\text {gr.2 }}$} & before adj. $\rightarrow$ & - & - & - & - & - & 0.100 \\
\hline & & after adj. $\rightarrow$ & 0.021 & 0.002 & 0.109 & -0.005 & -0.419 & 0.082 \\
\hline
\end{tabular}

${ }^{\text {(a) }}$ Diagonal values: variance values. Off-diagonal values: correlation coefficients.

\section{Conclusions}

A comprehensive validation analysis has been performed that incorporates representativity of multiple parameters, experiments, reference designs, and adjustment of the nuclear data. The work involves a new representativity study among selected reactor designs and several experiments.

Application, using existing experiments, to reference design like the ABTR and the SFR has demonstrated that it is possible to achieve a significant reduction of uncertainty on the main integral parameters of interest for their neutronic design. This is possible when the set of available experiments are relevant (i.e. representative of the reference designs), of good quality (i.e. of reduced uncertainty on experimental results), and consistent (i.e. not providing conflictive information).

In the future the proposed technique will be extended to a very large set of available experiments that will be analyzed with the best existing methodologies in order to minimize the impact of possible systematic calculational errors. 


\section{Appendix A. Uncertainty and Target Accuracy Assessment Using the Recent Covariance Data Evaluations}

\section{A.1. Background}

The choice of the preferred systems for the future has been made, under the auspices of the Gen IV initiative, based on a set of high-level requirements: waste minimization, sustainability, safety, economy, and nonproliferation. At the same time, in the framework of the Advanced Fuel Cycle (AFC) program, several systems have been considered as possible transmuters of Minor Actinides (MA). The physics of these reactors and their associated fuel cycles is rather well understood. However, their optimization, in order to comply more effectively with the requirements, and their timely deployment, requires focusing the research and development in all fields, in particular for innovative fuel development and processing, and also in the reactor physics field. In this last area, the role of nuclear data is quite significant. Most data are by and large available, but their accuracy and validation is still a major concern.

In order to make a comprehensive assessment, the tools of sensitivity and uncertainty analysis are needed. These tools have been widely developed in the past, in particular for the assessment in the '70s and ' 80 s of fast reactor performances.

Recently, the Working Party on Evaluation Cooperation (WPEC) of the OECD Nuclear Energy Agency Nuclear Science Committee has established an International Subgroup (Subgroup 26) to perform an activity in order to develop a systematic approach to define data needs for Gen-IV and, in general, for advanced reactor systems.

For this type of study, two major difficulties are encountered. First, it is needed to define at an early stage, representative, i.e., general enough, "images" of "future systems". Second, it is necessary to establish a realistic "compilation" of nuclear data uncertainties and their correlation (variance-covariance matrices). This analysis has been already carried out in the past [2].

- In Ref. 2, regarding the first point, reference "images" were defined to the best of the present knowledge for a SFR (in a TRU burning configuration i.e., with a Conversion Ratio $\mathrm{CR}<1$ ); for a large SFR, referred as EFR (with full recycling of MA and CR 1); for a GFR (with full recycling of MA); for a LFR (as defined for an IAEA benchmark); and for a VHTR with particle fuel. Finally, an extended burnup (100 GWd/t) PWR was also studied.

- As far as the second point, in Ref. 2, the study was carried out with an "educated" guess of uncertainties for all the isotopes of interest (actinides, structural and coolant materials), based, as much as possible, on the nuclear data performance in the analysis of selected, clean integral experiments (irradiated fuel and sample analysis, criticality and fission rates in zero-power critical facilities) [24]. For the correlations, as first guess a very crude hypothesis of Partial Energy Correlations (PEC) "by energy band" was used.

Recently, preliminary cross-section covariances have been developed within the WPEC Subgroup by joint efforts of several laboratories. The new set of uncertainties is called BOLNA.

In this appendix, the integral parameters uncertainties reported in Ref. 2 have been recalculated with the use of the new covariance matrix and compared with the results previously obtained. The methodology, the systems considered and the sensitivity approach are consistent with the work reported in Ref. 2. However, for the present study, the approach has been extended to the ABTR Na-cooled core, recently studied within the GNEP initiative [15] and to an Accelerator-Driven Minor Actinides Burner (ADMAB) investigated in Refs. 1 and 25. As in Ref. 2 , the integral parameters object of the uncertainty evaluation and characterizing the reference systems and their associated fuel cycle are: criticality ( $\mathrm{k}_{\mathrm{eff}}$ ), power peak in the core, Doppler and coolant void reactivity coefficients, reactivity swing during burnup, isotope concentrations in the spent fuel, decay heat of the spent fuel in a repository, dose (radiotoxicity) of the spent fuel or of the wastes in a repository, at selected times after storage and neutron source associated to the spent fuel e.g., at fuel fabrication. 
A successive study based both on the results of the uncertainty evaluation and on the definition of target accuracies for the various integral parameters, has been carried out in order to provide guidelines on priority requirements for data improvements. This kind of analysis was also performed in Ref. 2 in a preliminary form. Now, the study is carried out with well-established data target accuracies defined within the Subgroup 26.

Finally, part of the results and relative conclusions provided in this appendix has been already published in Refs. 3 (for the uncertainty evaluation) and 4 (for the target accuracy study).

\section{A.2 Covariance Matrices}

The "home made" ANL covariance matrix [14], has been obtained by updating the covariance matrix used in the ADS study [1] by taking into account the results of clean integral experiment analysis, in particular irradiated sample/fuel analysis, which gave valuable information on capture and some $(\mathrm{n}, 2 \mathrm{n})$ cross-sections, and fission rate measurements in critical assemblies [24]. The uncertainty values, have been given by "energy band", consistent with multigroup energy structures used for deterministic calculations both of thermal and fast reactors. Fifteen energy groups have been selected between $20 \mathrm{MeV}$ and thermal energy. The uncertainty values are given only for neutron cross-section data of actinides and structural materials. Fission products related uncertainties have not been considered. The diagonal values of the ANL covariance matrix are presented in Appendix C. Concerning the off-diagonal terms, in the ANL covariance matrix the hypothesis of Partial Energy Correlations (PEC) was adopted: as first guess, the same correlations for all isotopes and reactions, under the form of full energy correlation in 5 energy bands was used [2].

Rather than using the ANL covariance matrix, the present uncertainty assessment has been carried out with preliminary cross-section covariances that have been recently developed within the WPEC Subgroup by joint

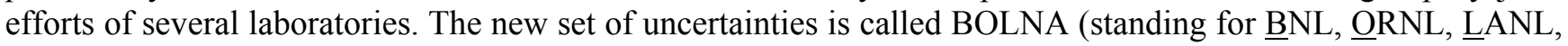

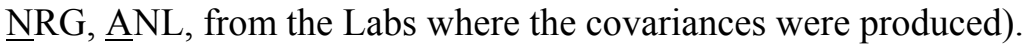

With more details, cross-section covariances for 45 out of 52 requested materials [26,27] have been developed at BNL. The cross-section covariances have been produced in 15- and 187-group representations as follows:

- 36 isotopes (O-16; F-19; Na-23; Al-27; Si-28; Cr-52; Fe-56,57; Ni-58; Zr-90,91,92,94; Er-166, 167,168,170; Pb-206,207,208; Bi-209; U-233,234,236; Np-237, Pu-238,240,241,242; Am-241,242m,243; Cm242,243,244,245) were evaluated using the BNL-LANL methodology, based on the ENDF/B-VII.0 library [28], the Atlas of Neutron resonances [29], the nuclear model code EMPIRE [30] and the Bayesian code Kalman [31];

- 6 isotopes (Gd-155,156,157,158,160 and Th-232) were taken from ENDF/BVII.0;

- 3 isotopes (H-1, U-238 and Pu-239) were taken from JENDL-3.3.

Covariances for the average number of neutrons per fission, total nu-bar, have been provided for 16 actinides identified as priority by the Subgroup.

LANL has evaluated the covariance matrices for U-235, U-238 and Pu-239, in the fast energy region, using only differential measurements and nuclear model calculations. A generalized-least-squares technique is used to evaluate a global covariance matrix based solely on experimental differential information. Since nuclear model calculations are used to complement experimental data, a Kalman filter is then used to combine experimental data and model calculations covariance matrices. This procedure has been used for the three isotopes U-235, U238, and Pu-239, for the reaction cross-sections of (n,fission), (n,capture), (n,total), (n,elastic), (n,inelastic), and $(\mathrm{n}, \mathrm{xn})$. The covariance matrices related to the average number of neutrons have been obtained from experimental data only.

To complete these data, at ORNL resonance-parameter covariance evaluations have been performed for U-235, U-238, and Pu-239 with the computer code SAMMY [32]. For U-235 the covariance evaluations have been done in the resolved and unresolved energy regions whereas for U-238 and Pu-239 only the resolved resonance covariance evaluations have been done. Experimental uncertainties are incorporated directly into the evaluation process in order to propagate them into the resonance parameter results [33]. 
Finally, covariance data files for Pb isotopes have been produced at NRG by a purely stochastic approach [34]. This is accomplished by subjecting the nuclear model code TALYS [35] to a Monte Carlo scheme for perturbing the input parameters of the various nuclear models, such as level densities, gamma-ray strength functions and the optical model.

In summary, for the BOLNA covariance matrix, all the available BNL data have been used, except the U-235, $\mathrm{U}-238$ and $\mathrm{Pu}-239$ data that have been taken from the combined LANL/ORNL evaluation and the Pb isotope data, taken from the NRG evaluation. Missing data have been taken from the ANL estimated covariance data [14]. The diagonal values of the BOLNA covariance matrix are presented in Appendix C.

\section{A.3. Systems and Integral Parameters Analyzed}

Eight systems, related to Gen-IV, AFCI and GNEP, have been considered, and their main features are:

1. ABTR: $250 \mathrm{MW}_{\text {th }}-\mathrm{Na}$ cooled; U-TRU-10Zr fuel; HT9(75\%)-Na(15\%) reflector; enrichment: $17 \%$, MA: $<1 \%$; irradiation cycle: 109.8 days (4 months at $90 \%$ capacity);

2. SFR: (Burner: $\mathrm{CR}=0.25) 840 \mathrm{MW}_{\text {th }}-\mathrm{Na}$ cooled; U-TRU-Zr metallic alloy fuel; SS reflector; enrichment: $56 \%$, MA: $10 \%$; irradiation cycle: 155 days;

3. EFR: $3600 \mathrm{MW}_{\text {th }}-\mathrm{Na}$ cooled; U-TRU oxide fuel; U blanket; enrichment: $22 \%$, MA: 1\%; irradiation cycle: 1700 days;

4. GFR: $2400 \mathrm{MW}_{\mathrm{e}}-\mathrm{He}$ cooled; $\mathrm{SiC}$ - (U-TRU)C fuel; $\mathrm{Zr}_{3} \mathrm{Si}_{2}$ reflector; enrichment: 17\%, MA: 5\%; irradiation cycle: 415 days;

5. LFR: $900 \mathrm{MW}_{\text {th }}-\mathrm{Pb}$ cooled; U-TRU-Zr metallic alloy fuel; Pb reflector; enrichment: 21\%, MA: 2\%; irradiation cycle: 310 days;

6. ADMAB: $377 \mathrm{MW}_{\text {th }}-\mathrm{Pb}-\mathrm{Bi}$ cooled; TRU fuel; HT9(70\%) Pb-Bi(30\%) reflector; enrichment: 32\%, MA: $67 \%$; irradiation cycle: 366 days;

7. VHTR: TRISO fuel; enrichment: 14\%; burnup: $90 \mathrm{GW} \mathrm{d/Kg}$;

8. Extended BU PWR: enrichment: 8.5\%; burnup: $100 \mathrm{GW} \mathrm{d/Kg}$.

The integral parameters considered in the study are:

- Criticality (multiplication factor);

- Power peak value;

- Doppler reactivity coefficient;

- Coolant void reactivity coefficient;

- Reactivity loss during irradiation;

- Transmutation potential (i.e. nuclide concentrations at end of irradiation, $\mathrm{n}_{\mathrm{f}}$, or density variation during burnup, $\Delta \mathrm{n}=\mathrm{n}_{\mathrm{f}}-\mathrm{n}_{\mathrm{i}}$ );

- Decay heat in a repository (at 100 years after disposal);

- Radiotoxicity at $\mathrm{t}=100000$ years after disposal.

- Radiation source at fuel discharge;

Nominal values calculated for each reactor are summarized in Tables 11 to 17. In the present study, the crosssections have been generated with the JEF libraries, in particular with JEF3.0 for the Fast Reactors (FRs) and with JEF2.2 for the ADMAD and the two thermal reactors VHTR and PWR. 
Table 11. ABTR, SFR, EFR Nominal Values

\begin{tabular}{|c|c|c|c|c|c|c|c|c|}
\hline Reactor & $\begin{array}{l}\text { Reactivity } \\
\text { [pcm] }\end{array}$ & $\begin{array}{l}\text { Power } \\
\text { Peak }\end{array}$ & $\begin{array}{c}\text { Doppler } \\
\text { [pcm] }\end{array}$ & $\begin{array}{l}\text { Void } \\
{[\mathrm{pcm}]}\end{array}$ & $\begin{array}{l}\text { Burnup } \\
\text { [pcm] }\end{array}$ & $\begin{array}{c}\text { Decay Heat }^{(0)} \\
{[\mathrm{W}]}\end{array}$ & $\begin{array}{c}\text { Dose }^{(p)} \\
{[\mathrm{Sv}]}\end{array}$ & $\begin{array}{c}\text { Neutron Source }{ }^{(\mathrm{q})} \\
{[\mathrm{n} / \mathbf{s}]}\end{array}$ \\
\hline ABTR & 3319.8 & $1.73^{(\mathrm{a})}$ & $368.3^{(\mathrm{b})}$ & $277^{(\mathrm{c})}$ & $-1325.8^{(\mathrm{d})}$ & $1.402 \mathrm{E}+03$ & $1.687 \mathrm{E}+01$ & $7.005 \mathrm{E}+09$ \\
\hline SFR & 5015.4 & $53^{(\mathrm{e})}$ & $231^{(\mathrm{f})}$ & $1831^{(\mathrm{g})}$ & $-3981.1^{(\mathrm{h})}$ & $1.400 \mathrm{E}+4$ & $2.319 \mathrm{E}+1$ & $8.537 \mathrm{E}+11$ \\
\hline EFR & 9786.5 & $1.63^{(\mathrm{i})}$ & $1289^{(1)}$ & $1934.5^{(\mathrm{m})}$ & $-9123.9^{(\mathrm{n})}$ & $4.324 \mathrm{E}+3$ & $1.235 \mathrm{E}+1$ & $1.996 \mathrm{E}+11$ \\
\hline & & & \multicolumn{3}{|c|}{$\begin{array}{l}\text { (e) }(\mathrm{R}, \mathrm{Z})=(66.59,143.03)_{\mathrm{cm}} \\
{ }^{(\mathrm{f})} \mathrm{T}_{\text {fule }}=300 \mathrm{~K}-\mathrm{T}_{\text {fulel }}=850 \mathrm{~K} \\
\text { (g) } \mathrm{Na} \text { loss in core } \\
\text { (h) } 155 \text { days }\end{array}$} & \multicolumn{2}{|c|}{$\begin{array}{l}\text { (i) }(\mathrm{R}, \mathrm{Z})=(153.24,125)_{\mathrm{cm}} \\
{ }^{(\text {l) }} \mathrm{T}_{\text {fucl }}=300 \mathrm{~K}-\mathrm{T}_{\text {fuel }}=1520 \mathrm{~K} \\
{ }^{(\mathrm{m})} \mathrm{Na} \text { loss in core and blanket } \\
\text { (n) } 1700 \text { days }\end{array}$} & $\begin{array}{l}\text { (o) } 100 \mathrm{y} \text { after discharge } \\
\text { (p) } 100000 \mathrm{y} \text { after discharge } \\
\text { (q) } 2 \mathrm{y} \text { after discharge }\end{array}$ \\
\hline
\end{tabular}

Table 12. GFR Nominal Values

\begin{tabular}{|c|c|c|c|c|c|c|c|}
\hline $\begin{array}{c}\text { Reactivity } \\
\text { [pcm] }\end{array}$ & $\begin{array}{l}\text { Power } \\
\text { Peak }\end{array}$ & $\begin{array}{c}\text { Doppler } \\
{[\mathrm{pcm}]}\end{array}$ & $\begin{array}{l}\text { Void } \\
\text { [pcm] }\end{array}$ & $\begin{array}{l}\text { Burnup } \\
\text { [pcm] }\end{array}$ & $\begin{array}{c}\text { Decay Heat } \\
{[W]}\end{array}$ & $\begin{array}{l}\text { Dose } \\
{[\mathrm{Sv}]}\end{array}$ & $\begin{array}{c}\text { Neutron Source } \\
{[\mathbf{n} / \mathbf{s}]}\end{array}$ \\
\hline 1038.0 & $1.45^{\text {(a) }}$ & $1549^{(b)}$ & $350.1^{(c)}$ & $1081.3^{(\mathrm{d})}$ & $6.246 \mathrm{E}+3$ & $1.028 \mathrm{E}+1$ & $2.183 \mathrm{E}+11$ \\
\hline
\end{tabular}

Table 13. LFR Nominal Values

\begin{tabular}{|c|c|c|c|c|c|c|c||}
\hline $\begin{array}{c}\text { Reactivity } \\
{[\mathbf{p c m}]}\end{array}$ & $\begin{array}{c}\text { Power } \\
\text { Peak }\end{array}$ & $\begin{array}{c}\text { Doppler } \\
{[\mathbf{p c m}]}\end{array}$ & $\begin{array}{c}\text { Void } \\
{[\mathbf{p c m}]}\end{array}$ & $\begin{array}{c}\text { Burnup } \\
{[\mathbf{p c m}]}\end{array}$ & $\begin{array}{c}\text { Decay Heat } \\
{[\mathbf{W}]}\end{array}$ & $\begin{array}{c}\text { Dose } \\
{[\mathbf{S v}]}\end{array}$ & $\begin{array}{c}\text { Neutron Source } \\
{[\mathbf{n} / \mathbf{s}]}\end{array}$ \\
\hline \hline 22.9 & $1.29^{(\mathrm{a})}$ & $228.1^{(\mathrm{b})}$ & $6575.5^{(\mathrm{c})}$ & $-1464^{(\mathrm{d})}$ & $4.616 \mathrm{E}+3$ & $1.140 \mathrm{E}+1$ & $2.275 \mathrm{E}+11$ \\
\hline
\end{tabular}

Table 14. ADMAB Nominal Values

\begin{tabular}{|c|c|c|c|c|c|c|c||}
\hline $\begin{array}{c}\text { Reactivity } \\
\text { [pcm] }\end{array}$ & $\begin{array}{c}\text { Power } \\
\text { Peak }\end{array}$ & $\begin{array}{c}\text { Doppler } \\
\text { [pcm] }\end{array}$ & $\begin{array}{c}\text { Void } \\
\text { [pcm] }\end{array}$ & $\begin{array}{c}\text { Burnup } \\
\text { [pcm] }\end{array}$ & $\begin{array}{c}\text { Decay Heat } \\
{[\mathbf{W}]}\end{array}$ & $\begin{array}{c}\text { Dose } \\
{[\text { [Sv] }}\end{array}$ & $\begin{array}{c}\text { Neutron Source } \\
{[\mathbf{n} / \mathbf{s}]}\end{array}$ \\
\hline \hline-5466.9 & $2.67^{(\mathrm{a})}$ & $28.3^{(\mathrm{b})}$ & $3138.4^{(\mathrm{c})}$ & $-1347.6^{(\mathrm{d})}$ & $1.545 \mathrm{E}+5$ & $2.653 \mathrm{E}+1$ & $3.122 \mathrm{E}+12$ \\
\hline
\end{tabular}

Table 15. VHTR Nominal Values

\begin{tabular}{|c|c|c|c|c|c|c|c|c|c|}
\hline $\mathbf{k}_{\text {eff }}{ }^{(a)}$ & $\mathbf{k}_{\text {eff }}{ }^{(b)}$ & $\begin{array}{l}\text { Power } \\
\text { Peak }^{(\mathbf{c})}\end{array}$ & $\begin{array}{l}\text { Power } \\
\text { Peak }^{(d)}\end{array}$ & $\begin{array}{c}\text { Doppler }^{(\mathrm{e})} \\
\text { [pcm] }\end{array}$ & $\begin{array}{c}\text { Doppler }^{(\mathrm{f})} \\
\text { [pcm] }\end{array}$ & $\begin{array}{c}\text { Burnup } \\
\text { [pem] }\end{array}$ & $\begin{array}{c}\text { Decay } \\
\text { Heat }^{(h)}[W]\end{array}$ & $\begin{array}{c}\text { Dose }^{(i)} \\
{[\mathrm{Sv}]}\end{array}$ & $\begin{array}{c}\text { Neutron } \\
\text { Source }^{(\mathrm{l})}[\mathrm{n} / \mathrm{s}]\end{array}$ \\
\hline 37767 & 1.01610 & & 2.25 & & 3416.3 & -25829.4 & $1.670 \mathrm{E}+1$ & $2.979 \mathrm{E}-2$ & $2.227 \mathrm{E}+8$ \\
\hline
\end{tabular}

\begin{tabular}{|c|c|c|}
\hline $\begin{array}{l}\text { (a) } \mathrm{BOC} \\
\text { (b) } \mathrm{EOC} \\
\text { (c) } \mathrm{BOC} \text { at }(\mathrm{R}, \mathrm{Z})=(147.6,556.5)_{\mathrm{cm}} \\
\text { (d) } \mathrm{EOC} \text { at }(\mathrm{R}, \mathrm{Z})=(147.6,556.5)_{\mathrm{cm}}\end{array}$ & $\begin{array}{l}\text { (e) } \mathrm{T}_{\text {fuel }}=773 \mathrm{~K}-\left(\mathrm{T}_{\text {fuel }}=1373 \mathrm{~K} ; \mathrm{T}_{\text {moderator }}=1200 \mathrm{~K}\right) \text { at BOC } \\
\text { (f) } \mathrm{T}_{\text {fule }}=773 \mathrm{~K}-\left(\mathrm{T}_{\text {fuel }}=1373 \mathrm{~K} ; \mathrm{T}_{\text {moderator }}=1200 \mathrm{~K}\right) \text { at EOC } \\
\text { (g) } 845.63 \text { days }\end{array}$ & $\begin{array}{l}\text { (h) } 100 \mathrm{y} \text { after discharge } \\
\text { (i) } 100000 \mathrm{y} \text { after discharge } \\
\text { (1) } 2 \mathrm{y} \text { after discharge }\end{array}$ \\
\hline
\end{tabular}

(d) EOC at $(\mathrm{R}, \mathrm{Z})=(147.6,556.5)_{\mathrm{cm}}$

Table 16. PWR Nominal Values

\begin{tabular}{|c|c|c|c|c|c|c|c|}
\hline $\mathbf{k}_{\text {eff }}{ }^{(a)}$ & $\mathbf{k}_{\text {eff }}{ }^{(b)}$ & $\begin{array}{c}\text { Doppler }^{(c)} \\
\text { [pcm] }\end{array}$ & \begin{tabular}{|c|} 
Doppler \\
[pcm]
\end{tabular} & $\begin{array}{c}\text { Burnup }^{(\mathrm{e})} \\
\text { [pcm] }\end{array}$ & $\begin{array}{c}\text { Decay } \\
\text { Heat }^{(f)}[\mathrm{W}]\end{array}$ & $\begin{array}{c}\text { Dose }^{(g)} \\
{[\mathrm{Sv}]} \\
\end{array}$ & $\begin{array}{c}\text { Neutron } \\
\text { Source }^{(h)}[n / s]\end{array}$ \\
\hline 1.49802 & 0.87231 & \begin{tabular}{|l|}
695.2 \\
\end{tabular} & 1054.6 & -47883.6 & $6.000 \mathrm{E}+2$ & $1.128 \mathrm{E}+0$ & $2.486 \mathrm{E}+10$ \\
\hline $\begin{array}{l}\text { a) } \\
\text { BOC } \\
\text { EOC } \\
\mathrm{T}_{\text {fuel }}=550 \mathrm{~K} \\
\mathrm{~T}_{\text {fuel }}=550 \mathrm{~K}\end{array}$ & \multicolumn{7}{|c|}{$\begin{array}{l}\text { (e) } 2773.5 \text { days } \\
\text { (f) } 100 \text { y after discharge } \\
\text { (g) } 100000 \text { y after discharge } \\
\text { (h) } 2 \text { y after discharge }\end{array}$} \\
\hline
\end{tabular}


Table 17. $\Delta \mathrm{n}$ and $\Delta \mathrm{n} / \mathrm{n}_{\mathrm{f}}$ Nominal Values

\begin{tabular}{|c|c|c|c|c|c|c|c|c|c|c|c|c|c|c|c|c|c|}
\hline & \\
\hline & & U235 & U238 & Np237 & Pu238 & Pu239 & Pu240 & Pu241 & Pu242 & Am241 & Am242m & Am243 & Cm242 & $\mathrm{Cm} 243$ & Cm244 & Cm245 & Cm246 \\
\hline \multirow{2}{*}{ ABTR } & $n=n_{f}-n_{i}$ & $-5.2 \mathrm{E}-7$ & $-4.3 \mathrm{E}-5$ & $1.9 \mathrm{E}-7$ & $2.1 \mathrm{E}-7$ & $-3.5 \mathrm{E}-5$ & $4.3 \mathrm{E}-6$ & $-1.4 \mathrm{E}-7$ & $4.6 \mathrm{E}-8$ & $-9.4 \mathrm{E}-9$ & $2.3 \mathrm{E}-8$ & 5.1E-9 & $1.9 \mathrm{E}-8$ & $9.6 \mathrm{E}-10$ & $2.6 \mathrm{E}-8$ & $1.6 \mathrm{E}-9$ & $1.8 \mathrm{E}-10$ \\
\hline & $\Delta \mathbf{n} / \mathbf{n}_{\mathrm{f}}$ & -0.04 & 0.00 & 0.02 & 0.05 & -0.02 & 0.02 & -0.01 & 0.00 & 0.00 & 0.08 & 0.00 & 0.05 & 0.08 & 0.05 & 0.03 & 0.06 \\
\hline \multirow{2}{*}{ SFR } & $\Delta n=n_{f}-n_{i}$ & $-1.4 \mathrm{E}-7$ & $-2.0 \mathrm{E}-5$ & $-5.0 \mathrm{E}-6$ & $2 \mathrm{E}-6$ & $-4.6 \mathrm{E}-5$ & $-2.3 \mathrm{E}-5$ & $-7.7 \mathrm{E}-6$ & $-5.2 \mathrm{E}-6$ & $-4.9 \mathrm{E}-6$ & $-8.5 \mathrm{E}-6$ & $-1.3 \mathrm{E}-6$ & $3.1 \mathrm{E}-7$ & $-7.5 E-9$ & $4.9 \mathrm{E}-7$ & $-7.5 \mathrm{E}-7$ & $-1.2 \mathrm{E}-7$ \\
\hline & $\Delta \mathbf{n} / \mathbf{n}_{\mathbf{f}}$ & -0.03 & -0.01 & -0.06 & -0.02 & -0.07 & -0.03 & -0.05 & -0.02 & -0.05 & -0.13 & -0.01 & 0.05 & -0.01 & 0.01 & -0.05 & -0.01 \\
\hline \multirow{2}{*}{ EFR } & $\Delta \mathbf{n}=\mathbf{n}_{\mathbf{f}}-\mathbf{n}_{\mathrm{i}}$ & $\mid-2.6 \mathrm{E}-6$ & $-9.1 \mathrm{E}-4$ & $-4.8 \mathrm{E}-7$ & $-3.4 \mathrm{E}-6$ & $-2.5 \mathrm{E}-4$ & $-6.2 \mathrm{E}-5$ & $1.7 \mathrm{E}-5$ & $\mid-3.9 \mathrm{E}-6$ & $-2.6 \mathrm{E}-5$ & $9.8 \mathrm{E}-8$ & $6.0 \mathrm{E}-7$ & $2.8 \mathrm{E}-6$ & $-3.8 \mathrm{E}-8$ & $3.4 \mathrm{E}-6$ & $-2.4 \mathrm{E}-7$ & $-2.3 \mathrm{E}-7$ \\
\hline & $\Delta \mathbf{n} / \mathbf{n}_{\mathbf{f}}$ & -0.78 & -0.16 & -0.05 & -0.10 & -0.29 & -0.10 & 0.20 & -0.06 & -0.79 & 0.03 & 0.03 & 1.00 & -0.10 & 0.22 & -0.09 & -0.15 \\
\hline \multirow{2}{*}{ GFR } & $\Delta n=n_{f}-n_{i}$ & $-4.9 \mathrm{E}-6$ & $-1.0 \mathrm{E}-4$ & $-5.1 \mathrm{E}-6$ & $8.3 \mathrm{E}-6$ & $1.4 \mathrm{E}-5$ & $5.0 \mathrm{E}-7$ & $-9.3 \mathrm{E}-6$ & $3.0 \mathrm{E}-8$ & $-2.1 \mathrm{E}-5$ & $2.8 \mathrm{E}-6$ & $-2.2 \mathrm{E}-6$ & 7.0E-6 & $9.8 \mathrm{E}-8$ & $3.2 \mathrm{E}-6$ & $6.3 \mathrm{E}-8$ & $6.3 \mathrm{E}-8$ \\
\hline & $\Delta \mathbf{n} / \mathbf{n}_{\mathbf{f}}$ & -0.17 & -0.02 & -0.11 & 0.18 & 0.03 & 0.00 & -0.13 & 0.00 & -0.13 & 0.80 & -0.05 & 0.99 & 0.32 & 0.18 & 0.18 & 0.18 \\
\hline \multirow{2}{*}{ LFR } & $\Delta \mathbf{n}=n_{f}-n_{i}$ & $\mid-5.7 \mathrm{E}-7$ & $-6.3 \mathrm{E}-5$ & $-1.9 \mathrm{E}-6$ & $\mid-5.3 \mathrm{E}-7$ & $-1.5 \mathrm{E}-5$ & $-9.0 \mathrm{E}-6$ & $-4.7 \mathrm{E}-7$ & $-1.4 \mathrm{E}-6$ & $-3.2 \mathrm{E}-6$ & $-7.3 \mathrm{E}-10$ & $-4.4 \mathrm{E}-7$ & $4.8 \mathrm{E}-7$ & $6.0 \mathrm{E}-9$ & $3.2 \mathrm{E}-7$ & $-3.0 \mathrm{E}-7$ & $-2.8 \mathrm{E}-8$ \\
\hline & $\Delta \mathbf{n} / \mathbf{n}_{\mathbf{f}}$ & -0.08 & -0.01 & -0.06 & -0.01 & -0.02 & -0.02 & -0.01 & -0.02 & -0.06 & 0.00 & -0.02 & 0.22 & 0.04 & 0.02 & -0.06 & -0.01 \\
\hline \multirow{2}{*}{ ADMAB } & $\Delta n=n_{f}-n_{i}$ & - & - & $-4.1 \mathrm{E}-5$ & 5.2E-5 & $-6.0 \mathrm{E}-5$ & $7.8 \mathrm{E}-6$ & $-1.8 \mathrm{E}-5$ & 9.6E-6 & $-8.6 \mathrm{E}-5$ & $8.3 \mathrm{E}-6$ & $-5.2 \mathrm{E}-5$ & $2.7 \mathrm{E}-5$ & $-1.9 \mathrm{E}-7$ & $2.3 \mathrm{E}-5$ & $1.5 \mathrm{E}-6$ & $5.0 \mathrm{E}-7$ \\
\hline & $\Delta \mathbf{n} / \mathbf{n}_{\mathbf{f}}$ & - & - & -0.10 & 0.55 & -0.13 & 0.03 & -0.17 & 0.10 & -0.12 & 0.43 & -0.10 & 1.00 & -0.06 & 0.09 & 0.05 & 0.48 \\
\hline \multirow{2}{*}{ VHTR } & $\Delta \mathbf{n}=\mathbf{n}_{\mathbf{f}}-\mathbf{n}_{\mathrm{i}}$ & $-1.4 \mathrm{E}-5$ & $-9.8 \mathrm{E}-6$ & $1.5 \mathrm{E}-7$ & $4.9 \mathrm{E}-8$ & $2.5 \mathrm{E}-6$ & 7.6E-7 & $8.9 \mathrm{E}-7$ & $2.4 \mathrm{E}-7$ & $2.1 \mathrm{E}-8$ & $4.2 \mathrm{E}-10$ & $3.4 \mathrm{E}-8$ & 7.6E-9 & $1.3 \mathrm{E}-10$ & 8.1E-9 & $4.3 \mathrm{E}-10$ & - \\
\hline & $\Delta \mathbf{n} / \mathbf{n}_{\mathbf{f}}$ & -1.29 & -0.07 & 1.00 & 1.00 & 1.00 & 1.00 & 1.00 & 1.00 & 1.00 & 1.00 & 1.00 & 1.00 & 1.00 & 1.00 & 1.00 & - \\
\hline \multirow{2}{*}{ PWR } & $\Delta n=n_{f}-n_{i}$ & $-5.1 \mathrm{E}-4$ & $-3.9 \mathrm{E}-4$ & 9.6E-6 & $6.9 \mathrm{E}-6$ & $5.1 \mathrm{E}-5$ & $2.5 \mathrm{E}-5$ & $1.7 \mathrm{E}-5$ & $1.0 \mathrm{E}-5$ & 8.7E-7 & $2.0 \mathrm{E}-8$ & $3.1 \mathrm{E}-6$ & $3.3 \mathrm{E}-7$ & $1.4 \mathrm{E}-8$ & 2.1E-6 & $2.1 \mathrm{E}-7$ & - \\
\hline & $\Delta \mathbf{n} / \mathbf{n}_{\mathbf{f}}$ & -7.58 & -0.07 & 1.00 & 1.00 & 1.00 & 1.00 & 1.00 & 1.00 & 1.00 & 1.00 & 1.00 & 1.00 & 1.00 & 1.00 & 1.00 & - \\
\hline
\end{tabular}

\section{A.4. Uncertainty Analysis}

A selection of the results obtained with the full BOLNA covariance matrix is shown in this section. Uncertainty evaluations and target accuracy assessment have been avoided only for the Doppler coefficient of the ADMAB due to its small calculated value.

Table 18 gives a summary of the integral parameter uncertainties in Fast Reactors (FRs), including the ADMAB, and Tables 19 and 20 for the VHTR and high burnup PWR respectively. Uncertainties obtained with the BOLNA covariance data are compared to the ones obtained with the PEC matrix used in Ref. 2. Uncertainties on the FR $\mathrm{k}_{\mathrm{eff}}$ are still very significant and generally beyond design target accuracies, even if a general reduction with respect to the data obtained in Ref. 2 is observed.

Table 18. Fast Neutron Systems: Total Uncertainties (\%)

\begin{tabular}{|c|c|c|c|c|c|c|c|c|c|}
\hline \multicolumn{2}{|c|}{ Reactor } & \multirow{2}{*}{$\frac{\mathbf{k}_{\text {eff }}}{}$} & \multirow{2}{*}{$\begin{array}{c}\begin{array}{c}\text { Power } \\
\text { Peak }\end{array} \\
0.6\end{array}$} & \multirow{2}{*}{$\begin{array}{c}\text { Doppler } \\
6.4\end{array}$} & \multirow{2}{*}{$\begin{array}{c}\text { Void } \\
12.5 \\
\end{array}$} & \multirow{2}{*}{$\begin{array}{c}\begin{array}{c}\text { Burnup } \\
\text { [pcm] }\end{array} \\
97\end{array}$} & \multirow{2}{*}{$\begin{array}{c}\begin{array}{c}\text { Decay } \\
\text { Heat }\end{array} \\
0.1\end{array}$} & \multirow{2}{*}{$\begin{array}{c}\text { Dose } \\
0.1\end{array}$} & \multirow{2}{*}{$\begin{array}{c}\begin{array}{c}\text { Neutron } \\
\text { Source }\end{array} \\
0.5\end{array}$} \\
\hline ABTR & PEC ${ }^{\text {(a) }}$ & & & & & & & & \\
\hline אר & BOLNA $^{(\mathbf{b})}$ & 0.92 & 0.3 & 4.4 & 6.0 & 52 & 0.2 & 0.1 & 0.5 \\
\hline \multirow{2}{*}{ SFR } & PEC & 1.66 & 0.5 & 6.0 & 23.4 & 234 & 0.3 & 0.2 & 0.9 \\
\hline & BOLNA & 1.82 & 0.4 & 5.6 & 17.1 & 272 & 0.4 & 0.3 & 1.0 \\
\hline \multirow{2}{*}{ EFR } & PEC & 1.57 & 1.1 & 5.1 & 12.1 & 989 & 2.3 & 1.7 & 6.0 \\
\hline & BOLNA & 1.18 & 1.2 & 3.8 & 7.8 & 871 & 2.4 & 1.2 & 6.6 \\
\hline \multirow{2}{*}{ GFR } & PEC & 1.90 & 1.8 & 5.5 & 7.1 & 384 & 0.5 & 0.6 & 1.8 \\
\hline & BOLNA & 1.88 & 1.7 & 5.5 & 7.7 & 381 & 0.4 & 0.5 & 1.4 \\
\hline \multirow{2}{*}{ LFR } & PEC & 2.26 & 1.0 & 7.8 & 20.6 & 258 & 0.5 & 0.5 & 1.1 \\
\hline & BOLNA & 1.43 & 0.6 & 4.3 & 7.2 & 198 & 0.6 & 0.4 & 1.1 \\
\hline \multirow{2}{*}{ ABMAB } & PEC & 3.25 & 24.0 & - & 56.6 & 962 & 0.9 & 1.4 & 2.7 \\
\hline & BOLNA & 2.94 & 21.4 & - & 15.5 & 1044 & 0.7 & 1.0 & 2.5 \\
\hline
\end{tabular}

(a) Partial Energy Correlation as used in Ref. 2

(b) BNL_ORNL_LANL_NRG_ANL 
Table 19. High Burnup VHTR: Uncertainties (\%)

\begin{tabular}{|c||c|c|c|c|c|c|c|c|c|c||}
\cline { 2 - 10 } \multicolumn{1}{c|}{} & $\begin{array}{c}\mathbf{k}_{\text {eff }} \\
\text { BOC }\end{array}$ & $\begin{array}{c}\mathbf{k}_{\text {eff }} \\
\text { EOC }\end{array}$ & $\begin{array}{c}\text { Power } \\
\text { Peak } \\
\text { BOC }\end{array}$ & $\begin{array}{c}\text { Power } \\
\text { Peak } \\
\text { EOC }\end{array}$ & $\begin{array}{c}\text { Doppler } \\
\text { BOC }\end{array}$ & $\begin{array}{c}\text { Doppler } \\
\text { EOC }\end{array}$ & $\begin{array}{c}\text { Burnup } \\
{[\mathbf{p c m}]}\end{array}$ & $\begin{array}{c}\text { Decay } \\
\text { Heat }\end{array}$ & Dose & $\begin{array}{c}\text { Neutron } \\
\text { Source }\end{array}$ \\
\hline PEC & 0.58 & 1.07 & 1.9 & 2.1 & 3.4 & 5.6 & 1574 & 3.1 & 2.6 & 14.3 \\
\hline BOLNA & 0.53 & 0.46 & 1.0 & 1.1 & 1.7 & 2.0 & 530 & 1.4 & 1.0 & 5.9 \\
\hline \hline
\end{tabular}

Table 20. High Burnup PWR: Uncertainties (\%)

\begin{tabular}{|c|c|c|c|c|c|c|c|c||}
\cline { 2 - 8 } \multicolumn{1}{c|}{} & $\begin{array}{c}\mathbf{k}_{\text {eff }} \\
\text { BOC }\end{array}$ & $\begin{array}{c}\mathbf{k}_{\text {eff }} \\
\text { EOC }\end{array}$ & $\begin{array}{c}\text { Doppler } \\
\text { BOC }\end{array}$ & $\begin{array}{c}\text { Doppler } \\
\text { EOC }\end{array}$ & $\begin{array}{c}\text { Burnup } \\
{[\mathbf{p c m}]}\end{array}$ & $\begin{array}{c}\text { Decay } \\
\text { Heat }\end{array}$ & Dose & $\begin{array}{c}\text { Neutron } \\
\text { Source }\end{array}$ \\
\hline \hline PEC & 0.52 & 1.27 & 3.1 & 4.6 & 2206 & 3.8 & 3.1 & 13.2 \\
\hline BOLNA & 0.51 & 0.74 & 1.4 & 1.9 & 851 & 1.5 & 1.0 & 5.2 \\
\hline
\end{tabular}

The uncertainties shown for the reactivity loss due to burnup, account only for the heavy element component, since individual fission product uncertainties are not generally available. In Ref. 2, an "integral" estimation of the uncertainty on the capture and scattering components of a "lumped" fission product was used, i.e. 10\% on the capture cross-section and $20 \%$ on the total scattering cross-section of a "lumped" fission product in a fast spectrum, and $2 \%$ on the capture cross-section of a "lumped" fission product in a thermal spectrum. The contribution of the fission product uncertainty to the overall burnup reactivity is significant only in the case of a fast reactors with an extended burnup (as it is the case of EFR, see Table 21). For that case, it would be valuable, to improve the uncertainty assessment, to have available the covariance data of the $\sim 20$ most important fission products, in particular in the fast energy range.

Table 21. $\Delta \rho$ Burnup Uncertainty Breakdown into Components [pcm]

\begin{tabular}{|c|c|c|c|c|c|c|}
\hline \begin{tabular}{c|}
\multicolumn{2}{|c|}{ System $\rightarrow$} \\
$\downarrow \Delta \rho$ component
\end{tabular} & SFR & EFR & GFR & LFR & VHTR & PWR \\
\hline Actinides & \pm 272 & \pm 871 & \pm 381 & \pm 198 & \pm 530 & \pm 851 \\
\hline Fission Products & \pm 73 & \pm 755 & \pm 130 & \pm 76 & \pm 215 & \pm 244 \\
\hline Total & \pm 282 & \pm 1153 & \pm 402 & \pm 212 & \pm 572 & \pm 885 \\
\hline
\end{tabular}

As for the other integral parameters, the results presented in Tables 18 to 20 confirm a relatively small impact of data uncertainties on the power peak values (except for the ADMAB) and on the Doppler coefficient. As for the void reactivity coefficients, the impact of nuclear data uncertainty can be not negligible in Na-cooled systems and could have some impact on current Na-void coefficient minimization studies.

In summary, most of the uncertainty values shown in Table 18, although sometimes significant, would not in principle affect the pre-conceptual design of any of the FR systems considered. However, some conservatism which could be suggested by the results shown in the table, can have some economic impact in later phases of the design, and new evaluation/experiment (differential or integral) could be well justified in order to reduce uncertainties and associated cost.

In order to point out potential high priority domains of investigation, the major features of the uncertainty impact for FRs are summarized in Tables 22 to 24. 
Table 22. Fast Reactor Systems: Uncertainties (\%) due to Pu Isotope Cross-Sections (BOLNA)

\begin{tabular}{|c|c|c|c|c|c|c|c|c|c|c|}
\hline \multirow[b]{2}{*}{ Isotope } & \multirow[b]{2}{*}{$\begin{array}{l}\text { Cross- } \\
\text { Section }\end{array}$} & ABTR & \multicolumn{2}{|c|}{ SFR } & \multicolumn{2}{|c|}{ GFR } & \multirow{2}{*}{$\begin{array}{c}\mathbf{L F R} \\
\mathbf{k}_{\text {eff }}\end{array}$} & \multicolumn{3}{|c|}{ ADMAD } \\
\hline & & $\mathbf{k}_{\text {eff }}$ & $\mathbf{k}_{\text {eff }}$ & Void & $\mathbf{k}_{\text {eff }}$ & $\begin{array}{c}\text { Power } \\
\text { Peak }\end{array}$ & & $\mathbf{k}_{\text {eff }}$ & $\begin{array}{c}\text { Power } \\
\text { Peak }\end{array}$ & Void \\
\hline \multirow{2}{*}{ Pu238 } & v & 0.01 & 0.34 & 0.44 & 0.15 & 0.03 & 0.23 & 0.13 & 0.94 & 0.22 \\
\hline & fission & 0.01 & 0.53 & 2.90 & 0.20 & 0.06 & 0.34 & 0.21 & 1.52 & 0.40 \\
\hline \multirow{2}{*}{ Pu239 } & fission & 0.24 & 0.12 & 0.87 & 0.15 & 0.03 & 0.21 & 0.12 & 0.90 & 0.27 \\
\hline & capture & 0.23 & 0.12 & 1.16 & 0.23 & 0.06 & 0.17 & 0.10 & 0.77 & 0.50 \\
\hline \multirow{3}{*}{ Pu240 } & $v$ & 0.08 & 0.39 & 2.18 & 0.20 & 0.06 & 0.33 & 0.14 & 1.02 & 0.24 \\
\hline & fission & 0.09 & 0.44 & 2.60 & 0.23 & 0.08 & 0.35 & 0.16 & 1.15 & 0.25 \\
\hline & capture & 0.06 & 0.31 & 1.80 & 0.17 & 0.06 & 0.27 & 0.08 & 0.63 & 0.32 \\
\hline Pu241 & fission & 0.12 & 0.96 & 4.09 & 0.82 & 0.16 & 0.61 & 1.04 & 7.61 & 2.04 \\
\hline \multirow{2}{*}{ Pu242 } & fission & 0.01 & 0.36 & 2.46 & 0.21 & 0.08 & 0.17 & 0.15 & 1.08 & 0.35 \\
\hline & capture & 0.01 & 0.17 & 2.21 & 0.17 & 0.05 & 0.08 & 0.06 & 0.45 & 0.33 \\
\hline
\end{tabular}

Table 23. Fast Reactor Systems: Uncertainties (\%) due to Selected MA Cross-Sections (BOLNA)

\begin{tabular}{|c|c|c|c|c|c|c|c|c|c|c|}
\hline \multirow[b]{2}{*}{ Isotope } & \multirow[b]{2}{*}{$\begin{array}{l}\text { Cross- } \\
\text { Section }\end{array}$} & ABTR & \multicolumn{2}{|c|}{ SFR } & \multicolumn{2}{|c|}{ GFR } & \multirow{2}{*}{$\begin{array}{c}\text { LFR } \\
k_{\text {eff }}\end{array}$} & \multicolumn{3}{|c|}{ ADMAD } \\
\hline & & $\mathbf{k}_{\text {eff }}$ & $\mathbf{k}_{\text {eff }}$ & Void & $\mathbf{k}_{\text {eff }}$ & $\begin{array}{c}\text { Power } \\
\text { Peak }\end{array}$ & & $\mathbf{k}_{\text {eff }}$ & $\begin{array}{c}\text { Power } \\
\text { Peak }\end{array}$ & Void \\
\hline Am241 & fission & 0.01 & 0.08 & 0.43 & 0.24 & 0.13 & 0.06 & 0.83 & 5.81 & 3.32 \\
\hline Am242m & fission & - & 0.73 & 3.70 & 0.01 & 0.01 & 0.07 & 0.14 & 1.05 & 0.32 \\
\hline Am243 & fission & - & 0.04 & 0.25 & 0.04 & 0.02 & 0.02 & 0.35 & 2.43 & 1.62 \\
\hline Cm244 & fission & - & 0.39 & 2.95 & 0.13 & 0.08 & 0.16 & 1.90 & 13.43 & 3.20 \\
\hline $\mathrm{Cm} 245$ & fission & - & 0.39 & 0.95 & 0.12 & 0.10 & 0.22 & 1.04 & 7.56 & 1.55 \\
\hline
\end{tabular}

Table 24. Fast reactor Systems: Uncertainties (\%) due to Inelastic and Capture (BOLNA)

\begin{tabular}{|c|c|c|c|c|c|c|c|c|c|c|}
\hline \multirow[b]{2}{*}{ Isotope } & \multirow[b]{2}{*}{$\begin{array}{c}\text { Cross- } \\
\text { Section }\end{array}$} & ABTR & \multicolumn{2}{|c|}{ SFR } & \multicolumn{2}{|c|}{ GFR } & \multirow{2}{*}{$\begin{array}{l}\mathbf{L F R} \\
\mathbf{k}_{\text {eff }}\end{array}$} & \multicolumn{3}{|c|}{ ADMAD } \\
\hline & & $\mathbf{k}_{\mathrm{eff}}$ & $\mathbf{k}_{\mathrm{eff}}$ & Void & $\mathbf{k}_{\text {eff }}$ & $\begin{array}{l}\text { Power } \\
\text { Peak }\end{array}$ & & $\mathbf{k}_{\text {eff }}$ & $\begin{array}{c}\text { Power } \\
\text { Peak }\end{array}$ & Void \\
\hline \multirow{2}{*}{ U238 } & inelastic & 0.69 & 0.23 & 1.96 & 1.41 & 1.54 & 0.73 & - & - & - \\
\hline & capture & 0.26 & 0.07 & 1.24 & 0.41 & 0.30 & 0.25 & - & - & - \\
\hline Fe56 & inelastic & 0.24 & 0.53 & 4.14 & - & - & 0.24 & 0.93 & 7.22 & 5.43 \\
\hline $\mathrm{Na}$ & inelastic & 0.07 & 0.25 & 13.43 & - & - & - & - & - & - \\
\hline Si28 & inelastic & - & - & - & 0.22 & 0.25 & - & - & - & - \\
\hline $\mathrm{C}$ & elastic & - & - & - & 0.31 & 0.28 & - & - & - & - \\
\hline Pb206 & inelastic & - & - & - & - & - & 0.18 & - & - & - \\
\hline Pb207 & inelastic & - & - & - & - & - & 0.16 & - & - & - \\
\hline Pb208 & elastic & - & - & - & - & - & 0.13 & - & - & - \\
\hline \multirow{3}{*}{$\mathbf{P b}{ }^{(*)}$} & inelastic & - & - & - & - & - & - & 0.04 & 0.28 & 2.28 \\
\hline & elastic & - & - & - & - & - & - & 0.05 & 0.09 & 2.84 \\
\hline & capture & - & - & - & - & - & - & 0.07 & 0.46 & 1.53 \\
\hline Bi209 & inelastic & - & - & - & - & - & - & 0.31 & 2.23 & 12.01 \\
\hline
\end{tabular}

${ }^{(*)}$ For the ADMAB calculations have been performed with the JEF2.2 library (see Section A.3) that does not distinguish the Pb isotopes.

One can point out three major data sources for the overall uncertainties:

1. the Pu isotopes (other than Pu-239) major reactions (fission, capture and nu-bar), see Table 22. In the case of $\mathrm{Pu}-239$, the major impact is due to the capture cross-section, since the uncertainties associated to this isotope and in particular to its fission cross-section are now extremely reduced, i.e. most often well below $1 \%$;

2. selected MA fission cross-sections (see Table 23), but only in TRU burner fast reactors like the SFR, which has a $15 \%$ MA content in the fuel, or in the ADMAB; 
3. inelastic cross-section data (see Table 24), and most notably of U-238, Fe-56 and Na-23 (in Na-cooled FRs).

Besides these three wide "categories" of uncertainty contributions, one should not neglect still some impact of the U-238 capture, despite the very small uncertainty values of the present covariance data evaluation.

As for the uncertainties on the nuclide densities variation between beginning and end of cycle, the most significant results are once more related to cases where the irradiation time is significant. Since the case of the EFR is the fast reactor case with the highest burnup, results are shown for Pu isotopes (Table 25) and for selected minor actinides (Table 26). These tables give the uncertainty on the nuclide density at end of cycle. In all cases, as expected, the uncertainties are due to the capture and fission cross-sections of the very same isotopes. The impact of such uncertainties can have some relevance on mass flows and inventories in the fuel cycle.

Table 25. Uncertainty (\%) on Pu Isotope Density at End of Cycle (Case of EFR)

\begin{tabular}{|c|c|c|c|c|c|c|}
\hline \multicolumn{2}{|c|}{ Uncertainty on $\rightarrow$} & \multirow{2}{*}{ Pu238 } & \multirow{2}{*}{ Pu239 } & \multirow{2}{*}{ Pu240 } & \multirow{2}{*}{ Pu241 } & \multirow{2}{*}{ Pu242 } \\
\hline due to & & & & & & \\
\hline U238 & capture & - & 1.1 & 0.2 & 0.1 & - \\
\hline \multirow{2}{*}{ Pu238 } & capture & 1.7 & 0.1 & - & - & - \\
\hline & fission & 4.6 & - & - & - & - \\
\hline \multirow{2}{*}{ Pu239 } & capture & 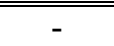 & 0.8 & 1.3 & 0.7 & 0.1 \\
\hline & fission & - & 0.2 & - & - & - \\
\hline \multirow{2}{*}{ Pu240 } & capture & 0.2 & - & 1.5 & 6.0 & 1.0 \\
\hline & fission & - & - & 0.8 & 0.4 & - \\
\hline \multirow{2}{*}{ Pu241 } & capture & - & - & - & 0.8 & 1.5 \\
\hline & fission & 0.2 & - & - & 5.0 & 0.7 \\
\hline \multirow{2}{*}{ Pu242 } & capture & - & 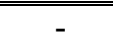 & - & - & 3.9 \\
\hline & fission & - & - & - & - & 2.2 \\
\hline \multirow{2}{*}{ Am241 } & capture & 1.3 & - & - & - & 0.2 \\
\hline & fission & 0.2 & - & - & - & - \\
\hline \multicolumn{2}{|c|}{ Total } & 5.1 & 1.3 & 2.1 & 7.9 & 4.9 \\
\hline
\end{tabular}

Table 26. Uncertainty (\%) on Selected MA Density at End of Cycle (Case of EFR)

\begin{tabular}{|c|c|c|c|c|c|c|}
\hline \multicolumn{2}{|c|}{ Uncertainty on $\rightarrow$} & \multirow{2}{*}{ Am241 } & \multirow{2}{*}{ Am242m } & \multirow{2}{*}{ Am243 } & \multirow{2}{*}{ Cm244 } & \multirow{2}{*}{$\mathrm{Cm} 245$} \\
\hline \multicolumn{2}{|c|}{$\downarrow$ due to } & & & & & \\
\hline \multirow{2}{*}{ Pu240 } & capture & 1.6 & 0.6 & 0.2 & - & - \\
\hline & fission & 0.1 & - & - & - & - \\
\hline \multirow{2}{*}{ Pu241 } & capture & 0.2 & 0.1 & 0.4 & 0.1 & - \\
\hline & fission & 1.2 & 0.4 & 0.1 & - & - \\
\hline \multirow{2}{*}{ Pu242 } & capture & - & - & 9.3 & 4.1 & 1.5 \\
\hline & fission & - & - & 0.6 & 0.2 & - \\
\hline \multirow{2}{*}{ Am241 } & capture & 3.1 & 2.0 & 0.1 & - & - \\
\hline & fission & 0.9 & 0.5 & - & - & - \\
\hline \multirow{2}{*}{ Am 242m } & capture & - & 1.6 & 0.3 & 0.2 & 0.1 \\
\hline & fission & - & 7.4 & 0.1 & - & - \\
\hline \multirow{2}{*}{ Am243 } & capture & - & - & 1.9 & 1.9 & 1.0 \\
\hline & fission & - & - & 0.5 & 0.2 & 0.1 \\
\hline \multirow{2}{*}{ Cm244 } & capture & - & - & - & 1.8 & 7.2 \\
\hline & fission & - & - & - & 6.0 & 2.8 \\
\hline \multirow{2}{*}{ Cm245 } & capture & - & - & - & - & 0.9 \\
\hline & fission & - & - & - & - & 15.6 \\
\hline \multicolumn{2}{|c|}{ Total } & 3.8 & 7.8 & 9.5 & 7.8 & 17.6 \\
\hline
\end{tabular}


As far as thermal neutron systems, relatively small uncertainties on integral parameters are observed, see Table 27 , since very small uncertainties are assumed on the low energy data of U-235, U-238, and Pu-239 and also of the $\mathrm{Pu}-240$ capture close to the first resonance. There is however a few significant contributions as, e.g., the Pu241 fission cross-section uncertainty to the PWR end-of-cycle reactivity.

As for the energy break-down of the uncertainties, Table 28 gives, as a typical example, the energy break-down in the case of the SFR $\mathrm{k}_{\text {eff }}$ of a few fission and capture contributions. The wide energy range $(\sim 5 \mathrm{MeV}-1 \mathrm{keV})$ of relevance is due to the variety of fast spectra considered.

Table 27. Thermal systems: Uncertainties (\%) due to Selected Isotopes and Reactions (BOLNA)

\begin{tabular}{||c|c||c||c||}
\cline { 3 - 4 } \multicolumn{2}{c|}{} & \multicolumn{1}{c|}{ PWR } & VHTR \\
\hline \multirow{2}{*}{ Isotope } & $\begin{array}{c}\text { Cross- } \\
\text { Section }\end{array}$ & $\mathbf{k}_{\text {eff }}$ EOC & $\mathbf{k}_{\text {eff }}$ EOC \\
\hline \multirow{2}{*}{ U238 } & $\mathbf{v}$ & 0.17 & 0.27 \\
\cline { 2 - 4 } & inelastic & 0.17 & 0.00 \\
\hline \multirow{2}{*}{ Pu239 } & capture & 0.26 & 0.19 \\
\cline { 2 - 4 } & fission & 0.18 & 0.10 \\
\hline \multirow{2}{*}{ ca240 } & capture & 0.07 & 0.11 \\
\hline \multirow{2}{*}{ cu241 } & fission & 0.12 & 0.06 \\
\hline & capture & 0.34 & 0.13 \\
\hline $\mathbf{O}$ & capture & 0.43 & 0.13 \\
\hline
\end{tabular}

Table 28. SFR $\mathrm{k}_{\text {eff }}$ Uncertainties (\%). Energy Breakdown [pcm] for Selected Isotopes/Reactions

\begin{tabular}{|c|c|c|c|c|c|}
\hline Group & Energy ${ }^{(a)}$ & $\begin{array}{c}\mathbf{P u - 2 3 8} \\
\sigma_{\text {fission }} \\
\end{array}$ & $\begin{array}{l}\text { Pu-240 } \\
\sigma_{\text {capture }} \\
\end{array}$ & $\begin{array}{c}\text { Pu-241 } \\
\sigma_{\text {fission }} \\
\end{array}$ & $\begin{array}{c}\mathbf{A m - 2 4 2 m} \\
\sigma_{\text {fission }} \\
\end{array}$ \\
\hline$\overline{11}$ & $19.6 \mathrm{MeV}$ & $\begin{array}{c}0.01 \\
\end{array}$ & $\begin{array}{c}0.00 \\
\end{array}$ & $\begin{array}{c}0.02 \\
\end{array}$ & 0.02 \\
\hline 2 & 6.07 MeV & 0.18 & 0.03 & 0.10 & 0.12 \\
\hline 3 & $2.23 \mathrm{MeV}$ & 0.23 & 0.05 & 0.26 & 0.15 \\
\hline 4 & $1.35 \mathrm{MeV}$ & 0.31 & 0.11 & 0.40 & 0.28 \\
\hline 5 & $498 \mathrm{keV}$ & 0.28 & 0.14 & 0.47 & 0.39 \\
\hline 6 & $183 \mathrm{keV}$ & 0.12 & 0.16 & 0.58 & 0.39 \\
\hline 7 & $67.4 \mathrm{keV}$ & 0.07 & 0.13 & 0.29 & 0.28 \\
\hline 8 & $24.8 \mathrm{keV}$ & 0.06 & 0.13 & 0.16 & 0.12 \\
\hline 9 & $9.12 \mathrm{keV}$ & 0.03 & 0.05 & 0.10 & 0.08 \\
\hline 10 & $2.03 \mathrm{keV}$ & 0.03 & 0.01 & 0.08 & 0.10 \\
\hline 11 & $454 \mathrm{eV}$ & 0.00 & 0.00 & 0.03 & 0.02 \\
\hline $12-15$ & $22.6 \mathrm{eV}$ & 0.00 & 0.00 & 0.00 & 0.00 \\
\hline \multicolumn{2}{|c|}{ Total } & 0.53 & 0.31 & 0.96 & 0.73 \\
\hline
\end{tabular}

(a) Upper energy boundary

The present results are of a very high relevance for future reactor system feasibility studies, since for the first time, a scientifically based, even if yet preliminary, set of variance-covariance data is available to reactor system designers, which allows to establish reliable uncertainties on all reactor and fuel cycle design parameters.

One important point seems to be the shift of priority from the three major actinide fission data to their inelastic (in particular for U-238) and capture data (for Pu-239, and, at a lesser extent, for U-238; the case of U-235 capture data in the $\mathrm{keV}$ region is presently under investigation). Higher priority should also be given to higher $\mathrm{Pu}$ isotopes (and in particular to their fission data) and to selected coolant/structural material inelastic cross-sections (e.g. Fe-56 and Na-23). Minor actinide data play a significant role only for dedicated burner reactors (ADMAB or critical) with Conversion Ratio $\mathrm{CR}=0$ and a content of $\mathrm{MA}$ in the fuel of $50 \%$ or higher. For more conventional burners $(\mathrm{Pu} / \mathrm{Ma} \sim 5)$ and down to $\mathrm{CR} \sim 0.25$, only selected $\mathrm{MA}$ data require significant improvements. 
Finally, a complementary re-assessment of the uncertainty on decay heat and on some other fuel cycle parameters for innovative systems will be performed as part of the future activity of the WPEC Subgroup.

\section{A.5. Target Accuracy Assessment}

Within the Subgroup 26, a preliminary list of design target accuracies has been agreed upon for fast reactor systems (at first, independently of the coolant or the fuel type), see Table 29, for (V)HTRs, see Table 30, and for high burnup PWRs, see Table 31. These target accuracies reflect the perceived status of the art, even if they are not the result of a systematic analysis, which should necessarily involve industrial partners. Moreover, it has to be kept in mind that no well defined "images" for any of the Gen-IV systems exist at present. This means that the target accuracies shown in particular in Table 29 reflect the current thinking of systems with innovative fuels and core configurations described in Ref. 2, i.e. the Na-cooled systems (burners with different fuel types as the SFR and ABTR, or self-sustaining as the EFR), gas-cooled GFR and lead-cooled LFR. The case of the (V)HTR is somewhat different, since the target accuracies shown in Table 30 were suggested by a major industry (AREVA). In absence of specific information, the same target accuracies of the FRs have been selected for the ADMAB, while the accuracy requirements for the PWR have been taken from Ref. 2.

Table 29. Fast Reactor and ADMAB Target Accuracies ( $1 \sigma)$

\begin{tabular}{|l|c|}
\hline Multiplication factor (BOL) & $300 \mathrm{pcm}$ \\
\hline Power peak (BOL) & $2 \%$ \\
\hline Burnup reactivity swing & $300 \mathrm{pcm}$ \\
\hline Reactivity coefficients (Coolant void and Doppler - BOL) & $7 \%$ \\
\hline Major nuclide density at end of irradiation cycle & $2 \%$ \\
\hline Other nuclide density at end of irradiation cycle & $10 \%$ \\
\hline
\end{tabular}

Table 30. Target Accuracy $(1 \sigma)$ for $\mathrm{UO}_{2}$ - and $\mathrm{PuO}_{2}$-Fuelled HTR's

(Source: AREVA-NP, reproduced with permission for WPEC/SG26)

\begin{tabular}{|l|c|}
\hline Criticality & $300 \mathrm{pcm}$ (operation); 500 pcm (safety) \\
\hline $\begin{array}{l}\text { Local power } \\
\text { (in fuel compact) }\end{array}$ & $\begin{array}{c}6 \% \text { (2\% in pin-wise fission rate of fresh fuel; } \\
4 \% \text { in main fissile isotope conc. of irradiated fuel) }\end{array}$ \\
\hline Burnup (cycle length) & $1 \%(\Rightarrow \sim 500 \mathrm{MWd} / \mathrm{t})$ \\
\hline Doppler coefficient & $20 \%$ \\
\hline Moderator temperature coefficient & $1 \mathrm{pcm} /{ }^{\circ} \mathrm{C}$ \\
\hline Nuclide inventories at EOL & $4 \%$ \\
Main fissile isotopes & $5 \%$ \\
Fertile isotopes & $20 \%$ \\
MAs and FPs & \\
\hline
\end{tabular}

Table 31. PWR Target Accuracies $(1 \sigma)$

\begin{tabular}{|c|c|c|c|}
\hline $\mathrm{k}_{\mathrm{eff}}$ & $\begin{array}{c}\text { Doppler } \\
\text { Reactivity Coefficient }\end{array}$ & $\begin{array}{c}\text { Burnup } \\
\Delta \rho\end{array}$ & Transmutation \\
\hline $0.5 \%$ & $10 \%$ & $500 \mathrm{pcm}$ & $5 \%$ \\
\hline
\end{tabular}

The cross-sections uncertainties required for satisfying the target accuracies have been calculated by a minimization process [2] that satisfies the nonlinear constraints with bounded parameters. Several optimization codes (including OPTIMA, KNITRO, SNOPT, etc.) were tested for this minimization process in order to verify that consistent answers were obtained and not local minima. At the end, the SNOPT code [36] was selected because of the ease in using the FORTRAN interface. 
At the first stage it was decided not to account for correlations between data. This assumption is of course rather arbitrary, but it is consistent with standard requirements for reactor design in early phases of development. The "BOLNA diagonal" uncertainties are provided in Table 32 (in red are the uncertainties out of the required accuracies). As general view, it can be observed that the power peak, the Doppler and void reactivity coefficients, meet the accuracy requirements in all cases with the only exception of the ADMAB for the three parameters and of the SFR for the void coefficient. The worst situation is represented by the ADMAB, where all integral parameter uncertainties (with the only exception of the nuclide densities at end of irradiation, due to the short burnup) do not meet the accuracy requirements.

Additionally, to avoid the introduction of meaningless parameters, as unknown parameters (i.e., as cross-sections for which target accuracies are required), only those which globally account at least for $98 \%$ of the overall uncertainty for each integral parameter have been chosen.

Table 32. Integral Parameter Uncertainties (\%) Using the BOLNA Diagonal Covariance Matrix

\begin{tabular}{|c|c|c|c|c|c|c|c|c|}
\hline & ABTR & SFR & EFR & GFR & LFR & ADMAB & VHTR & PWR \\
\hline $\mathbf{k}_{\text {eff }} \mathbf{B O C}$ & 0.62 & 1.04 & 0.79 & 1.24 & 0.88 & 1.95 & 0.37 & 0.36 \\
\hline $\mathbf{k}_{\text {eff }}$ EOC & - & - & - & - & - & - & 0.41 & 0.64 \\
\hline Power Peak BOC & 0.32 & 0.31 & 0.81 & 1.18 & 0.45 & 14.22 & 0.85 & - \\
\hline Power Peak EOC & - & - & - & - & - & - & 0.90 & - \\
\hline Doppler BOC & 2.86 & 3.62 & 2.46 & 3.62 & 2.85 & - & 4.27 & 1.53 \\
\hline Doppler EOC & - & - & - & - & - & - & 2.77 & 2.01 \\
\hline Void & 5.11 & 15.66 & 6.68 & 5.46 & 4.97 & 13.11 & - & - \\
\hline Burnup [pem] & 37.4 & 152.1 & 584.9 & 254.2 & 127.7 & 602.9 & 487.0 & 684.6 \\
\hline $\mathbf{N}_{\mathrm{f}, \mathrm{U} 235}$ & 0.07 & 0.31 & 2.57 & 0.42 & 0.36 & - & 0.25 & 0.46 \\
\hline $\mathbf{N}_{\mathrm{f}, \mathrm{U} 238}$ & 0.01 & 0.02 & 0.24 & 0.04 & 0.03 & - & 0.05 & 0.04 \\
\hline $\mathbf{N}_{\mathrm{f}, \mathrm{Np237}}$ & 0.25 & 0.11 & 2.51 & 0.25 & 0.18 & 0.20 & 1.03 & 1.05 \\
\hline $\mathbf{N}_{\mathrm{f}, \mathrm{Pu} 238}$ & 0.21 & 0.42 & 2.71 & 0.64 & 0.56 & 1.13 & 1.28 & 1.05 \\
\hline $\mathbf{N}_{\mathbf{f}, \mathbf{P u 2 3 9}}$ & 0.04 & 0.06 & 1.13 & 0.37 & 0.20 & 0.12 & 0.96 & 0.88 \\
\hline $\mathbf{N}_{\mathrm{f}, \mathrm{Pu} 240}$ & 0.13 & 0.10 & 1.25 & 0.31 & 0.16 & 0.26 & 1.25 & 1.11 \\
\hline $\mathbf{N}_{\mathrm{f}, \mathrm{Pu} 241}$ & 0.35 & 0.62 & 3.99 & 0.83 & 1.19 & 0.90 & 2.04 & 2.02 \\
\hline $\mathbf{N}_{\mathrm{f}, \mathrm{Pu} 242}$ & 0.13 & 0.25 & 2.75 & 0.51 & 0.35 & 0.54 & 4.75 & 3.87 \\
\hline $\mathbf{N}_{\mathrm{f}, \mathrm{Am} 241}$ & 0.08 & 0.18 & 2.12 & 0.35 & 0.27 & 0.31 & 2.13 & 2.50 \\
\hline $\mathbf{N}_{\mathrm{f}, \mathrm{Am} 242 \mathrm{~m}}$ & 0.47 & 0.70 & 4.26 & 2.17 & 1.17 & 1.72 & 5.63 & 5.41 \\
\hline $\mathbf{N}_{\mathbf{f}, \mathbf{A m 2 4 3}}$ & 0.35 & 0.47 & 6.41 & 1.07 & 0.91 & 0.27 & 5.58 & 4.48 \\
\hline $\mathbf{N}_{\mathrm{f}, \mathrm{Cm} 242}$ & 1.13 & 1.38 & 1.58 & 2.43 & 2.49 & 2.78 & 1.88 & 1.87 \\
\hline $\mathbf{N}_{\mathrm{f}, \mathrm{Cm} 243}$ & 1.30 & 1.90 & 10.59 & 3.91 & 3.29 & 3.04 & 8.37 & 5.50 \\
\hline $\mathbf{N}_{\mathrm{f}, \mathrm{Cm} 244}$ & 0.38 & 0.73 & 4.83 & 0.91 & 0.88 & 1.07 & 6.01 & 4.77 \\
\hline $\mathbf{N}_{\mathrm{f}, \mathrm{Cm} 245}$ & 0.90 & 1.47 & 9.37 & 1.83 & 2.35 & 2.48 & 8.02 & 6.84 \\
\hline $\mathbf{N}_{\mathrm{f}, \mathrm{Cm} 246}$ & 0.51 & 0.47 & 4.48 & 1.35 & 0.57 & 3.12 & - & - \\
\hline
\end{tabular}

Concerning the cost parameters, quantifying the effort of improving specific nuclear data with respect to the others, as already done in previous work [2], a constant value of one is initially associated to all cross-sections, no matter which is the isotope or the energy range.

Table 33 shows a summary of the results obtained over the whole set of fast reactors. Values are given as uncertainty ranges within selected energy intervals and only the most significant values are shown. 
Table 33. Summary Target Accuracies for Fast Reactors

\begin{tabular}{|c|c|c|c|c|}
\hline & & Energy Range & $\begin{array}{c}\text { Current } \\
\text { Accuracy (\%) } \\
\end{array}$ & $\begin{array}{c}\text { Target } \\
\text { Accuracy }(\%) \\
\end{array}$ \\
\hline \multirow{2}{*}{ U238 } & $\sigma_{\text {inel }}$ & $6.07 \div 0.498 \mathrm{MeV}$ & $10 \div 20$ & $2 \div 3$ \\
\hline & $\sigma_{\text {capt }}$ & $24.8 \div 2.04 \mathrm{keV}$ & $3 \div 9$ & $1.5 \div 2$ \\
\hline Pu241 & $\sigma_{\text {fiss }}$ & $1.35 \mathrm{MeV} \div 454 \mathrm{eV}$ & $8 \div 20$ & $\begin{array}{lc}2 \div 3 & \text { (SFR,GFR,LFR) } \\
5 \div 8 & \text { (ABTR,EFR) }\end{array}$ \\
\hline Pu239 & $\sigma_{\text {capt }}$ & $498 \div 2.04 \mathrm{keV}$ & $7 \div 15$ & $4 \div 7$ \\
\hline \multirow{2}{*}{ Pu240 } & $\sigma_{\text {fiss }}$ & $1.35 \div 0.498 \mathrm{MeV}$ & 6 & $1.5 \div 2$ \\
\hline & $\mathbf{v}$ & $1.35 \div 0.498 \mathrm{MeV}$ & 4 & $1 \div 3$ \\
\hline Pu242 & $\sigma_{\text {fiss }}$ & $2.23 \div 0.498 \mathrm{MeV}$ & $19 \div 21$ & $3 \div 5$ \\
\hline Pu238 & $\sigma_{\text {fiss }}$ & $1.35 \div 0.183 \mathrm{MeV}$ & 17 & $3 \div 5$ \\
\hline Am242m & $\sigma_{\text {fiss }}$ & $1.35 \mathrm{MeV} \div 67.4 \mathrm{keV}$ & 17 & $3 \div 4$ \\
\hline Am241 & $\sigma_{\text {fiss }}$ & $6.07 \div 2.23 \mathrm{MeV}$ & 12 & 3 \\
\hline $\mathrm{Cm} 244$ & $\sigma_{\text {fiss }}$ & $1.35 \div 0.498 \mathrm{MeV}$ & 50 & 5 \\
\hline $\mathrm{Cm} 245$ & $\sigma_{\text {fiss }}$ & $183 \div 67.4 \mathrm{keV}$ & 47 & 7 \\
\hline Fe56 & $\sigma_{\text {inel }}$ & $2.23 \div 0.498 \mathrm{MeV}$ & $16 \div 25$ & $3 \div 6$ \\
\hline $\mathrm{Na23}$ & $\sigma_{\text {inel }}$ & $1.35 \div 0.498 \mathrm{MeV}$ & 28 & $4 \div 10$ \\
\hline Pb206 & $\sigma_{\text {inel }}$ & $2.23 \div 1.35 \mathrm{MeV}$ & 14 & 3 \\
\hline Pb207 & $\sigma_{\text {inel }}$ & $1.35 \div 0.498 \mathrm{MeV}$ & 11 & 3 \\
\hline \multirow{2}{*}{ Si28 } & $\sigma_{\text {inel }}$ & $6.07 \div 1.35 \mathrm{MeV}$ & $14 \div 50$ & $3 \div 6$ \\
\hline & $\sigma_{\text {capt }}$ & $19.6 \div 6.07 \mathrm{MeV}$ & 53 & 6 \\
\hline
\end{tabular}

Several relevant features can be pointed out. As expected from the results of the uncertainty analysis, very tight requirements are shown for the $\sigma_{\text {inel }}$ of U-238 (2-3\%), Fe-56 (3-6\%), Na-23 (4-10\%) and even for Pb isotopes. The required accuracies are probably beyond achievable limits with current techniques. Additionally, using specific sets of cost parameters, it has been demonstrated [4] that there are little margins to relax the requirements on $\sigma_{\text {inel }}$ if one does not want to produce comparably difficult requirements on some $\mathrm{Pu}$ isotope $\sigma_{\text {fiss }}$ and $\sigma_{\text {capt }}$. In any case, the accuracy requirements for Pu isotopes are very tight (very often $<2-3 \%$ ). As for $\sigma_{\text {capt }}$, the requirements for U-238 and Pu-239 aim to cut by more then a factor of 2 the current uncertainties. The high content of $\mathrm{Pu}$ in the fuel and the relatively clean $\mathrm{Pu}$ vector are at the origin of the observations made. The requirement for improved accuracy of the higher $\mathrm{Pu}$ isotopes, and in particular the fission of $\mathrm{Pu}-241$, is more stringent for the EFR, GFR and LFR cases.

In the case of MA, uncertainties improvements for selected isotopes and reactions in some cases are very significant. However, this is the case when MA play an important role in the critical balance, as for MA dedicated burner with a fuel heavily loaded with MA (SFR and ADMAD). For these very specific cases, the accuracy requirement for $\sigma_{\text {fiss }}$ of selected MA isotopes can go from 3 to $7 \%$.

A few specific requirements are shown according to specificities of some cores, e.g. Si data requirements for the GFR and $\mathrm{Pb}$ data for the LFR and ADMAB.

Tables 34 and 35 give a summary of the main data requirements related to the thermal neutron systems, i.e. the VHTR (Table 34) and the extended burnup PWR (Table 35). The present analysis indicates few relevant requirements. In the case of the VHTR, it is required to improve Pu-241 $\sigma_{\text {fiss }}$ below $\sim 400 \mathrm{eV}$. Pu-239 and Pu-241 very tight $\sigma_{\text {capt }}$ requirement below $\sim 0.5 \mathrm{eV}$ are also shown, together with $\mathrm{C}$ data improvements (both capture and inelastic) with respect to current uncertainty estimates. For the PWR with extended burnup, the requirements to improve $\mathrm{Pu}-241$ and some $\mathrm{O}$ data can be stressed. 
Table 34. VHTR: Uncertainty Reduction Requirements Needed to Meet Integral Parameter Target Accuracies

\begin{tabular}{|c|c|c|c|c|}
\hline \multirow{2}{*}{ Isotope } & \multirow{2}{*}{$\begin{array}{l}\text { Cross- } \\
\text { Section } \\
\end{array}$} & \multirow{2}{*}{ Energy Range } & \multicolumn{2}{|c|}{ Uncertainty (\%) } \\
\hline & & & Initial & Required \\
\hline U238 & $\sigma_{\text {capt }}$ & $454-22.6 \mathrm{eV}$ & 1.7 & 1.2 \\
\hline $\mathbf{C}$ & $\sigma_{\text {inel }}$ & $19.6-6.07 \mathrm{MeV}$ & 30.0 & 7.1 \\
\hline \multirow{2}{*}{$\mathbf{C}$} & \multirow{2}{*}{$\sigma_{\text {capt }}$} & $19.6-6.07 \mathrm{MeV}$ & 20.0 & 7.1 \\
\hline & & $4-0.54 \mathrm{eV}$ & 20.0 & 5.0 \\
\hline Pu239 & $\sigma_{\text {capt }}$ & $0.54 \mathrm{eV}-0.1 \mathrm{eV}$ & 1.4 & 0.9 \\
\hline \multirow{3}{*}{ Pu241 } & \multirow{3}{*}{$\sigma_{\text {fiss }}$} & $454-22.6 \mathrm{eV}$ & 19.4 & 6.4 \\
\hline & & $4-0.54 \mathrm{eV}$ & 26.8 & 9.4 \\
\hline & & $0.54 \mathrm{eV}-0.1 \mathrm{eV}$ & 2.9 & 1.5 \\
\hline Pu241 & $\sigma_{\text {capt }}$ & $0.54 \mathrm{eV}-0.1 \mathrm{eV}$ & 6.8 & 2.4 \\
\hline
\end{tabular}

Table 35. PWR: Uncertainty Reduction Requirements Needed to Meet Integral Parameter Target Accuracies

\begin{tabular}{|c|c|c|c|c|}
\hline \multirow{2}{*}{ Isotope } & \multirow{2}{*}{$\begin{array}{l}\text { Cross- } \\
\text { Section }\end{array}$} & \multirow{2}{*}{ Energy Range } & \multicolumn{2}{|c|}{ Uncertainty (\%) } \\
\hline & & & Initial & Required \\
\hline \multirow{2}{*}{$\mathbf{O}$} & \multirow{2}{*}{$\sigma_{\text {capt }}$} & $19.6-6.07 \mathrm{MeV}$ & 100.0 & 12.1 \\
\hline & & $6.07-2.23 \mathrm{MeV}$ & 100.0 & 9.9 \\
\hline \multirow{4}{*}{ Pu241 } & \multirow{4}{*}{$\sigma_{\text {fiss }}$} & $454-22.6 \mathrm{eV}$ & 19.4 & 4.7 \\
\hline & & $4-0.54 \mathrm{eV}$ & 26.8 & 7.7 \\
\hline & & $0.54 \mathrm{eV}-0.1 \mathrm{eV}$ & 2.9 & 1.7 \\
\hline & & $0.1 \mathrm{eV}$ - thermal & 3.3 & 1.9 \\
\hline Pu239 & $\sigma_{\text {capt }}$ & $0.54 \mathrm{eV}-0.1 \mathrm{eV}$ & 1.4 & 1.0 \\
\hline \multirow{2}{*}{ U238 } & \multirow{2}{*}{$\sigma_{\text {capt }}$} & $24.8-9.12 \mathrm{keV}$ & 9.4 & 4.6 \\
\hline & & $454-22.6 \mathrm{eV}$ & 1.7 & 1.4 \\
\hline U238 & $\sigma_{\text {inel }}$ & $6.07-2.23 \mathrm{MeV}$ & 14.6 & 5.1 \\
\hline Pu241 & $\overline{\sigma_{\text {capt }}}$ & $0.54 \mathrm{eV}-0.1 \mathrm{eV}$ & 6.8 & 3.0 \\
\hline Pu240 & $\sigma_{\text {capt }}$ & $0.1 \mathrm{eV}$ - thermal & 4.8 & 3.1 \\
\hline \multirow{2}{*}{$\mathbf{O}$} & \multirow{2}{*}{$\sigma_{\text {inel }}$} & $6.07-2.23 \mathrm{MeV}$ & 54.9 & 12.6 \\
\hline & & $19.6-6.07 \mathrm{MeV}$ & 84.6 & 15.6 \\
\hline
\end{tabular}

The required cross-section accuracies, obtained from the optimization procedures, are such that the design target accuracies are fulfilled in most cases.

Since many of the requirements are very tight (as e.g. for some $\sigma_{\text {inel, }}$, in particular for U-238; for the $\sigma_{\text {fiss }}$ of Pu241 , between $\sim 1-500 \mathrm{keV}$; and for $\sigma_{\text {capt }}$ of Pu-239 at $\sim 1-500 \mathrm{keV}$ ) and difficult to be met within a reasonable time horizon, it seems that a strategy of combined use of integral and differential measurements should be pursued (see Sections IV and V). Finally, it should be stressed the essential role played by the recent effort in several laboratories to assess credible uncertainty data, which help to define a sound strategy for nuclear data improvements to meet the needs of future reactors and their associated fuel cycles. 


\section{Appendix B. Model Description}

Table 36. ABTR Geometry and Homogenized Compositions $\left[10^{24} \mathrm{at} / \mathrm{cm}^{3}\right]$

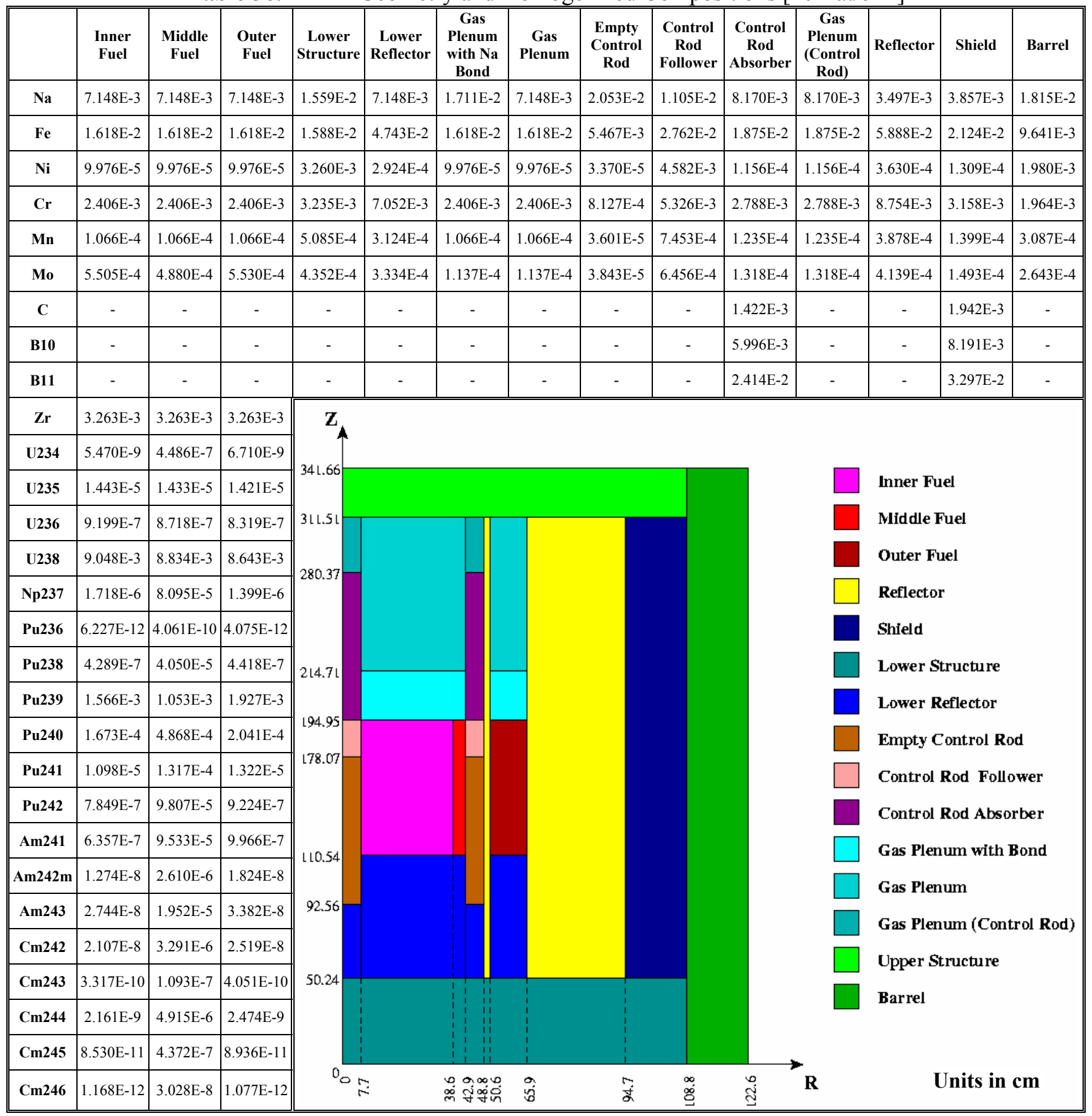


Table 37. SFR Geometry and Homogenized Compositions $\left[10^{24} \mathrm{at} / \mathrm{cm}^{3}\right]$

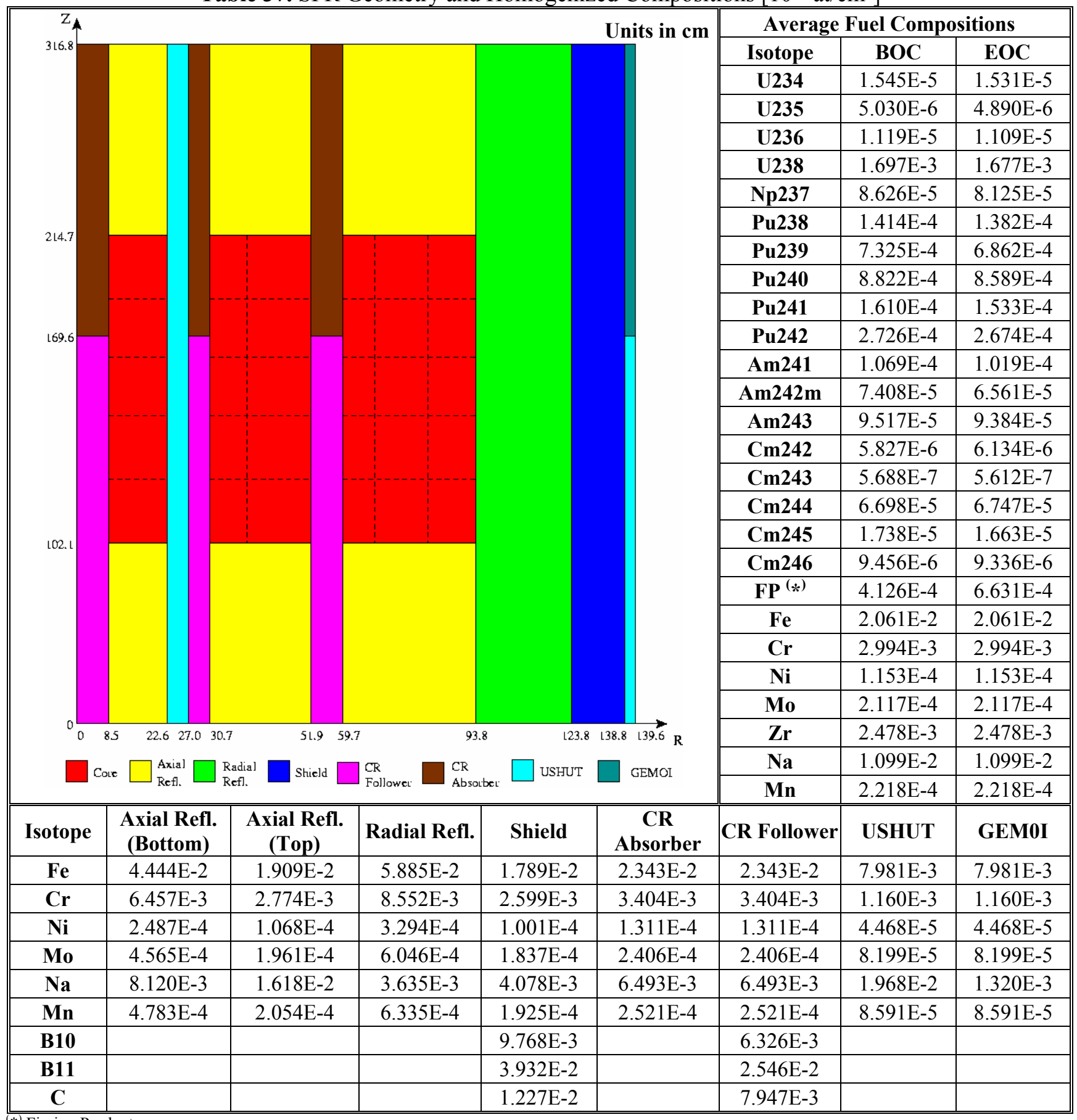

(*) Fission Products 
Table 38. EFR Geometry and Homogenized Compositions $\left[10^{24} \mathrm{at} / \mathrm{cm}^{3}\right]$

\begin{tabular}{|c|c|c|c|c|c|c|c|c|c|c|}
\hline & & & & & & & Avera & Fuel Con & ositions & \\
\hline & & & & & & & & & Bla & ket \\
\hline & & & & & & & BOC & EOC & BOC & EOC \\
\hline${ }_{240}^{20}$ & & & & & & U234 & $9.517 \mathrm{E}-6$ & $7.239 \mathrm{E}-6$ & $6.577 \mathrm{E}-8$ & $5.542 \mathrm{E}-8$ \\
\hline & & & & & & U235 & $5.975 \mathrm{E}-6$ & $3.357 \mathrm{E}-6$ & $8.748 \mathrm{E}-6$ & $5.322 \mathrm{E}-6$ \\
\hline & & & & & & U236 & $6.585 \mathrm{E}-6$ & $6.347 \mathrm{E}-6$ & $2.798 \mathrm{E}-6$ & $3.273 \mathrm{E}-6$ \\
\hline & & & & & & U238 & $6.613 \mathrm{E}-3$ & $5.701 \mathrm{E}-3$ & $9.555 \mathrm{E}-3$ & $8.951 \mathrm{E}-3$ \\
\hline & & & & & & Np237 & $9.356 \mathrm{E}-6$ & $8.880 \mathrm{E}-6$ & $1.089 \mathrm{E}-14$ & $1.268 \mathrm{E}-6$ \\
\hline & & & & & & Pu238 & $3.902 \mathrm{E}-5$ & $3.561 \mathrm{E}-5$ & $1.084 \mathrm{E}-14$ & $2.887 \mathrm{E}-7$ \\
\hline & & & & & & Pu239 & $1.109 \mathrm{E}-3$ & $8.623 \mathrm{E}-4$ & $1.079 \mathrm{E}-14$ & $4.211 \mathrm{E}-4$ \\
\hline & & & & & & Pu240 & $6.633 \mathrm{E}-4$ & $6.015 \mathrm{E}-4$ & $1.075 \mathrm{E}-14$ & $4.081 \mathrm{E}-5$ \\
\hline & & & & & & Pu241 & $6.598 \mathrm{E}-5$ & $8.287 \mathrm{E}-5$ & $1.070 \mathrm{E}-14$ & $3.299 \mathrm{E}-6$ \\
\hline & & & & & & Pu242 & $7.264 \mathrm{E}-5$ & $6.870 \mathrm{E}-5$ & $1.066 \mathrm{E}-14$ & $1.621 \mathrm{E}-7$ \\
\hline & & & & & & Am241 & $5.991 \mathrm{E}-5$ & $3.354 \mathrm{E}-5$ & $1.070 \mathrm{E}-14$ & $2.032 \mathrm{E}-7$ \\
\hline & & & & & & Am242m & $2.974 \mathrm{E}-6$ & $3.073 \mathrm{E}-6$ & $1.066 \mathrm{E}-14$ & $3.787 \mathrm{E}-9$ \\
\hline & & & & & & Am243 & $1.685 \mathrm{E}-5$ & $1.745 \mathrm{E}-5$ & $1.062 \mathrm{E}-14$ & $6.707 \mathrm{E}-9$ \\
\hline & & & & & & Cm242 & $7.985 \mathrm{E}-9$ & $2.774 \mathrm{E}-6$ & $1.066 \mathrm{E}-14$ & $8.353 \mathrm{E}-9$ \\
\hline & & & & & & Cm243 & $4.087 \mathrm{E}-7$ & $3.707 \mathrm{E}-7$ & $1.062 \mathrm{E}-14$ & $3.101 \mathrm{E}-10$ \\
\hline & & & & & & Cm244 & $1.217 \mathrm{E}-5$ & $1.554 \mathrm{E}-5$ & $1.057 \mathrm{E}-14$ & $8.114 \mathrm{E}-10$ \\
\hline & & & & & & Cm245 & $2.816 \mathrm{E}-6$ & $2.577 \mathrm{E}-6$ & $1.053 \mathrm{E}-14$ & $3.483 \mathrm{E}-11$ \\
\hline & & & & & & Cm246 & $1.776 \mathrm{E}-6$ & $1.544 \mathrm{E}-6$ & $1.049 \mathrm{E}-14$ & $6.773 \mathrm{E}-13$ \\
\hline & 49.455 .0 & $99.2 \quad 104.0$ & & $202.5 \quad 220.5$ & $270.3 \mathrm{R}$ & Cm247 & $1.893 \mathrm{E}-7$ & $2.583 \mathrm{E}-7$ & $1.044 \mathrm{E}-14$ & $2.496 \mathrm{E}-14$ \\
\hline$\square \underbrace{\text { Intinal }}_{\text {Cort }}$ & $\square \substack{\text { Extetinal } \\
\text { Coute }}$ & $\square$ Axial & & $\square$ stucture & Reffector & Cm248 & $1.107 \mathrm{E}-7$ & $1.587 \mathrm{E}-7$ & $1.040 \mathrm{E}-14$ & $1.021 \mathrm{E}-14$ \\
\hline & & & & & & $\mathbf{F P} \mathbf{P}^{(*)}$ & $1.190 \mathrm{E}-13$ & $2.474 \mathrm{E}-3$ & $7.581 \mathrm{E}-14$ & $2.764 \mathrm{E}-4$ \\
\hline & & & & & & $\mathbf{O}$ & $1.721 \mathrm{E}-2$ & $1.721 \mathrm{E}-2$ & $1.894 \mathrm{E}-2$ & $1.894 \mathrm{E}-2$ \\
\hline & & & & & its in $\mathrm{cm}$ & $\mathbf{F e}$ & $1.298 \mathrm{E}-2$ & $1.298 \mathrm{E}-2$ & $1.246 \mathrm{E}-2$ & $1.246 \mathrm{E}-2$ \\
\hline & & & & & & $\mathrm{Cr}$ & $3.075 \mathrm{E}-3$ & $3.075 \mathrm{E}-3$ & $2.951 \mathrm{E}-3$ & $2.951 \mathrm{E}-3$ \\
\hline & & & & & & $\mathbf{N i}$ & $2.913 \mathrm{E}-3$ & $2.913 \mathrm{E}-3$ & $2.796 \mathrm{E}-3$ & $2.796 \mathrm{E}-3$ \\
\hline & Reflector & Structure & & Reflector & Structure & Mo & $1.724 \mathrm{E}-4$ & $1.724 \mathrm{E}-4$ & $1.654 \mathrm{E}-4$ & $1.654 \mathrm{E}-4$ \\
\hline $\mathrm{Fe}$ & $2.759 \mathrm{E}-2$ & $4.967 \mathrm{E}-3$ & $\mathrm{Ti}$ & $1.957 \mathrm{E}-4$ & $3.523 \mathrm{E}-5$ & Ti & $9.206 \mathrm{E}-5$ & $9.206 \mathrm{E}-5$ & $8.837 \mathrm{E}-5$ & $8.837 \mathrm{E}-5$ \\
\hline $\mathrm{Cr}$ & $6.536 \mathrm{E}-3$ & $1.176 \mathrm{E}-3$ & $\mathrm{Si}$ & $7.092 \mathrm{E}-4$ & $1.277 \mathrm{E}-4$ & Si & $3.336 \mathrm{E}-4$ & $3.336 \mathrm{E}-4$ & $3.203 \mathrm{E}-4$ & $3.203 \mathrm{E}-4$ \\
\hline $\mathbf{N i}$ & $6.192 \mathrm{E}-3$ & $1.115 \mathrm{E}-3$ & $\mathrm{Mn}$ & $6.398 \mathrm{E}-4$ & $1.152 \mathrm{E}-4$ & Mn & $3.010 \mathrm{E}-4$ & $3.010 \mathrm{E}-4$ & $2.889 \mathrm{E}-4$ & $2.889 \mathrm{E}-4$ \\
\hline Mo & $3.664 \mathrm{E}-4$ & $6.595 \mathrm{E}-5$ & $\mathrm{Na}$ & $1.093 \mathrm{E}-2$ & $1.995 \mathrm{E}-2$ & $\mathbf{N a}$ & $7.180 \mathrm{E}-3$ & $7.180 \mathrm{E}-3$ & $7.162 \mathrm{E}-3$ & $7.162 \mathrm{E}-3$ \\
\hline
\end{tabular}


Table 39. GFR Geometry and Homogenized Compositions $\left[10^{24} \mathrm{at} / \mathrm{cm}^{3}\right]$

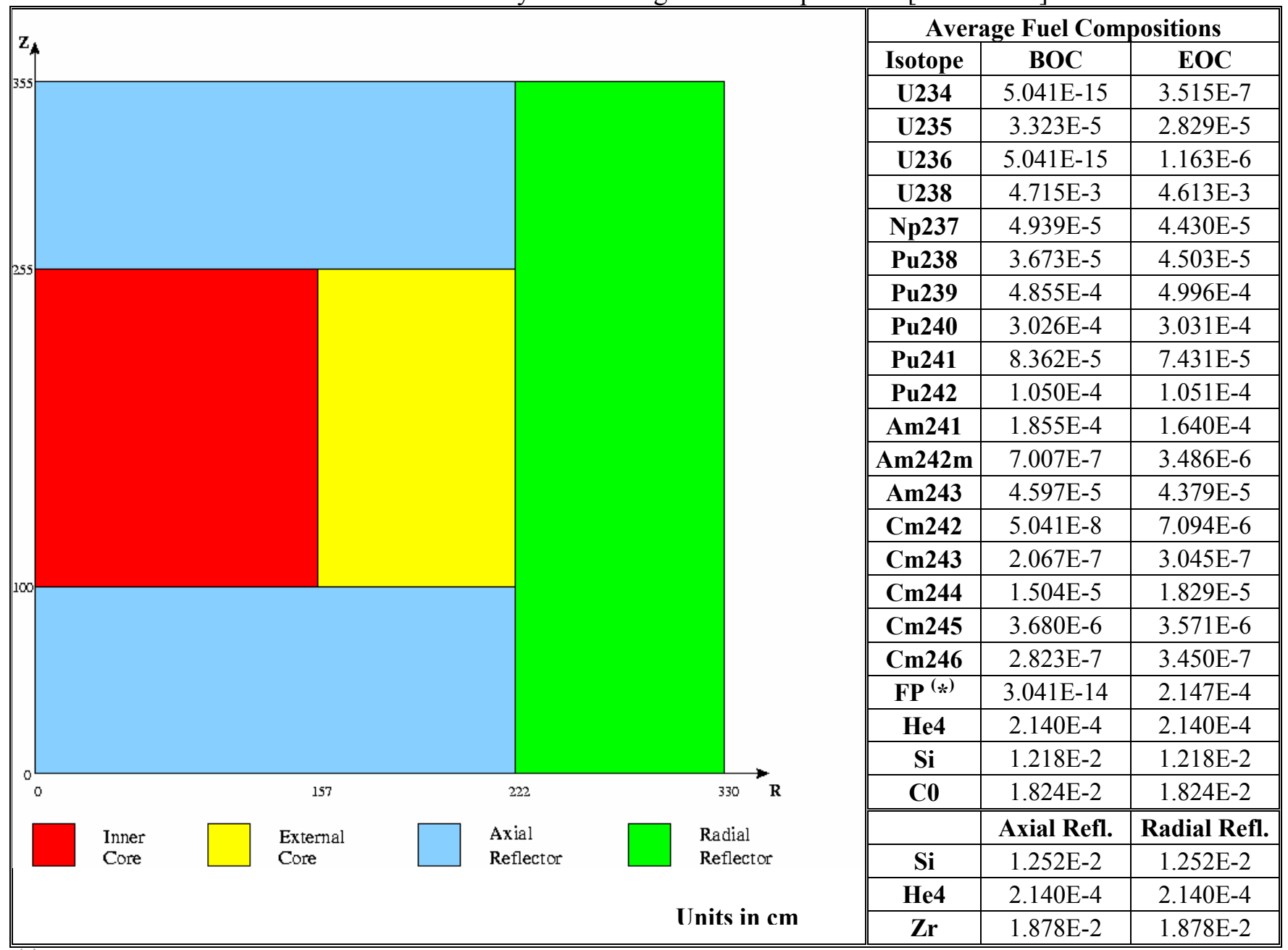

(*) Fission Products 
Table 40. LFR Geometry and Homogenized Compositions $\left[10^{24} \mathrm{at} / \mathrm{cm}^{3}\right]$

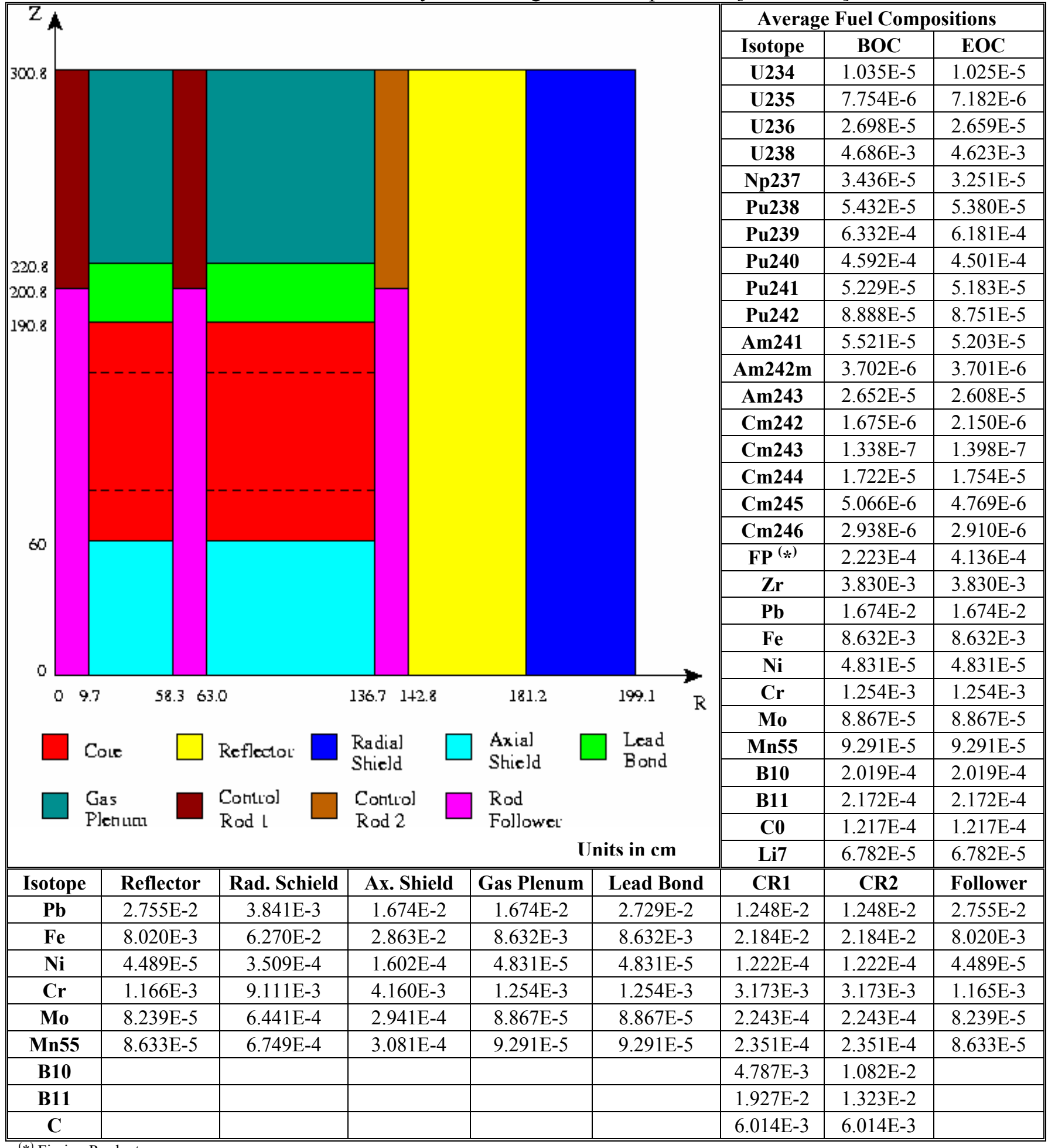

(*) Fission Products 
Table 41. ADMAB Geometry and Homogenized Compositions $\left[10^{24} \mathrm{at} / \mathrm{cm}^{3}\right]$

\begin{tabular}{|c|c|c|c|c|c|c|c|c|c|c|}
\hline \multirow[b]{4}{*}{ Np237 } & \multirow{2}{*}{\multicolumn{2}{|c|}{$\begin{array}{c}\text { Fuel } \\
\end{array}$}} & \multirow{3}{*}{\multicolumn{4}{|c|}{ Reflector }} & \multirow{3}{*}{\multicolumn{2}{|c|}{ Reflector }} & \multirow{3}{*}{\multicolumn{2}{|c|}{ Reflector }} \\
\hline & & & & & & & & & & \\
\hline & \multirow{2}{*}{$\begin{array}{c}\text { BOC } \\
4.377 \mathrm{E}-4\end{array}$} & \multirow{2}{*}{$\begin{array}{c}\text { EOC } \\
3.971 \mathrm{E}-4\end{array}$} & & & & & & & & \\
\hline & & & \multicolumn{2}{|c|}{ Fe54 } & \multicolumn{2}{|c|}{$2.990 \mathrm{E}-3$} & Ni58 & $1.977 \mathrm{E}-4$ & $\mathbf{B i}$ & $5.039 \mathrm{E}-3$ \\
\hline Pu238 & $4.226 \mathrm{E}-5$ & $9.415 \mathrm{E}-5$ & \multicolumn{2}{|c|}{ Fe56 } & \multicolumn{2}{|c|}{$4.560 \mathrm{E}-2$} & Ni60 & $7.305 \mathrm{E}-5$ & W182 & $2.140 \mathrm{E}-5$ \\
\hline Pu239 & $5.051 \mathrm{E}-4$ & $4.451 \mathrm{E}-4$ & \multicolumn{2}{|c|}{ Fe57 } & \multicolumn{2}{|c|}{$1.075 \mathrm{E}-3$} & Ni61 & $3.111 \mathrm{E}-6$ & W183 & $1.155 \mathrm{E}-5$ \\
\hline Pu240 & $2.321 \mathrm{E}-4$ & $2.399 \mathrm{E}-4$ & \multicolumn{2}{|c|}{ Fe58 } & \multicolumn{2}{|c|}{$1.344 \mathrm{E}-4$} & Ni62 & $9.724 \mathrm{E}-6$ & W184 & $2.465 \mathrm{E}-5$ \\
\hline Pu241 & $1.232 \mathrm{E}-4$ & $1.051 \mathrm{E}-4$ & \multicolumn{2}{|c|}{ Cr50 } & \multicolumn{2}{|c|}{$3.458 \mathrm{E}-4$} & Ni64 & $2.388 \mathrm{E}-6$ & W186 & $2.280 \mathrm{E}-5$ \\
\hline Pu242 & $9.102 \mathrm{E}-5$ & $1.006 \mathrm{E}-4$ & \multicolumn{2}{|c|}{ Cr52 } & \multicolumn{2}{|c|}{$6.422 \mathrm{E}-3$} & Mo & $3.565 \mathrm{E}-4$ & \multicolumn{2}{|c|}{ Target/Buffer } \\
\hline Am241 & $8.084 \mathrm{E}-4$ & $7.220 \mathrm{E}-4$ & \multicolumn{2}{|c|}{ Cr53 } & \multicolumn{2}{|c|}{$7.134 \mathrm{E}-4$} & Mn & $3.412 \mathrm{E}-4$ & $\mathbf{P b}$ & $1.320 \mathrm{E}-2$ \\
\hline Am242m & $1.089 \mathrm{E}-5$ & $1.923 \mathrm{E}-5$ & \multicolumn{2}{|c|}{ Cr54 } & & $741 \mathrm{E}-4$ & $\mathbf{P b}$ & $4.075 \mathrm{E}-3$ & $\mathbf{B i}$ & $1.632 \mathrm{E}-2$ \\
\hline Am243 & $5.827 \mathrm{E}-4$ & $5.303 \mathrm{E}-4$ & & & & & & & & \\
\hline $\mathrm{Cm} 242$ & $4.079 \mathrm{E}-8$ & $2.686 \mathrm{E}-5$ & & & & & & & & \\
\hline $\mathrm{Cm} 243$ & $3.326 \mathrm{E}-6$ & $3.141 \mathrm{E}-6$ & 200 & & & & & & & \\
\hline $\mathrm{Cm} 244$ & $2.371 \mathrm{E}-4$ & $2.599 \mathrm{E}-4$ & 200 & & & & & & & \\
\hline Cm245 & $3.164 \mathrm{E}-5$ & $3.314 \mathrm{E}-5$ & & & & & & & & \\
\hline Cm246 & $5.355 \mathrm{E}-7$ & $1.032 \mathrm{E}-6$ & & 目 & & & & & & \\
\hline $\mathrm{Zr}$ & $7.477 \mathrm{E}-3$ & $7.477 \mathrm{E}-3$ & & $\frac{0}{>}$ & & & & & & \\
\hline N15 & $1.058 \mathrm{E}-2$ & $1.058 \mathrm{E}-2$ & & & & & & & & \\
\hline Fe54 & $9.759 \mathrm{E}-4$ & $9.759 \mathrm{E}-4$ & 150 & & -- & & & & & \\
\hline Fe56 & $1.488 \mathrm{E}-2$ & $1.488 \mathrm{E}-2$ & & & & & & & & \\
\hline Fe57 & $3.507 \mathrm{E}-4$ & $3.507 \mathrm{E}-4$ & & & $\alpha$ & & & & & \\
\hline Fe58 & $4.386 \mathrm{E}-5$ & $4.386 \mathrm{E}-5$ & & & 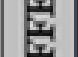 & & & & & \\
\hline Cr50 & $1.128 \mathrm{E}-4$ & $1.128 \mathrm{E}-4$ & & & 菂 & & & & & \\
\hline Cr52 & $2.096 \mathrm{E}-3$ & $2.096 \mathrm{E}-3$ & 120 & & 19 & & $\mathrm{COH}$ & & REFLE & TOR \\
\hline Cr53 & $2.328 \mathrm{E}-4$ & $2.328 \mathrm{E}-4$ & & & 吕 & & & & & \\
\hline Cr54 & $5.682 \mathrm{E}-5$ & $5.682 \mathrm{E}-5$ & & & $\underbrace{}_{0}$ & & & & & \\
\hline Ni58 & $6.451 \mathrm{E}-5$ & $6.451 \mathrm{E}-5$ & & & 岁 & & & & & \\
\hline Ni60 & $2.384 \mathrm{E}-5$ & $2.384 \mathrm{E}-5$ & & & $\theta$ & & & & & \\
\hline Ni61 & $1.015 \mathrm{E}-6$ & $1.015 \mathrm{E}-6$ & & & & & & & & \\
\hline Ni62 & $3.173 \mathrm{E}-6$ & $3.173 \mathrm{E}-6$ & 50 & 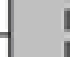 & & & & & & \\
\hline Ni64 & 7.792E-7 & 7.792E-7 & & & & & & & & \\
\hline Mo & $1.163 \mathrm{E}-4$ & $1.163 \mathrm{E}-4$ & & 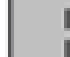 & & & & & & \\
\hline Mn & $1.114 \mathrm{E}-4$ & $1.114 \mathrm{E}-4$ & & & & & & & & \\
\hline $\mathbf{P b}$ & $6.360 \mathrm{E}-3$ & $6.360 \mathrm{E}-3$ & & & & & & & & \\
\hline $\mathbf{B i}$ & $7.865 \mathrm{E}-3$ & $7.865 \mathrm{E}-3$ & 0 & & i & & & & & \\
\hline W182 & $6.984 \mathrm{E}-6$ & $6.984 \mathrm{E}-6$ & & & & & & & & \\
\hline W183 & $3.770 \mathrm{E}-6$ & $3.770 \mathrm{E}-6$ & & 0 & 8.9 & 20 & & & 92 & 142 \\
\hline W184 & $8.045 \mathrm{E}-6$ & $8.045 \mathrm{E}-6$ & & & & & & & & \\
\hline W186 & 7.439E-6 & $7.439 \mathrm{E}-6$ & & & & & & & Uni & in $\mathbf{c m}$ \\
\hline $\mathbf{F P}{ }^{(*)}$ & - & $2.636 \mathrm{E}-4$ & & & & & & & & \\
\hline
\end{tabular}


Table 42. VHTR Geometry and Homogenized Compositions $\left[10^{24} \mathrm{at} / \mathrm{cm}^{3}\right]$

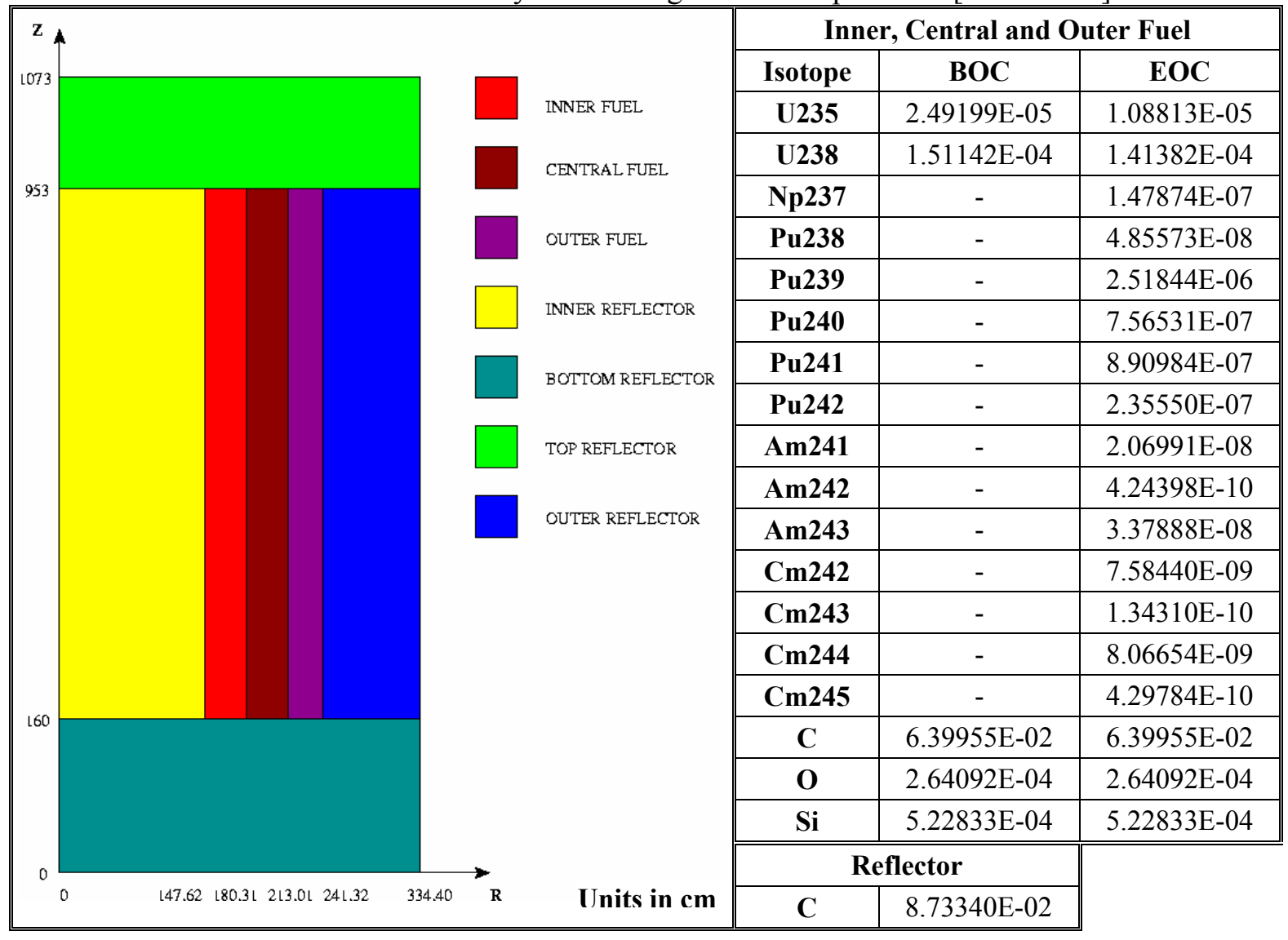


Table 43. PWR Homogenized Compositions $\left[10^{24} \mathrm{at} / \mathrm{cm}^{3}\right]$ and Fuel Cell Configuration

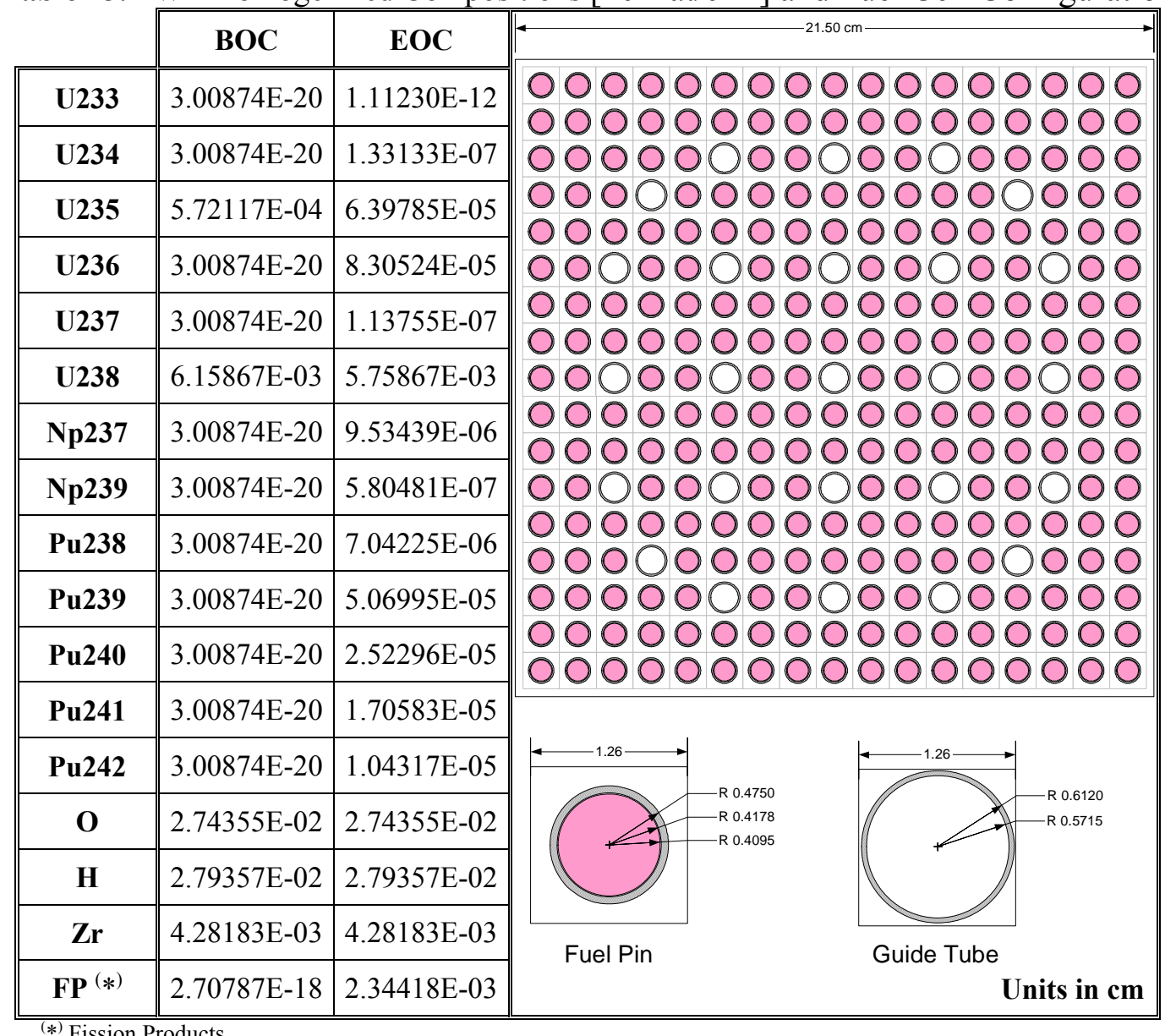


Table 44. CIRANO RZ Geometry and Compositions $\left[10^{24} \mathrm{at} / \mathrm{cm}^{3}\right]$

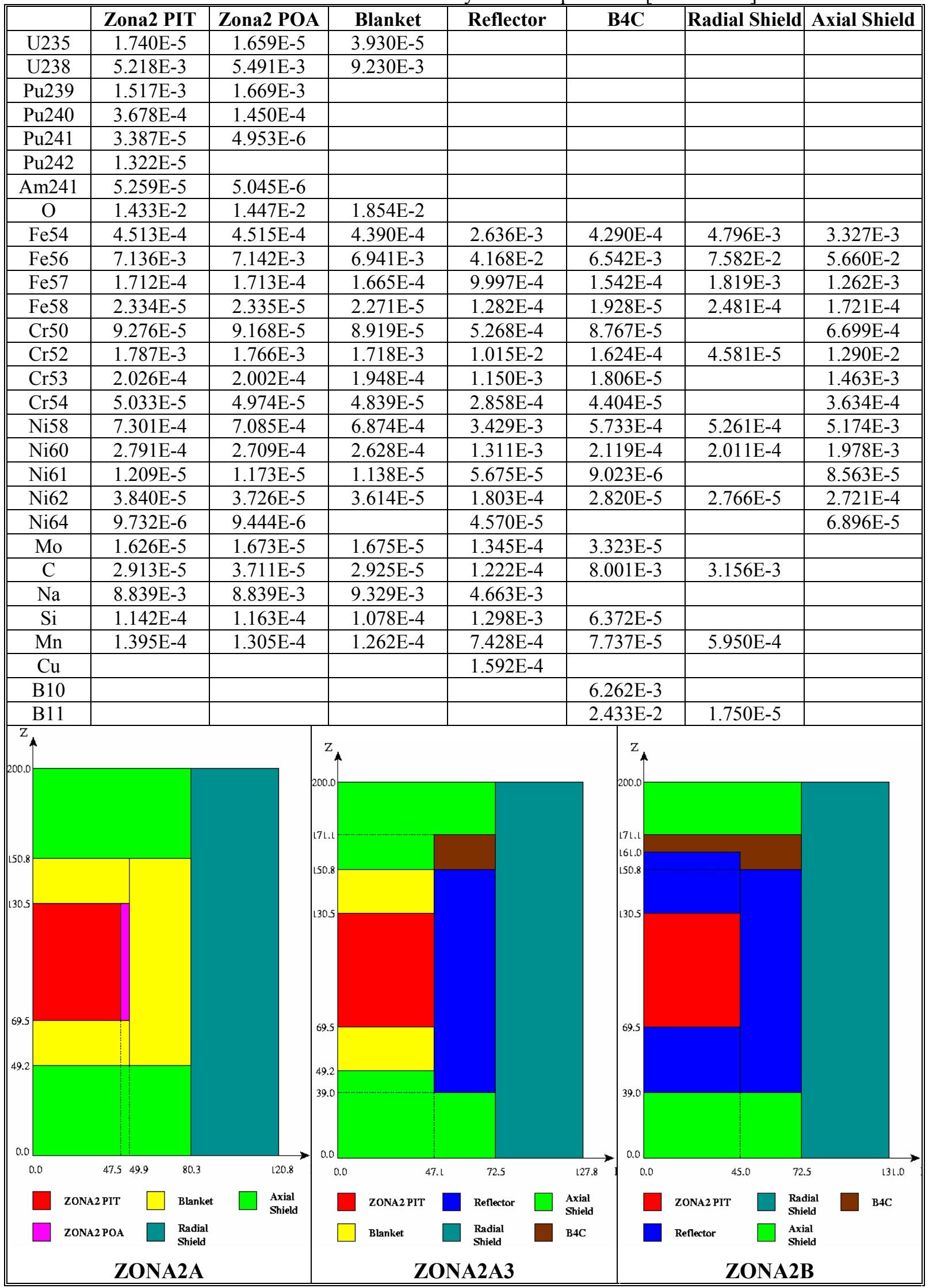


Table 45. MUSE4 RZ Geometry and Compositions $\left[10^{24} \mathrm{at} / \mathrm{cm}^{3}\right]$

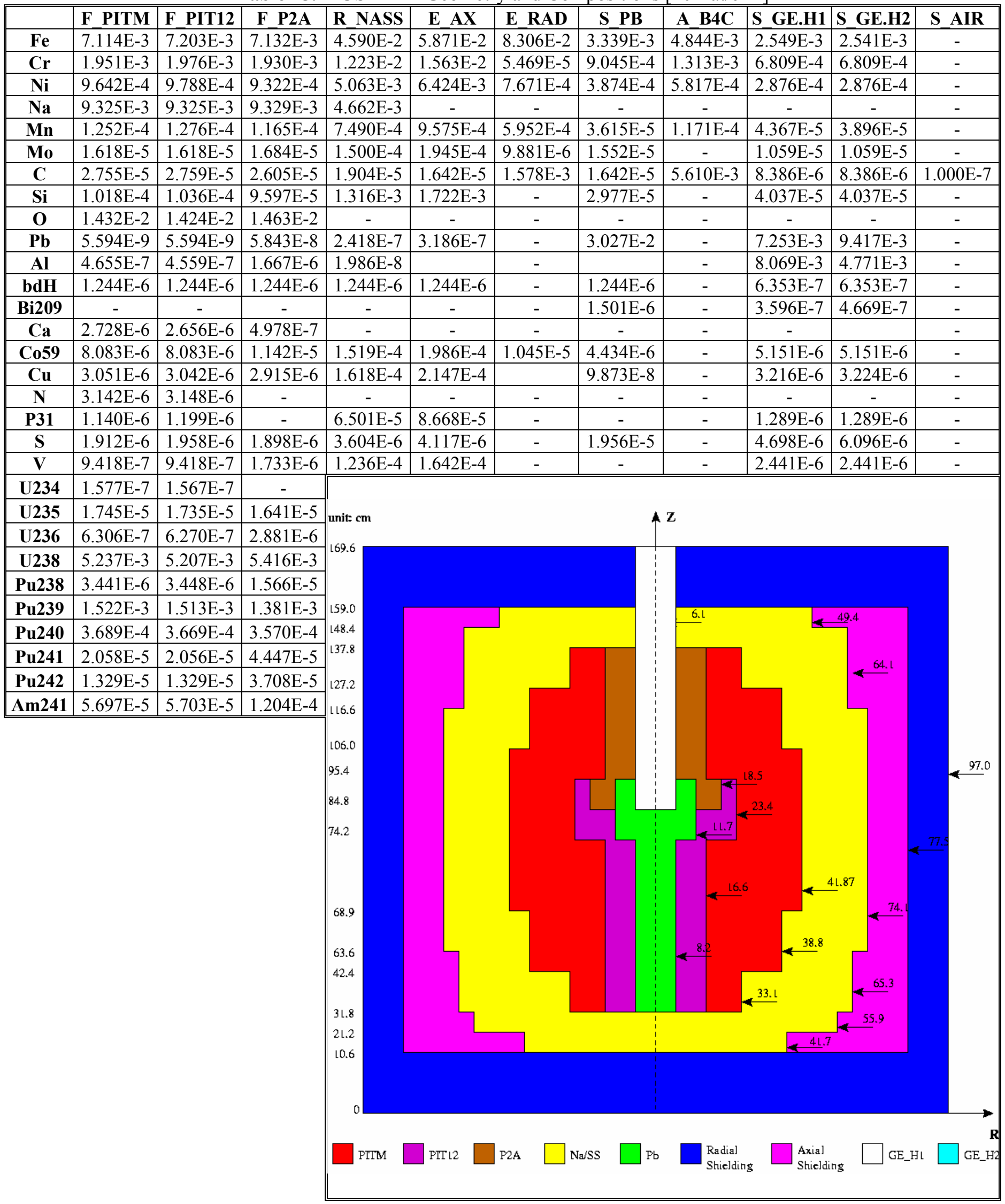


Table 46. GODIVA, JEZEBEL1, JEZEBEL2 Geometry and Compositions $\left[10^{24} \mathrm{at} / \mathrm{cm}^{3}\right]$

\begin{tabular}{|c|c|c|c|c|c|}
\hline \multicolumn{2}{|c|}{$\begin{array}{c}\text { GODIVA } \\
\text { Sphere of } 8.74 \mathrm{~cm} \text { radius }\end{array}$} & \multicolumn{2}{|c|}{$\begin{array}{c}\text { JEZEBEL1 } \\
\text { Spere of } 6.38 \mathrm{~cm} \text { radius }\end{array}$} & \multicolumn{2}{|c|}{$\begin{array}{c}\text { JEZEBEL2 } \\
\text { Sphere of } 6.38 \mathrm{~cm} \text { radius } \\
\end{array}$} \\
\hline U234 & $4.918 \mathrm{E}-4$ & Pu239 & $3.705 \mathrm{E}-2$ & Pu239 & $2.993 \mathrm{E}-2$ \\
\hline U235 & $4.499 \mathrm{E}-2$ & Pu240 & $1.751 \mathrm{E}-3$ & $\mathrm{Pu} 240$ & $7.875 \mathrm{E}-3$ \\
\hline U238 & $2.498 \mathrm{E}-3$ & $\mathrm{Pu} 241$ & $1.167 \mathrm{E}-4$ & $\mathrm{Pu} 241$ & $1.215 \mathrm{E}-3$ \\
\hline & & $\mathrm{Ga}$ & $1.375 \mathrm{E}-3$ & $\mathrm{Pu} 242$ & $1.567 \mathrm{E}-4$ \\
\hline & & & & $\mathrm{Ga}$ & $1.372 \mathrm{E}-3$ \\
\hline
\end{tabular}


Table 47. ANL Variance Matrix (Fissile Isotopes). Values in \%

\begin{tabular}{|c|c|c|c|c|c|c|c|c|c|c|c|c|c|c|c|c|c|c|c|c|c|c|c|c|c|c|c|c|c|c|c|c|c|c|c|c|c|}
\hline \multirow{2}{*}{\multicolumn{2}{|c|}{\begin{tabular}{l|l|l}
$\mathbf{G r}$ & $\mathrm{E}[\mathrm{MeV}]$
\end{tabular}}} & \multicolumn{6}{|c|}{ Th232 } & \multicolumn{6}{|c|}{$\mathrm{U} 233$} & \multicolumn{6}{|c|}{ U234 } & \multicolumn{6}{|c|}{ U235 } & & & $\mathrm{U} 2$ & & & & & & $\mathrm{U} 2$ & 38 & & \\
\hline & & $v$ & $\sigma_{f}$ & 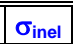 & 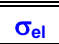 & $\sigma_{\text {capt }}$ & $\sigma_{n, 2 n}$ & $v$ & $\sigma_{\mathrm{f}}$ & $\sigma_{\text {inel }}$ & \begin{tabular}{c|}
$\sigma_{\mathrm{el}}$ \\
\end{tabular} & $\sigma_{\text {capt }}$ & $\sigma_{n, 2 n}$ & $v$ & $\sigma_{f}$ & 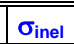 & \begin{tabular}{|c|}
$\sigma_{\mathrm{el}}$ \\
\end{tabular} & $\sigma_{\text {capt }}$ & $\sigma_{n, 2 n}$ & $v$ & $\sigma_{\mathrm{f}}$ & 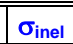 & $\bar{~} \overline{\sigma_{\mathrm{el}}}$ & $\sigma_{\text {capt }}$ & $\sigma_{n, 2 n}$ & $v$ & $\sigma_{f}$ & 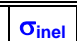 & $\sigma_{\mathrm{el}}$ & $\sigma_{\text {capt }}$ & $\sigma_{n, 2 n}$ & $v$ & $\sigma_{f}$ & $\overline{\mid \sigma_{\text {inel }}}$ & $\mid$\begin{tabular}{|c|}
$\sigma_{\text {el }}$ \\
\end{tabular} & $\sigma_{\text {capt }}$ & ${ }_{t} \sigma_{n, 2 n}$ \\
\hline 1 & 19.6 & 2 & 5 & 15 & 10 & 20 & \begin{tabular}{|l|}
100 \\
\end{tabular} & 2 & 20 & 20 & 10 & 10 & $\begin{array}{ll}100 \\
\end{array}$ & 3 & 20 & 15 & \begin{tabular}{|l|}
10 \\
\end{tabular} & 20 & \begin{tabular}{|l|}
100 \\
\end{tabular} & 1 & 5 & 10 & 5 & \begin{tabular}{|l|}
15 \\
\end{tabular} & \begin{tabular}{|l|}
50 \\
\end{tabular} & 3 & 20 & 15 & 10 & 20 & 100 & 3 & 5 & 20 & \begin{tabular}{|c|}
5 \\
\end{tabular} & 30 & 30 \\
\hline 2 & 6.07 & 2 & 5 & 15 & 10 & 20 & 100 & 2 & 20 & 20 & 10 & 10 & 100 & 3 & 20 & 15 & 10 & 20 & \begin{tabular}{|l|} 
\\
\end{tabular} & 1 & 5 & 10 & 5 & 15 & 50 & 2 & 20 & 15 & 10 & 20 & 0 & 2 & 5 & 15 & 5 & 10 & 0 \\
\hline 3 & 2.23 & 2 & 5 & 15 & 10 & 20 & 0 & 2 & 10 & 20 & 10 & 10 & 0 & 3 & 20 & 15 & 10 & 20 & 0 & 1 & 5 & 10 & 5 & 15 & 0 & 2 & 20 & 15 & 10 & 20 & 0 & 2 & 5 & 10 & 5 & 5 & 0 \\
\hline 4 & 1.35 & 2 & 5 & 15 & 10 & 20 & 0 & 2 & 10 & 20 & 10 & 10 & 0 & 3 & 20 & 15 & 10 & 20 & 0 & 1 & 5 & 15 & 5 & 15 & 0 & 2 & 20 & 15 & 10 & 20 & 0 & 2 & 5 & 10 & 5 & 5 & 0 \\
\hline 5 & $4.98 \mathrm{e}-1$ & 2 & 5 & 20 & 10 & 15 & 0 & 2 & 10 & 30 & 10 & 10 & 0 & 3 & 20 & 20 & 10 & 20 & 0 & 1 & 5 & 15 & 5 & 15 & 0 & 2 & 20 & 20 & 10 & 20 & 0 & 2 & 5 & 10 & 5 & 5 & 0 \\
\hline 6 & $1.83 \mathrm{e}-1$ & 2 & 5 & 0 & 10 & 15 & 0 & 2 & 10 & 0 & 10 & 10 & 0 & 3 & 20 & 20 & 10 & 20 & 0 & 1 & 5 & 15 & 5 & 15 & 0 & 2 & 20 & 20 & 10 & 20 & 0 & 2 & 20 & 10 & 5 & 5 & 0 \\
\hline 7 & $6.74 \mathrm{e}-2$ & 2 & 5 & 0 & 10 & 15 & 0 & 2 & 10 & 0 & 10 & 10 & 0 & 3 & 20 & 25 & 10 & 20 & 0 & 1 & 5 & 20 & 5 & 10 & 0 & 2 & 20 & 25 & 10 & 20 & 0 & 2 & 20 & 15 & 5 & 5 & 0 \\
\hline 8 & $2.48 \mathrm{e}-2$ & 2 & 5 & 0 & 10 & 10 & 0 & 2 & 10 & 0 & 10 & 20 & 0 & 3 & 20 & 0 & 10 & 20 & 0 & 1 & 5 & 25 & 5 & 10 & 0 & 2 & 20 & 0 & 10 & 20 & 0 & 2 & 20 & 0 & 5 & 5 & 0 \\
\hline 9 & $9.12 \mathrm{e}-3$ & 2 & 10 & 0 & 10 & 10 & 0 & 2 & 10 & 0 & 10 & 20 & 0 & 3 & 20 & 0 & 10 & 20 & 0 & 1 & 5 & 25 & 5 & 5 & 0 & 2 & 20 & 0 & 10 & 20 & 0 & 2 & 20 & 0 & 5 & 3 & 0 \\
\hline 10 & $2.04 \mathrm{e}-3$ & 2 & 10 & 0 & 10 & 10 & 0 & 2 & 10 & 0 & 10 & 20 & 0 & 3 & 20 & 0 & 10 & 20 & 0 & 0.5 & 3 & 30 & 5 & 5 & 0 & 2 & 20 & 0 & 10 & 8 & 0 & 2 & 20 & 0 & 5 & 3 & 0 \\
\hline 11 & \begin{tabular}{|l|}
$4.54 \mathrm{e}-4$ \\
\end{tabular} & 2 & 10 & 0 & 10 & 10 & 0 & 2 & 10 & 0 & 10 & 10 & 0 & 3 & 20 & 0 & 10 & 10 & 0 & 0.5 & 3 & 0 & 5 & 5 & 0 & 2 & 20 & 0 & 10 & 8 & 0 & 2 & 20 & 0 & 5 & 3 & 0 \\
\hline 12 & $2.26 \mathrm{e}-5$ & 2 & 10 & 0 & 10 & 5 & 0 & 2 & 10 & 0 & 10 & 5 & 0 & 3 & 20 & 0 & 10 & 10 & 0 & 0.5 & 3 & 0 & 5 & 5 & 0 & 2 & 20 & 0 & 10 & 8 & 0 & 2 & 20 & 0 & 5 & 3 & 0 \\
\hline 13 & \begin{tabular}{|l|l}
$4.00 \mathrm{e}-6$ \\
\end{tabular} & 2 & 10 & 0 & 10 & 5 & 0 & 2 & 5 & 0 & 10 & 5 & 0 & 3 & 20 & 0 & 10 & 10 & 0 & 0.5 & 3 & 0 & 5 & 3 & 0 & 2 & 20 & 0 & 10 & 8 & 0 & 2 & 20 & 0 & 5 & 3 & 0 \\
\hline 14 & \begin{tabular}{|l}
$5.40 \mathrm{e}-7$ \\
\end{tabular} & 2 & 50 & 0 & 5 & 1 & 0 & 2 & 2 & 0 & 10 & 3 & 0 & 3 & 20 & 0 & 2 & 10 & 0 & 0.5 & 1 & 0 & 5 & 1 & 0 & 2 & 20 & 0 & 7 & 4 & 0 & 2 & 20 & 0 & 1 & 1 & 0 \\
\hline 15 & 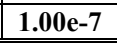 & 2 & 50 & 0 & 5 & 1 & 0 & 2 & 2 & 0 & 10 & 3 & 0 & 3 & 20 & 0 & 2 & 5 & 0 & 0.3 & 1 & 0 & 5 & 1 & 0 & 2 & 20 & 0 & 7 & 4 & 0 & 2 & 20 & 0 & 1 & 1 & 0 \\
\hline & & & & $\mathrm{Np}$ & 237 & & & & & $\mathrm{Pu}$ & 238 & & & & & $\mathrm{Pu}$ & 239 & & & & & $\mathrm{Pu}$ & 240 & & & & & $\mathrm{Pu}$ & 241 & & & & & $\mathrm{Pu}$ & 242 & & \\
\hline $\mathbf{G r}$ & $\mathrm{E}[\mathrm{MeV}]$ & $v$ & $\sigma_{\mathrm{f}}$ & $\sigma_{\text {inel }}$ & 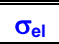 & $\sigma_{\text {capt }}$ & $\sigma_{n, 2 n}$ & $v$ & $\sigma_{\mathrm{f}}$ & $\sigma_{\text {inel }}$ & 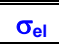 & $\sigma_{\text {capt }}$ & $\sigma_{n, 2 n}$ & $v$ & $\sigma_{f}$ & $\sigma_{\text {inel }}$ & 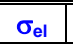 & $\sigma_{\text {capt }}$ & $\sigma_{n, 2 n}$ & $v$ & $\sigma_{\mathrm{f}}$ & $\bar{\sigma}_{\text {inel }}$ & $\overline{\sigma_{\mathrm{el}}}$ & $\sigma_{\text {capt }}$ & $\sigma_{\mathrm{n}, 2 \mathrm{n}}$ & $v$ & $\sigma_{f}$ & $\sigma_{\text {inel }}$ & $\sigma_{\mathrm{el}}$ & $\sigma_{\text {capt }}$ & $\sigma_{n, 2 n}$ & $v$ & $\sigma_{f}$ & $\sigma_{\text {inel }}$ & $\sigma_{\mathrm{el}}$ & $\sigma_{\text {capt }}$ & $\begin{array}{l}t \\
\sigma_{n, 2 n}\end{array}$ \\
\hline 1 & \begin{tabular}{|l|}
19.6 \\
\end{tabular} & 3 & 10 & 50 & 5 & 10 & \begin{tabular}{|l|}
100 \\
\end{tabular} & 3 & 10 & 15 & 10 & 10 & \begin{tabular}{|l|l|}
100 \\
\end{tabular} & 1 & 5 & \begin{tabular}{|l|}
10 \\
\end{tabular} & \begin{tabular}{|c|}
5 \\
\end{tabular} & \begin{tabular}{|l|}
15 \\
\end{tabular} & \begin{tabular}{|l|}
$50,2 n$ \\
\end{tabular} & 3 & 5 & \begin{tabular}{|l|}
15 \\
\end{tabular} & 10 & \begin{tabular}{|c|}
20 \\
\end{tabular} & \begin{tabular}{|l|}
100 \\
\end{tabular} & 1 & 20 & \begin{tabular}{|l|l|}
15 \\
\end{tabular} & 10 & 10 & 100 & 3 & 10 & \begin{tabular}{|l|}
15 \\
\end{tabular} & \begin{tabular}{|l|}
10 \\
\end{tabular} & \begin{tabular}{|l}
20 \\
\end{tabular} & 100 \\
\hline 2 & 6.07 & 2 & 10 & 50 & 5 & 10 & 0 & 2 & 10 & 15 & 10 & 10 & 0 & 1 & 5 & 10 & 5 & 15 & 50 & 2 & 5 & 15 & 10 & \begin{tabular}{|l|}
20 \\
\end{tabular} & \begin{tabular}{|c|} 
\\
\end{tabular} & 1 & 20 & 15 & 10 & 10 & \begin{tabular}{|l|}
100 \\
\end{tabular} & 2 & 10 & 15 & 10 & 20 & 0 \\
\hline 3 & 2.23 & 2 & 10 & 50 & 5 & 10 & 0 & 2 & 10 & 15 & 10 & 10 & 0 & 1 & 5 & 10 & 5 & 15 & 0 & 2 & 5 & 15 & 10 & 20 & 0 & 1 & 10 & 15 & 10 & 10 & 0 & 2 & 10 & 15 & 10 & 20 & 0 \\
\hline 4 & $\begin{array}{l}1.35 \\
\end{array}$ & 2 & 10 & 50 & 5 & 10 & 0 & 2 & 10 & 15 & 10 & 10 & 0 & 1 & 5 & 15 & 5 & 15 & 0 & 2 & 5 & 15 & 10 & 20 & 0 & 1 & 10 & 15 & 10 & 10 & 0 & 2 & 10 & 15 & 10 & 20 & 0 \\
\hline 5 & \begin{tabular}{|l|}
$4.98 \mathrm{e}-1$ \\
\end{tabular} & 2 & 10 & 50 & 5 & 10 & 0 & 2 & 10 & 20 & 10 & 10 & 0 & 1 & 5 & 15 & 5 & 15 & 0 & 2 & 5 & 20 & 10 & 20 & 0 & 1 & 10 & 20 & 10 & 10 & 0 & 2 & 20 & 20 & 10 & 20 & 0 \\
\hline 6 & $1.83 \mathrm{e}-1$ & 2 & 10 & 50 & 5 & 10 & 0 & 2 & 10 & 20 & 10 & 10 & 0 & 1 & 5 & 15 & 5 & 15 & 0 & 2 & 5 & 20 & 10 & 20 & 0 & 1 & 10 & 20 & 10 & 10 & 0 & 2 & 20 & 20 & 10 & 15 & 0 \\
\hline 7 & $6.74 \mathrm{e}-2$ & 2 & 10 & 60 & 5 & 10 & 0 & 2 & 30 & 25 & 10 & 10 & 0 & 1 & 5 & 20 & 5 & 10 & 0 & 2 & 5 & 25 & 10 & 20 & 0 & 1 & 10 & 25 & 10 & 10 & 0 & 2 & 20 & 25 & 10 & 10 & 0 \\
\hline 8 & $2.48 \mathrm{e}-2$ & 2 & 10 & 0 & 5 & 10 & 0 & 2 & 30 & 0 & 10 & 20 & 0 & 1 & 5 & 25 & 5 & 10 & 0 & 2 & 5 & 0 & 10 & 10 & 0 & 1 & 10 & 0 & 10 & 20 & 0 & 2 & 20 & 0 & 10 & 10 & 0 \\
\hline 9 & $9.12 e-3$ & 2 & 10 & 0 & 5 & 10 & 0 & 2 & 30 & 0 & 10 & 20 & 0 & 1 & 5 & 30 & 5 & 5 & 0 & 2 & 10 & 0 & 10 & 10 & 0 & 1 & 10 & 0 & 10 & 20 & 0 & 2 & 20 & 0 & 10 & 10 & 0 \\
\hline 10 & \begin{tabular}{|l|}
$2.04 \mathrm{e}-3$ \\
\end{tabular} & 2 & 20 & 0 & 5 & 10 & 0 & 2 & 30 & 0 & 10 & 20 & 0 & 0.5 & 3 & 0 & 5 & 5 & 0 & 2 & 10 & 0 & 10 & 10 & 0 & 1 & 10 & 0 & 10 & 20 & 0 & 2 & 20 & 0 & 10 & 10 & 0 \\
\hline 11 & \begin{tabular}{|l|}
$4.54 \mathrm{e}-4$ \\
\end{tabular} & 2 & 20 & 0 & 5 & 10 & 0 & 2 & 30 & 0 & 10 & 20 & 0 & 0.5 & 3 & 0 & 5 & 5 & 0 & 2 & 10 & 0 & 10 & 10 & 0 & 1 & 10 & 0 & 10 & 10 & 0 & 2 & 20 & 0 & 10 & 10 & 0 \\
\hline 12 & \begin{tabular}{|l|}
$2.26 e-5$ \\
\end{tabular} & 2 & 20 & 0 & 5 & 10 & 0 & 2 & 20 & 0 & 10 & 10 & 0 & \begin{tabular}{|l|}
0.5 \\
\end{tabular} & 3 & 0 & 5 & 5 & 0 & 2 & 10 & 0 & 10 & 10 & 0 & 1 & 10 & 0 & 10 & 5 & 0 & 2 & 20 & 0 & 10 & 5 & 0 \\
\hline 13 & \begin{tabular}{|l|l}
$4.00 \mathrm{e}-6$ \\
\end{tabular} & 2 & 20 & 0 & 5 & 10 & 0 & 2 & 20 & 0 & 10 & 10 & 0 & 0.5 & 3 & 0 & 5 & 4 & 0 & 2 & 10 & 0 & 10 & 7 & 0 & 1 & 5 & 0 & 10 & 5 & 0 & 2 & 20 & 0 & 10 & 5 & 0 \\
\hline 14 & \begin{tabular}{|l|}
$5.40 \mathrm{e}-7$ \\
\end{tabular} & 2 & 20 & 0 & 5 & 4 & 0 & 2 & 20 & 0 & 7 & 10 & 0 & 0.5 & 2 & 0 & 5 & 3 & 0 & 2 & 50 & 0 & 5 & 3 & 0 & 0.5 & 2 & 0 & 7 & 3 & 0 & 2 & 50 & 0 & 7 & 4 & 0 \\
\hline 15 & \begin{tabular}{|l|l}
$1.00 \mathrm{e}-7$ \\
\end{tabular} & 2 & 20 & 0 & 5 & 4 & 0 & 2 & 20 & 0 & 7 & 10 & 0 & 0.3 & 1 & 0 & 5 & 2 & 0 & 2 & 50 & 0 & 5 & 2 & 0 & 0.5 & 2 & 0 & 7 & 3 & 0 & 2 & 50 & 0 & 7 & 3 & 0 \\
\hline & & & & $\overline{\mathrm{Amm}}$ & 241 & & & & & $\overline{\text { Am2 }}$ & $42 \mathrm{~m}$ & & & & & $\overline{\mathrm{Amm}}$ & 243 & & & & $\overline{\mathrm{n} 242}$ & $/ \mathrm{Cm}$ & 243 & $/ \mathrm{Cm} 24$ & & & & 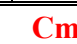 & 245 & & & & & & & & \\
\hline $\mathbf{G r}$ & E [MeV] & $v$ & $\sigma_{\mathrm{f}}$ & $\sigma_{\text {inel }}$ & 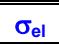 & $\sigma_{\text {capt }}$ & $\sigma_{n, 2 n}$ & $v$ & $\sigma_{\mathrm{f}}$ & $\sigma_{\text {inel }}$ & $\begin{array}{c}\sigma_{\mathrm{el}} \\
\end{array}$ & $\sigma_{\text {capt }}$ & $\sigma_{n, 2 n}$ & $v$ & $\sigma_{\mathrm{f}}$ & $\sigma_{\text {inel }}$ & $\mid$\begin{tabular}{|l|}
$\sigma_{\mathrm{el}}$ \\
\end{tabular} & $\sigma_{\text {capt }}$ & $\sigma_{n, 2 n}$ & $v$ & $\bar{\sigma}_{\mathrm{f}}$ & $\sigma_{\text {inel }}$ & $\frac{\sigma_{\mathrm{el}}}{}$ & $\sigma_{\text {capt }}$ & $\sigma_{n, 2 n}$ & $v$ & $\sigma_{f}$ & $\sigma_{\text {inel }}$ & $\sigma_{\mathrm{el} 1}$ & $\sigma_{\text {capt }}$ & $\sigma_{n, 2 n}$ & & & & & & \\
\hline 1 & \begin{tabular}{|l|}
19.6 \\
\end{tabular} & 3 & 10 & 50 & 10 & 10 & \begin{tabular}{|l|}
100 \\
\end{tabular} & 5 & 20 & 50 & 10 & 40 & 100 & 5 & 10 & \begin{tabular}{|l|}
50 \\
\end{tabular} & \begin{tabular}{|l|}
10 \\
\end{tabular} & \begin{tabular}{|c|}
10 \\
\end{tabular} & \begin{tabular}{|l|}
100 \\
\end{tabular} & 5 & 40 & 50 & 10 & \begin{tabular}{|l|}
40 \\
\end{tabular} & \begin{tabular}{|l|l|}
100 \\
\end{tabular} & 5 & 40 & 50 & 10 & 40 & 100 & & & & & & \\
\hline 2 & 6.07 & 2 & 10 & 50 & 10 & 10 & 0 & 3 & 20 & 50 & 10 & 40 & 100 & 3 & 10 & 50 & 10 & \begin{tabular}{l|}
10 \\
\end{tabular} & 0 & 5 & 40 & 50 & 10 & 40 & 0 & 5 & 40 & 50 & 10 & 40 & \begin{tabular}{|l|}
100 \\
\end{tabular} & & & & & & \\
\hline 3 & 2.23 & 2 & 10 & 50 & 10 & 10 & 0 & 3 & 20 & 50 & 10 & 40 & 0 & 3 & 10 & 50 & 10 & 10 & 0 & 5 & 40 & 50 & 10 & 40 & 0 & 5 & 40 & 50 & 10 & 40 & 0 & & & & & & \\
\hline 4 & 1.35 & 2 & 10 & 50 & 10 & 10 & 0 & 3 & 20 & 50 & 10 & 40 & 0 & 3 & 10 & 50 & 10 & 10 & 0 & 5 & 40 & 50 & 10 & 40 & 0 & 5 & 40 & 50 & 10 & 40 & & & & & & & \\
\hline 5 & $4.98 \mathrm{e}-1$ & 2 & 10 & 50 & 10 & 10 & 0 & 3 & 20 & 50 & 10 & 40 & 0 & 3 & 10 & 50 & 10 & 10 & 0 & 5 & 40 & 50 & 10 & 40 & 0 & 5 & 40 & 50 & 10 & 40 & 0 & & & & & & \\
\hline 6 & \begin{tabular}{|c|c|}
$1.83 \mathrm{e}-1$ \\
\end{tabular} & 2 & 10 & 50 & 10 & 10 & 0 & 3 & 20 & 50 & 10 & 40 & 0 & 3 & 10 & 50 & 10 & 10 & 0 & 5 & 40 & 50 & 10 & 40 & 0 & 5 & 40 & 50 & 10 & 40 & 0 & & & & & & \\
\hline 7 & $6.74 \mathrm{e}-2$ & 2 & 10 & 55 & 10 & 10 & 0 & 3 & 20 & 55 & 10 & 40 & 0 & 3 & 10 & 55 & 10 & 10 & 0 & 5 & 40 & 55 & 10 & 40 & 0 & 5 & 40 & 55 & 10 & 40 & 0 & & & & & & \\
\hline 8 & $2.48 \mathrm{e}-2$ & 2 & 20 & 0 & 10 & 10 & 0 & 3 & 10 & 0 & 10 & 40 & 0 & 3 & 10 & 0 & 10 & 10 & 0 & 5 & 40 & 0 & 10 & 40 & 0 & 5 & 40 & 0 & 10 & 40 & 0 & & & & & & \\
\hline 9 & $9.12 \mathrm{e}-3$ & 2 & 20 & 0 & 10 & 10 & 0 & 3 & 10 & 0 & 10 & 40 & 0 & 3 & 10 & 0 & 10 & 10 & 0 & 5 & 40 & 0 & 10 & 40 & 0 & 5 & 40 & 0 & 10 & 40 & & & & & & & \\
\hline 10 & \begin{tabular}{|c|}
$2.04 \mathrm{e}-3$ \\
\end{tabular} & 2 & 20 & 0 & 10 & 10 & 0 & 3 & 10 & 0 & 10 & 40 & 0 & 3 & 10 & 0 & 10 & 10 & 0 & 5 & 40 & 0 & 10 & 40 & 0 & 5 & 40 & 0 & 10 & 40 & 0 & & & & & & \\
\hline 11 & \begin{tabular}{|l|l|}
$4.54 \mathrm{e}-4$ \\
\end{tabular} & 2 & 20 & 0 & 10 & 10 & 0 & 3 & 10 & 0 & 10 & 40 & 0 & 3 & 20 & 0 & 10 & 20 & 0 & 5 & 40 & 0 & 10 & 40 & 0 & 5 & 40 & 0 & 10 & 40 & 0 & & & & & & \\
\hline 12 & $2.26 \mathrm{e}-5$ & 2 & 20 & 0 & 10 & 10 & 0 & 3 & 10 & 0 & 10 & 40 & 0 & 3 & 40 & 0 & 10 & 20 & 0 & 5 & 40 & 0 & 10 & 40 & 0 & 5 & 40 & 0 & 10 & 40 & 0 & & & & & & \\
\hline 13 & \begin{tabular}{|l|l}
$4.00 \mathrm{e}-6$ \\
\end{tabular} & 2 & 20 & 0 & 10 & 10 & 0 & 3 & 5 & 0 & 10 & 40 & 0 & 3 & 40 & 0 & 10 & 20 & 0 & 5 & 40 & 0 & 10 & 40 & 0 & 5 & 40 & 0 & 10 & 40 & 0 & & & & & & \\
\hline 14 & \begin{tabular}{|l|l|l}
$5.40-7$ \\
\end{tabular} & 2 & 20 & 0 & 10 & 10 & 0 & 3 & 5 & 0 & 10 & 40 & 0 & 3 & 40 & 0 & 10 & 20 & 0 & 5 & 40 & 0 & 10 & 40 & 0 & 5 & 40 & 0 & 10 & 40 & 0 & & & & & & \\
\hline 15 & \begin{tabular}{|l|l}
$1.00 e-7$ \\
\end{tabular} & 2 & 20 & 0 & 10 & 10 & 0 & 3 & 5 & 0 & 10 & 40 & 0 & 3 & 40 & 0 & 10 & 20 & 0 & 5 & 40 & 0 & 10 & 40 & 0 & 5 & 40 & 0 & 10 & 40 & 0 & & & & & & \\
\hline
\end{tabular}


Table 48. ANL Variance Matrix (Structural Isotopes). Values in \%

Fe56 $\mid$\begin{tabular}{c||c||c|}
\hline Fe57 & Ni58 & Cr52 \\
\hline
\end{tabular}

$\mathrm{Pb}$

$\mathrm{Bi}$

$\mathrm{Zr}$

N15

Si

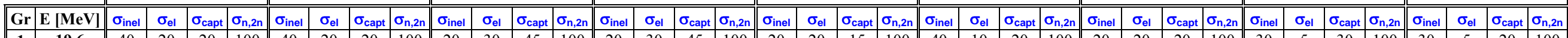

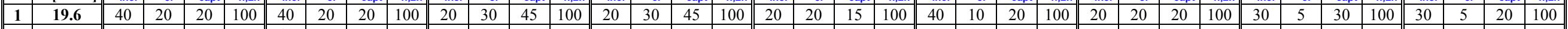

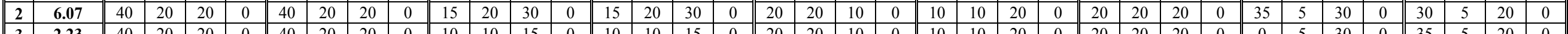

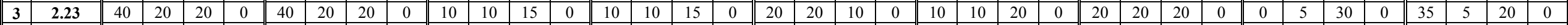

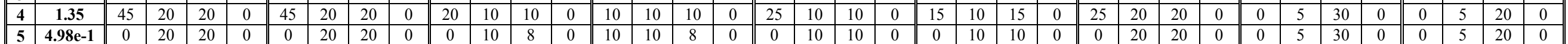

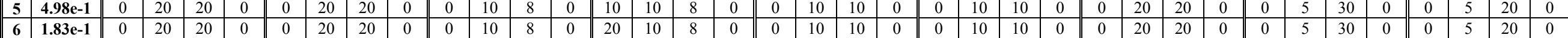

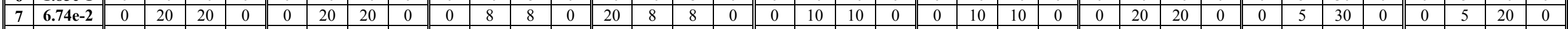

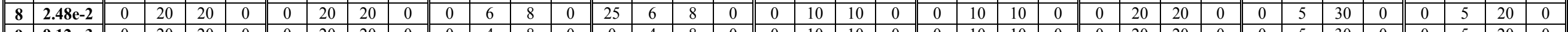

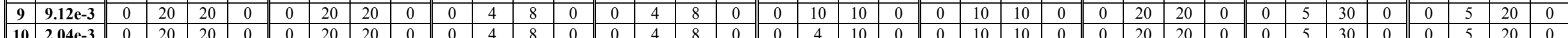

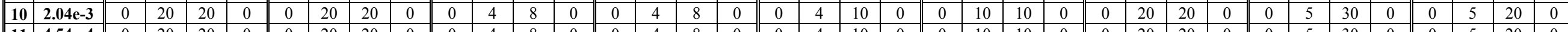

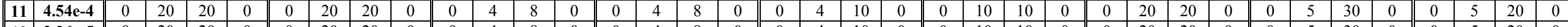

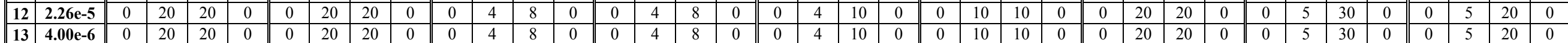

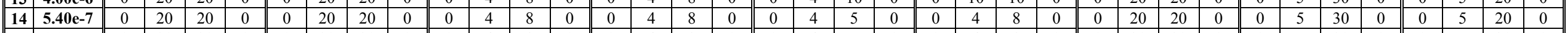

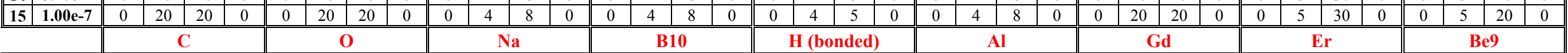

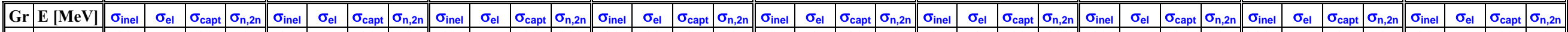

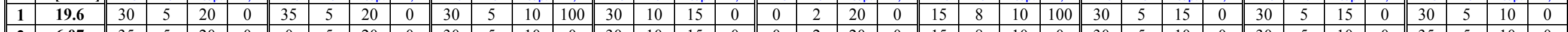

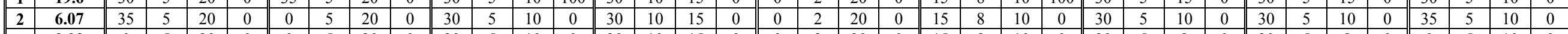

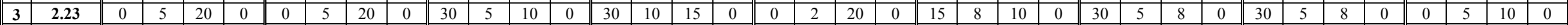

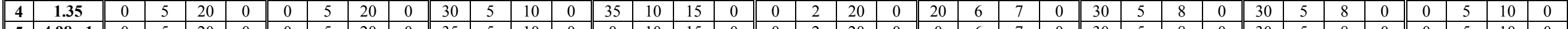

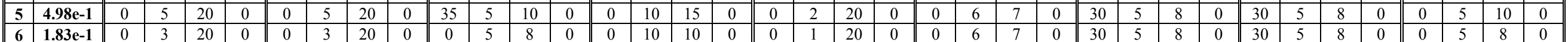

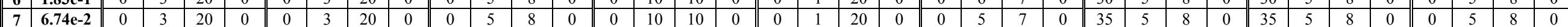

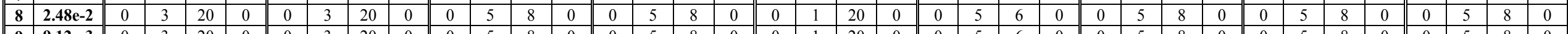

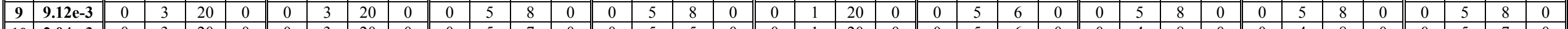

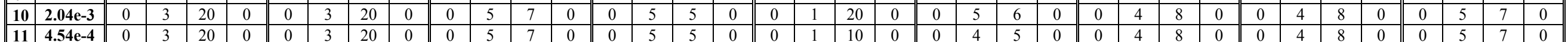

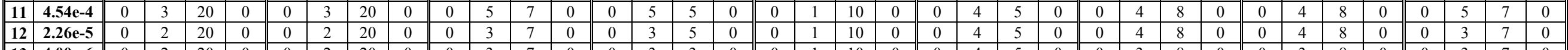

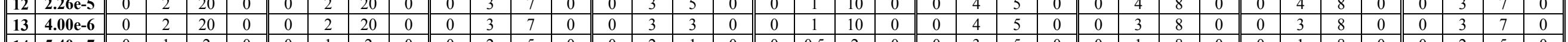

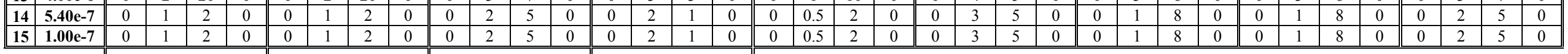
\begin{tabular}{|l|l|l|l|l|l|l|l|l|l|}
\hline 15 & $1.00 \mathrm{e}-7$ & 0 & Li6 & Li7 & F19 & He4 \\
\hline
\end{tabular}

\begin{tabular}{|c|c|c|c|c|c|c|c|c|c|c|c|c|c|c|c|c|c|}
\hline $\mathbf{G r}$ & $\mathbf{E}[\mathbf{M e V}]$ & $\sigma_{\text {inel }}$ & $\sigma_{\text {el }}$ & $\sigma_{\text {capt }}$ & $\sigma_{\mathrm{n}, 2 \mathrm{n}}$ & $\sigma_{\text {inel }}$ & $\sigma_{\text {el }}$ & $\sigma_{\text {capt }}$ & $\sigma_{\mathrm{n}, 2 \mathrm{n}}$ & $\sigma_{\text {inel }}$ & $\sigma_{\text {el }}$ & $\sigma_{\text {capt }}$ & $\sigma_{\mathrm{n}, 2 \mathrm{n}}$ & $\sigma_{\text {inel }}$ & $\sigma_{\text {el }}$ & $\sigma_{\text {capt }}$ & $\sigma_{\mathrm{n}, 2 \mathrm{n}}$ \\
\hline
\end{tabular} \begin{tabular}{||c||c||c|c|c|c||c|c|c|c||c|c|c|c|c|c|c|c||}
\hline $\mathbf{G r}$ & $\mathbf{E}[\mathrm{MeV}]$ & $\sigma_{\text {inel }}$ & $\sigma_{\text {el }}$ & $\sigma_{\text {capt }}$ & $\sigma_{\mathrm{n}, 2 \mathrm{n}}$ & $\sigma_{\text {inel }}$ & $\sigma_{\text {el }}$ & $\sigma_{\text {capt }}$ & $\sigma_{\mathrm{n}, 2 \mathrm{n}}$ & $\sigma_{\text {inel }}$ & $\sigma_{\text {el }}$ & $\sigma_{\text {capt }}$ & $\sigma_{\mathrm{n}, 2 \mathrm{n}}$ & $\sigma_{\text {inel }}$ & $\sigma_{\text {el }}$ & $\sigma_{\text {capt }}$ & $\sigma_{\mathrm{n}, 2 \mathrm{n}}$ \\
\hline $\mathbf{1}$ & $\mathbf{1 9 . 6}$ & 30 & 5 & 10 & 0 & 30 & 5 & 10 & 100 & 30 & 5 & 10 & 100 & 0 & 5 & 20 & 0 \\
\hline $\mathbf{2}$ & $\mathbf{6 . 0 7}$ & 30 & 5 & 10 & 0 & 30 & 5 & 10 & 0 & 30 & 5 & 10 & 0 & 0 & 5 & 20 & 0 \\
\hline $\mathbf{3}$ & $\mathbf{2 . 2 3}$ & 35 & 5 & 10 & 0 & 30 & 5 & 10 & 0 & 30 & 5 & 10 & 0 & 0 & 5 & 20 & 0 \\
\hline $\mathbf{4}$ & $\mathbf{1 . 3 5}$ & 0 & 5 & 10 & 0 & 35 & 5 & 10 & 0 & 30 & 5 & 10 & 0 & 0 & 5 & 20 & 0 \\
\hline $\mathbf{5}$ & $\mathbf{4 . 9 8 e - 1}$ & 0 & 5 & 10 & 0 & 0 & 5 & 10 & 0 & 30 & 5 & 10 & 0 & 0 & 5 & 20 & 0 \\
\hline $\mathbf{6}$ & $\mathbf{1 . 8 3 e - 1}$ & 0 & 5 & 8 & 0 & 0 & 5 & 8 & 0 & 35 & 5 & 8 & 0 & 0 & 3 & 20 & 0 \\
\hline 7 & $\mathbf{6 . 7 4 e - 2}$ & 0 & 5 & 8 & 0 & 0 & 5 & 8 & 0 & 0 & 5 & 8 & 0 & 0 & 3 & 20 & 0 \\
\hline $\mathbf{8}$ & $\mathbf{2 . 4 8 e - 2}$ & 0 & 5 & 8 & 0 & 0 & 5 & 8 & 0 & 0 & 5 & 8 & 0 & 0 & 3 & 20 & 0 \\
\hline $\mathbf{9}$ & $\mathbf{9 . 1 2 e}-3$ & 0 & 5 & 8 & 0 & 0 & 5 & 8 & 0 & 0 & 5 & 8 & 0 & 0 & 3 & 20 & 0 \\
\hline $\mathbf{1 0}$ & $\mathbf{2 . 0 4 e - 3}$ & 0 & 5 & 7 & 0 & 0 & 5 & 7 & 0 & 0 & 5 & 7 & 0 & 0 & 3 & 20 & 0 \\
\hline $\mathbf{1 1}$ & $\mathbf{4 . 5 4 e - 4}$ & 0 & 5 & 7 & 0 & 0 & 5 & 7 & 0 & 0 & 5 & 7 & 0 & 0 & 3 & 20 & 0 \\
\hline $\mathbf{1 2}$ & $\mathbf{2 . 2 6 e - 5}$ & 0 & 3 & 7 & 0 & 0 & 3 & 7 & 0 & 0 & 3 & 7 & 0 & 0 & 2 & 20 & 0 \\
\hline $\mathbf{1 3}$ & $\mathbf{4 . 0 0 e - 6}$ & 0 & 3 & 7 & 0 & 0 & 3 & 7 & 0 & 0 & 3 & 7 & 0 & 0 & 2 & 20 & 0 \\
\hline $\mathbf{1 4}$ & $\mathbf{5 . 4 0 e - 7}$ & 0 & 2 & 5 & 0 & 0 & 2 & 5 & 0 & 0 & 2 & 5 & 0 & 0 & 1 & 2 & 0 \\
\hline $\mathbf{1 5}$ & $\mathbf{1 . 0 0 e}-7$ & 0 & 2 & 5 & 0 & 0 & 2 & 5 & 0 & 0 & 2 & 5 & 0 & 0 & 1 & 2 & 0 \\
\hline \hline
\end{tabular} 
Table 49. 4Gr. ANL Variance Matrix (Fissile Isotopes)

$$
\text { Th232 }
$$
$\mathrm{U} 233$ $\mathrm{U} 234$ U235

$\mathrm{U} 236$
U238

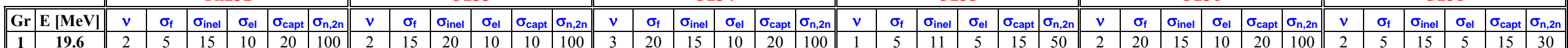

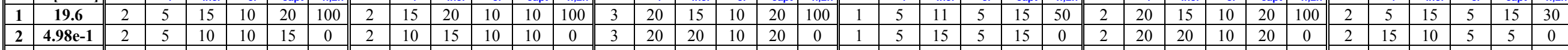

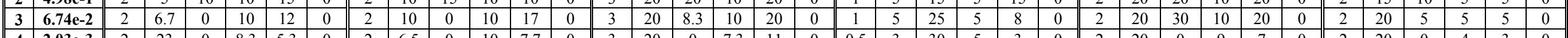

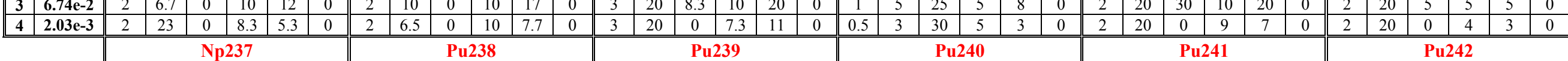

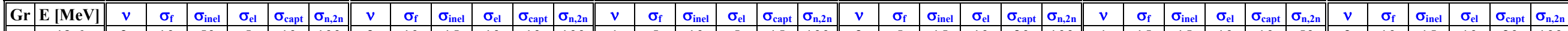

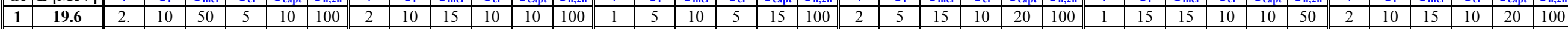

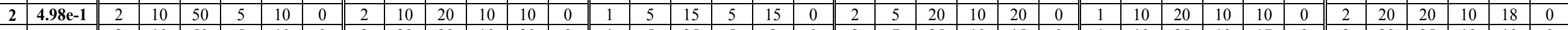

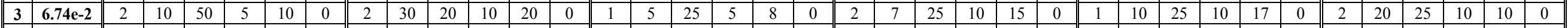
\begin{tabular}{||l||l|l|l|l|l|l||c|c|c|c|c|c|c|c|c|}
\hline $\mathbf{4}$ & $\mathbf{2 . 0 3 e - 3}$ & 2 & 20 & 0 & 5 & 8 & 0 & 2 & 20 & 0 & 10 & 10 & 0 & 0.5 & 3 \\
\hline
\end{tabular}

\section{Am241} Am242m Am243 $\mathrm{Cm} 242 / \mathrm{Cm} 243 / \mathrm{Cm} 244 \mathrm{Cm} 245$

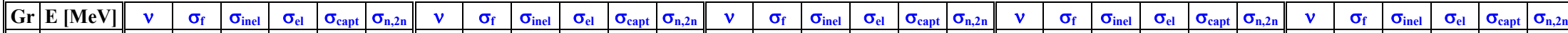

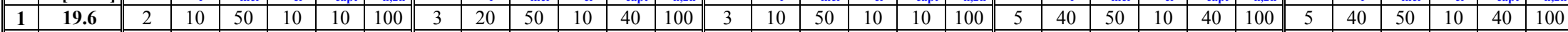

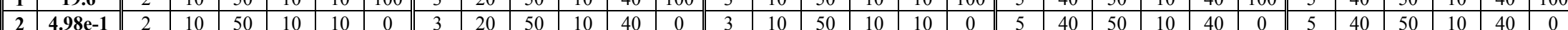

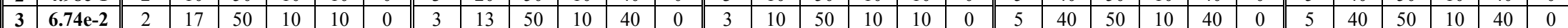

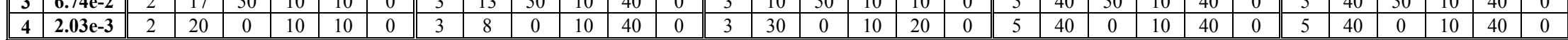

Table 50. 4Gr. ANL Variance Matrix (Structural Isotopes)

\begin{tabular}{|c|c|c|c|c|c|c|c|c|c|c|c|c|c|c|c|c|c|c|c|c|c|c|c|c|c|c|c|c|c|c|c|c|c|c|c|c|c|}
\hline \multirow[b]{2}{*}{$\mathbf{G r}$} & \multirow[b]{2}{*}{$\mathrm{E}[\mathrm{MeV}]$} & \multicolumn{4}{|c|}{$\mathrm{Pb}$} & \multicolumn{4}{|c|}{$\mathrm{Bi}$} & \multicolumn{4}{|c|}{$\mathrm{Fe} 56$} & \multicolumn{4}{|c|}{ Fe57 } & \multicolumn{4}{|c|}{ Ni58 } & \multicolumn{4}{|c|}{ Cr52 } & \multicolumn{4}{|c|}{$\mathrm{Zr}$} & \multicolumn{4}{|c|}{ N15 } & \multicolumn{4}{|c|}{$\mathrm{Si}$} \\
\hline & & $\sigma_{\text {inel }}$ & 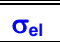 & $\sigma_{\text {capt }}$ & $\sigma_{n, 2 n}$ & $\sigma_{\text {inel }}$ & $\overline{\sigma e l}$ & $\sigma_{\text {capt }}$ & $\sigma_{n, 2 n}$ & $\sigma_{\text {inel }}$ & $\overline{\sigma_{\mathrm{el}}}$ & $\sigma_{\text {capt }}$ & $\sigma_{n, 2 n}$ & $\sigma_{\text {inel }}$ & $\bar{~} \sigma_{\mathrm{el}}$ & $\sigma_{\text {capt }}$ & $\sigma_{n, 2 n}$ & $\sigma_{\text {inel }}$ & $\overline{\sigma_{\mathrm{el}}}$ & $\sigma_{\text {capt }}$ & $\sigma_{n, 2 n}$ & $\mid \sigma_{\text {inel }}$ & $\sigma_{\mathrm{el}}$ & $\sigma_{\text {capt }}$ & $\sigma_{n, 2 n}$ & $\sigma_{\text {inel }}$ & $\overline{\sigma_{\mathrm{el}}}$ & $\sigma_{\text {capt }}$ & $\sigma_{n, 2 n}$ & $\sigma_{\text {inel }}$ & $\sigma_{\mathrm{el}}$ & $\sigma_{\text {capt }}$ & $\sigma_{n, 2 n}$ & $\sigma_{\text {inel }}$ & $\sigma_{\mathrm{el}}$ & $\sigma_{\text {capt }}$ & $\sigma_{n, 2 n}$ \\
\hline 1 & 19.6 & 40 & 20 & 20 & 100 & 40 & 20 & 20 & 100 & \begin{tabular}{|l|}
20 \\
\end{tabular} & 18 & 25 & 100 & 14 & 18 & 25 & 100 & 25 & 18 & 11 & 100 & 20 & 10 & 19 & 100 & 25 & 20 & 20 & 100 & 25 & 5 & \begin{tabular}{|l|}
30 \\
\end{tabular} & 100 & 25 & 5 & \begin{tabular}{|l|}
20 \\
\end{tabular} & 100 \\
\hline 2 & $4.98 \mathrm{e}-1$ & 0 & 20 & 20 & 0 & 0 & 20 & 20 & 0 & 0 & 10 & 8 & 0 & 15 & 10 & 8 & 0 & 0 & 10 & 10 & 0 & 0 & 10 & 10 & 0 & 0 & 20 & 20 & 0 & 0 & 5 & 30 & 0 & 0 & 5 & 20 & 0 \\
\hline 3 & $6.74 \mathrm{e}-2$ & 0 & 20 & 20 & 0 & 0 & 20 & 20 & 0 & 0 & 6 & 8 & 0 & 25 & 6 & 8 & 0 & 0 & 10 & 10 & 0 & 0 & 10 & 10 & 0 & 0 & 20 & 20 & 0 & 0 & 5 & 30 & 0 & 0 & 5 & 20 & 0 \\
\hline \multirow[t]{2}{*}{4} & $2.03 \mathrm{e}-3$ & 0 & 20 & 20 & 0 & 0 & 20 & 20 & 0 & 0 & 4 & 8 & 0 & 0 & 4 & 8 & 0 & 0 & 4 & 8.3 & 0 & 0 & 8 & 9.3 & 0 & 0 & 20 & 20 & 0 & 0 & 5 & 30 & 0 & 0 & 5 & 20 & 0 \\
\hline & & \multicolumn{4}{|c|}{$\mathrm{C}$} & \multicolumn{4}{|c|}{$\mathrm{O}$} & \multicolumn{4}{|c|}{$\mathrm{Na}$} & \multicolumn{4}{|c|}{ B10 } & \multicolumn{4}{|c|}{ H (bonded) } & \multicolumn{4}{|c|}{$\mathrm{Al}$} & \multicolumn{4}{|c|}{ Gd } & \multicolumn{4}{|c|}{ Er } & \multicolumn{4}{|c|}{ Be9 } \\
\hline $\mathbf{G r}$ & $\mathbf{E}[\mathrm{MeV}]$ & $\sigma_{\text {inel }}$ & $\sigma_{\mathrm{el}}$ & $\sigma_{\text {capt }}$ & $\sigma_{n, 2 n}$ & $\sigma_{\text {inel }}$ & $\sigma_{\mathrm{el}}$ & $\sigma_{\text {capt }}$ & $\sigma_{n, 2 n}$ & $\sigma_{\text {inel }}$ & $\sigma_{\mathrm{el}}$ & $\sigma_{\text {capt }}$ & $\sigma_{n, 2 n}$ & $\sigma_{\text {inel }}$ & $\sigma_{\mathrm{el}}$ & $\sigma_{\text {capt }}$ & $\sigma_{n, 2 n}$ & $\sigma_{\text {inel }}$ & $\sigma_{\mathrm{el}}$ & $\sigma_{\text {capt }}$ & $\sigma_{n, 2 n}$ & $\sigma_{\text {inel }}$ & $\sigma_{\mathrm{el}}$ & $\sigma_{\text {capt }}$ & $\sigma_{n, 2 n}$ & $\sigma_{\text {inel }}$ & $\sigma_{\mathrm{el}}$ & $\sigma_{\text {capt }}$ & $\sigma_{n, 2 n}$ & $\sigma_{\text {inel }}$ & $\sigma_{\mathrm{el}}$ & $\sigma_{\text {capt }}$ & $\sigma_{n, 2 n}$ & $\sigma_{\text {inel }}$ & $\sigma_{\mathrm{el}}$ & $\sigma_{\text {capt }}$ & $\sigma_{n, 2 n}$ \\
\hline 1 & 19.6 & 30 & 5 & 20 & 0 & \begin{tabular}{|l|}
35 \\
\end{tabular} & 5 & \begin{tabular}{|l|}
20 \\
\end{tabular} & 0 & 30 & 5 & 10 & 100 & 31 & 10 & \begin{tabular}{|l|}
15 \\
\end{tabular} & 0 & 0 & 2 & 20 & 0 & 16 & 7.5 & \begin{tabular}{|l|l|}
9.3 \\
\end{tabular} & 100 & \begin{tabular}{|l|}
30 \\
\end{tabular} & 5 & 10 & 0 & 30 & 5 & \begin{tabular}{|l|}
10 \\
\end{tabular} & 0 & 16 & 5 & 10 & 0 \\
\hline 2 & $4.98 \mathrm{e}-1$ & 0 & 4 & 20 & 0 & 0 & 4 & 20 & 0 & 35 & 5 & 9 & 0 & 0 & 10 & 13 & 0 & 0 & 1.5 & 20 & 0 & 0 & 6 & 7 & 0 & 30 & 5 & 8 & 0 & 30 & 5 & 8 & 0 & 0 & 5 & 9 & 0 \\
\hline 3 & $6.74 \mathrm{e}-2$ & 0 & 3 & 20 & 0 & 0 & 3 & 20 & 0 & 0 & 5 & 8 & 0 & 0 & 6.7 & 8.7 & 0 & 0 & 1 & 20 & 0 & 0 & 5 & 6.3 & 0 & 12 & 5 & 8 & 0 & 12 & 5 & 8 & 0 & 0 & 5 & 8 & 0 \\
\hline 4 & $2.03 \mathrm{e}-3$ & 0 & 2 & 14 & 0 & 0 & 2 & 14 & 0 & 0 & 4 & 7 & 0 & 0 & 3.3 & 3.3 & 0 & 0 & 0.8 & 9 & 0 & 0 & 3.8 & 5.2 & 0 & 0 & 2.8 & 8 & 0 & 0 & 2.8 & 8 & 0 & 0 & 3.3 & 6.3 & 0 \\
\hline & & & $\bar{L}$ & i6 & & & $\bar{L}$ & i7 & & & & 19 & & & H & e4 & & & & & & & & & & & & & & & & & & & & & \\
\hline $\mathbf{G r}$ & $\mathrm{E}[\mathrm{MeV}]$ & $\sigma_{\text {inel }}$ & $\sigma_{\mathrm{el}}$ & $\sigma_{\text {capt }}$ & $\sigma_{n, 2 n}$ & $\sigma_{\text {inel }}$ & $\sigma_{\mathrm{el}}$ & $\sigma_{\text {capt }}$ & $\sigma_{n, 2 n}$ & $\sigma_{\text {inel }}$ & $\sigma_{\mathrm{el}}$ & $\sigma_{\text {capt }}$ & $\sigma_{n, 2 n}$ & $\sigma_{\text {inel }}$ & $\sigma_{\mathrm{el}}$ & $\sigma_{\text {capt }}$ & $\sigma_{n, 2 n}$ & & & & & & & & & & & & & & & & & & & & \\
\hline 1 & \begin{tabular}{|l|}
19.6 \\
\end{tabular} & 24 & 5 & 10 & 0 & \begin{tabular}{|l|}
31 \\
\end{tabular} & 5 & 10 & 100 & \begin{tabular}{|l|}
30 \\
\end{tabular} & 5 & 10 & 100 & \begin{tabular}{|l|}
0 \\
\end{tabular} & 5 & 20 & 0 & & & & & & & & & & & & & & & & & & & & \\
\hline 2 & $4.98 \mathrm{e}-1$ & 0 & 5 & 9 & 0 & 0 & 5 & 9 & 0 & 33 & 5 & 9 & 0 & 0 & 4 & 20 & 0 & & & & & & & & & & & & & & & & & & & & \\
\hline 3 & $6.74 \mathrm{e}-2$ & 0 & 5 & 8 & 0 & 0 & 5 & 8 & 0 & 0 & 5 & 8 & 0 & 0 & 3 & 20 & 0 & & & & & & & & & & & & & & & & & & & & \\
\hline 4 & $2.03 e-3$ & 0 & 3.3 & 6.3 & 0 & 0 & 3.3 & 6.3 & 0 & 0 & 3.3 & 6.3 & 0 & 0 & 2 & 14 & 0 & & & & & & & & & & & & & & & & & & & & \\
\hline
\end{tabular}


Table 51. BOLNA Variance Matrix (Fissile Isotopes): U235, U238 and Pu239 (with nu-bar corrected) from ORNL; Cm246 from ANL. Values in \%

\begin{tabular}{|c|c|c|c|c|c|c|c|c|c|c|c|c|c|c|c|c|c|c|c|c|c|c|c|c|c|c|c|c|c|c|c|c|c|c|c|c|c|c|c|c|}
\hline \multirow{2}{*}{\multicolumn{2}{|c|}{\begin{tabular}{|l|l|l|l|}
$G r$ & EeV]
\end{tabular}}} & \multicolumn{5}{|c|}{ Th232 } & \multicolumn{6}{|c|}{ U233 } & & & $\mathrm{U} 23$ & & & & & & U23 & & & & & & $\mathrm{U} 2$ & & & & & & $\mathrm{U} 23$ & & & & $\mathrm{Cm} 2$ & 1245 & & n246 \\
\hline & & & $\sigma_{f}$ & $\left|\overline{\mid \sigma_{\text {inel }}}\right|$ & $\sigma_{\text {ell }} \sigma_{\text {cap }}$ & \begin{tabular}{l|l}
$\mathrm{tt}$ & $\sigma_{\mathrm{n},}$
\end{tabular} & $v$ & $\sigma_{f}$ & $\left|\sigma_{\text {inel }}\right|$ & $\overline{\left|\sigma_{\mathrm{el} \mid}\right|}$ & $\sigma_{\text {capt }} \mid$ & $\sigma_{n, 2 n}$ & $y$ & $\sigma_{f}$ & 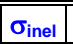 & $\sigma_{\mathrm{ell}} \sigma_{\mathrm{\sigma}}$ & $\bar{c}$ capt $\mid \sigma$ & $\sigma_{n, 2 n}$ & $v$ & $\sigma_{\mathrm{f}}$ & $\mid \sigma_{\text {inel }}$ & $\overline{\mid \sigma_{\mathrm{el} \mid} \mathrm{C}}$ & $\sigma_{\text {capt }} \sigma$ & $\sigma_{n, 2 n}$ & & $\sigma_{f}$ & $\sigma_{\text {inel }}$ & $\overline{\mid \sigma_{\mathrm{el}} \mathrm{C}_{\mathrm{O}}}$ & $\sigma_{\text {capt }}$ & & & $\sigma_{f}$ & $\mid \sigma_{\text {inel }}$ & $\sigma_{\mathrm{ell}} \sigma_{0}$ & & & \begin{tabular}{l|l|}
$v$ \\
\end{tabular} & $\sigma_{\mathrm{f}}$ & $v$ & $\sigma_{\mathrm{f}}$ \\
\hline 1 & & & 2.11 & 851 & \begin{tabular}{|l|l|}
1.39 & 17.4 \\
\end{tabular} & \begin{tabular}{|l|l|}
4 & 10 \\
\end{tabular} & 0.84 & \begin{tabular}{|l|}
3.98 \\
\end{tabular} & 10.79 & 2.515 & 57.011 & 18.44 & & \begin{tabular}{|l|}
12.9 \\
\end{tabular} & 32.41 & \begin{tabular}{l|l}
1.6 & 5 \\
\end{tabular} & 6.743. & 34.85 & \begin{tabular}{|l|}
0.89 \\
\end{tabular} & \begin{tabular}{|l|}
0.5 \\
\end{tabular} & \begin{tabular}{|l|}
21.73 \\
\end{tabular} & & & 20.35 & & 14.64 & 32.82 & 1.014 & 48.32 & \begin{tabular}{|l|}
18.49 \\
\end{tabular} & 1.26 & \begin{tabular}{|l|}
0.57 \\
\end{tabular} & & 13.32 & \begin{tabular}{|l|l|l|l}
21.41 & 5
\end{tabular} & 5.32 & \begin{tabular}{|l|}
9.64 \\
\end{tabular} & 18.11 & & 40 \\
\hline 2 & 6.07 & & \begin{tabular}{|l|}
2.1 \\
\end{tabular} & & 1.2225 .6 & 0 & 25 & \begin{tabular}{|l|l|}
6.44 \\
\end{tabular} & \begin{tabular}{|l|l|}
4.48 \\
\end{tabular} & \begin{tabular}{|l|l|l|} 
& \\
\end{tabular} & \begin{tabular}{ll|}
61.4 \\
\end{tabular} & & & 23.52 & 29.45 & 2.062 & 6.11 & 0 & \begin{tabular}{|l|}
0.69 \\
\end{tabular} & \begin{tabular}{|l|l|}
0.47 \\
\end{tabular} & \begin{tabular}{|l|l|}
6.79 & 4 \\
\end{tabular} & 4.153 & & 8.86 & & \begin{tabular}{|l|}
26.9 \\
\end{tabular} & \begin{tabular}{|l|}
7.07 \\
\end{tabular} & $|0.89|^{4}$ & 47.92 & & \begin{tabular}{|l|}
1.17 \\
\end{tabular} & \begin{tabular}{|l|}
0.55 \\
\end{tabular} & 19.75 & $\begin{array}{ll}14.5 & 1\end{array}$ & 13.5 & & \begin{tabular}{|l|}
2.91 \\
\end{tabular} & 30.96 & & \\
\hline 3 & & & \begin{tabular}{|l|}
2.1 \\
\end{tabular} & & \begin{tabular}{|l|l|l|}
4.41 \\
\end{tabular} & 0 & & & 58 & \begin{tabular}{|l|l|}
3 & 3 \\
\end{tabular} & 38.88 & & & & & & 5.91 & & & 48 & $5.41 \sqrt{4}$ & 4.541 & 19.14 & & & 28.88 & 5.45 & & 36 & & 34 & 0.6 & & 18.7 & 6.05 & & 85 & & & \\
\hline 4 & & & 2.15 & & \begin{tabular}{|l|l}
1.8 & 1.89 \\
\end{tabular} & & & & \begin{tabular}{|l|}
40.46 \\
\end{tabular} & \begin{tabular}{|l|l|l|l|l|} 
& \\
\end{tabular} & 30.35 & & & \begin{tabular}{|l|l|}
37.97 \\
\end{tabular} & \begin{tabular}{|l|l|}
14.61 \\
\end{tabular} & \begin{tabular}{l|l|l|l|l|}
2 & 1 \\
\end{tabular} & 1.99 & & & 46 & & 3.56 & \begin{tabular}{|l|l|}
16.1 \\
\end{tabular} & & & \begin{tabular}{|l|l|}
31.97 \\
\end{tabular} & 37.2 & \begin{tabular}{|l|}
0.65 \\
\end{tabular} & 15.1 & & \begin{tabular}{l|}
3 \\
\end{tabular} & 91 & 11.56 & $\begin{array}{l}5.35 \\
\end{array}$ & 2.27 & & 2.95 & 49.43 & & \\
\hline 5 & $8 \mathrm{e}-$ & & 95.17 & & \begin{tabular}{|l|l|l}
1.65 \\
\end{tabular} & 0 & & & 29 & \begin{tabular}{|l|l|}
2.49 & \\
\end{tabular} & 10.62 & & & 97 & & 2.751. & 3.98 & c & & \begin{tabular}{l|l}
.5 \\
\end{tabular} & & 2.872 & 22.13 & & & $\begin{array}{l}97 \\
\end{array}$ & & & & & & \begin{tabular}{|l|l|}
5.26 \\
\end{tabular} & \begin{tabular}{|l|l|}
4.19 \\
\end{tabular} & $\begin{array}{ll}1.92 & 1 \\
\end{array}$ & 1.41 & & .01 & & & \\
\hline 6 & & & 46.92 & & \begin{tabular}{|l|l|l|l}
1.18 & 1.14 \\
\end{tabular} & & & & 0 & 3.16 & 8.94 & & & 31.61 & 31.49 & \begin{tabular}{l|l|l}
1.6 & 1
\end{tabular} & 2921 & & & & & 2.383 & 30.64 & & & 16.47 & 4.14 & \begin{tabular}{|l|l|} 
\\
\end{tabular} & 10.53 & & & 14 & & & 1.67 & & 3.01 & & & \\
\hline 7 & & & \begin{tabular}{|l|}
0 \\
\end{tabular} & \begin{tabular}{l|l}
0 & 0 \\
\end{tabular} & \begin{tabular}{|l|l|}
0.48 & 1.4 \\
\end{tabular} & 0 & & & 0 & 661 & 13.29 & & & 22.84 & \begin{tabular}{|l|}
0 \\
\end{tabular} & 5.32 & 2.72 & & & \begin{tabular}{|l|}
0.5 \\
\end{tabular} & & & & & & & 0 & \begin{tabular}{|l|}
0.76 \\
\end{tabular} & 7.84 & & & \begin{tabular}{|l|l|}
5.14 \\
\end{tabular} & \begin{tabular}{|l|l|}
11.12 \\
\end{tabular} & $3.76 \mid 1$ & 1.64 & & & & & \\
\hline 8 & & & 0 & 0 & \begin{tabular}{|l|l|l|l|l|}
1 & 1.46 \\
\end{tabular} & & & & & 911 & 13. & & & \begin{tabular}{|l|l|}
19.41 \\
\end{tabular} & 0 & 4.861 & & & & & \begin{tabular}{l|l}
50 & 3 \\
\end{tabular} & 3.243 & 34.03 & & & & & 46 & 7. & & & .31 & \begin{tabular}{l|l}
0 & 1
\end{tabular} & 1.52 & 9.43 & & & & & \\
\hline 9 & & & 0 & 0 & \begin{tabular}{l|l}
0.48 & 2.8 \\
\end{tabular} & & & & & 9.041 & 14.19 & & & \begin{tabular}{|l|l|}
13.69 \\
\end{tabular} & 0 & 3.581 & $\begin{array}{l}1.53 \\
\end{array}$ & & & 18 & \begin{tabular}{|l|l|l|l|}
48.8 & \\
\end{tabular} & 5.163 & 33.92 & & & 35 & 0 & 0.46 & 3.89 & & & \begin{tabular}{|l|}
214.6 \\
\end{tabular} & 0 & 0.67 & 3.11 & & \begin{tabular}{l|l|}
3.01 \\
\end{tabular} & 1 & & 40 \\
\hline 10 & & & 0 & 0 & \begin{tabular}{l|l}
53 & 3.35 \\
\end{tabular} & 0 & & & 0 & \begin{tabular}{|l|}
6.17 \\
\end{tabular} & & & & 14.97 & 0 & $\begin{array}{l}6.94 \\
\end{array}$ & & & & 77 & & 2.07 & 4.56 & & & & & 2.26 & 1.24 & & & $\begin{array}{l}9.69 \\
\end{array}$ & & & 2.1 & & 3.01 & & & \\
\hline & & & & 0 & 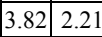 & & & & 0 & \begin{tabular}{l|l}
6 & \\
\end{tabular} & 4.28 & & & 5.11 & 0 & 23.12 & 242 & & & 44 & & 1.33 & 0.63 & & & & 0 & \begin{tabular}{l|l}
5.96 \\
\end{tabular} & $\begin{array}{l}1.2 \\
\end{array}$ & & & 2.38 & & \begin{tabular}{|l|l|}
2.39 & 1 \\
\end{tabular} & 1.71 & & 3.01 & & & \\
\hline & & & & 0 & \begin{tabular}{|l|l|}
53 & 3.2 \\
\end{tabular} & & & & & 5.61 & & & & 17.49 & 0 & 7.1 & & & & & & 1.52 & & & & & & 2.35 & & & & 8.82 & & & & & & & & \\
\hline & & & 0 & 0 & \begin{tabular}{|l|l}
0.86 & 1.9 \\
\end{tabular} & & & & 0 & \begin{tabular}{|l|l|}
4.16 \\
\end{tabular} & & & & 21.85 & & \begin{tabular}{l|l}
2.32 \\
\end{tabular} & & & & & & 1.78 & & & & & 0 & $|4.77|$ & 3.47 & & & .89 & & 0.82 & 2.45 & & 1 & & & \\
\hline 14 & & & 0 & 0 & \begin{tabular}{l|l|l|l|}
0.81 & 1.3 \\
\end{tabular} & & & & 0 & 2.14 & 2.59 & & & $24.67 \mid$ & 0 & $2.02 \sqrt{3}$ & 3.08 & & & & & 3.42 & 1. & & & \begin{tabular}{|l|l|}
19.58 \\
\end{tabular} & 0 & 4.91 & 3.44 & & & 5.1 & c & 0.92 & 1.66 & & 3.01 & & & 40 \\
\hline & & & 0 & 0 & \begin{tabular}{|l|l|l|}
0.75 \\
\end{tabular} & 0 & & & 0 & 5.34 & 4.23 & 7 & & 24.81 & 0 & $1 . 9 8 \longdiv { 2 }$ & 2.9 & c & & & 0 & 4.9 & & & & & 0 & \begin{tabular}{|l|}
4.89 \\
\end{tabular} & 3.58 & & & 5.4 & 0 & \begin{tabular}{l|l|l|l|l|} 
& 0.94 \\
\end{tabular} & 1.64 & & & & & \\
\hline & & & & Np23 & & & & & Pu2: & & & & & & Pu2: & & & & & & Pu24 & 40 & & & & & Pu2 & & & & & & Pu2 & & & & $\mathrm{Cm} 2$ & 2245 & & \\
\hline & $\mathrm{E}[\mathrm{MeV}]$ & & & & & & & & & $\sigma$ & & & & $\sigma_{\mathrm{f}}$ & & & & & & & & $\sigma_{\mathrm{el}}$ & & & & & & & & & & & & $\left.\sigma_{\mathrm{ell}}\right|_{\mathrm{g}}$ & & & $\sigma_{\text {inel }}$ & $\sigma_{\mathrm{el}}$ & & $\sigma_{\mathrm{el}}$ \\
\hline 1 & & 1.94 & \begin{tabular}{|l|l|}
5.58 \\
\end{tabular} & & 2.3941 .4 & 9.51 & \begin{tabular}{|l|}
2.17 \\
\end{tabular} & \begin{tabular}{|l|}
25.2 \\
\end{tabular} & \begin{tabular}{|l|}
24.56 \\
\end{tabular} & \begin{tabular}{|l|l|l|l|l|} 
\\
\end{tabular} & 50.915 & 58.36 & \begin{tabular}{|l|}
0.5 \\
\end{tabular} & \begin{tabular}{|l|}
0.63 \\
\end{tabular} & 23.06 & 6.943 & $\begin{array}{l}37.08 \\
\end{array}$ & 8.53 & \begin{tabular}{|l|}
1.09 \\
\end{tabular} & \begin{tabular}{|l|}
9.56 \\
\end{tabular} & 37.112 & 2.345 & 52.165 & 54.09 & 0.45 & 24.09 & \begin{tabular}{|l|l|}
25.15 \\
\end{tabular} & 4.455 & 55.39 & 39.68 & \begin{tabular}{|l|}
0.9 \\
\end{tabular} & \begin{tabular}{|l|l|}
37.24 \\
\end{tabular} & 26.25 & 0.87 & 78.47 & 51.7 & 85.1 & 4.81 & & \\
\hline & & & & & \begin{tabular}{|lll}
3.7 & 36.4
\end{tabular} & 0 & & & & $\begin{array}{l}0.822 \\
\end{array}$ & 28.81 & & & \begin{tabular}{|l|l|}
0.69 \\
\end{tabular} & \begin{tabular}{|l|l|l|}
22.18 \\
\end{tabular} & $9.36 \sqrt{3}$ & \begin{tabular}{ll|}
37.8 \\
\end{tabular} & |4.34 & $\mid 2.65$ & \begin{tabular}{|l|}
4.8 \\
\end{tabular} & \begin{tabular}{|l|l|l|}
9.65 & \\
\end{tabular} & 5.193 & \begin{tabular}{|l|l|}
32.47 \\
\end{tabular} & & .27 & \begin{tabular}{|l|l|}
14.16 \\
\end{tabular} & 47 & 3.74 & \begin{tabular}{|l|l|}
54.1 \\
\end{tabular} & 33.43 & 2.21 & \begin{tabular}{|l|l|}
15.1 \\
\end{tabular} & 3.27 & 0.512 & 22.72 & & 13.01 & & & 10 \\
\hline 3 & & & & & \begin{tabular}{|l|l|}
4.12 & 17.6 \\
\end{tabular} & 0 & & & & $\left.6.24\right|_{2}$ & 21.5 & & & & \begin{tabular}{|l|}
19 \\
\end{tabular} & 10.32 & 26.56 & & & 65 & & 5.421 & & & & & & 4.393 & 38.41 & & & 42 & 29.28 & & & & 2 & & & \\
\hline 4 & & & & & \begin{tabular}{l|l}
3.62 & 10.3 \\
\end{tabular} & 0 & & & 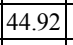 & \begin{tabular}{|l|l}
6 \\
\end{tabular} & 9.74 & & & & 29.01 & $\begin{array}{ll}10.21 & 1 \\
0.2 & \end{array}$ & 8.18 & & & 82 & & 4.761 & 16.28 & & 28 & 62 & .78 & 5.383 & 31.66 & & 11 & 8.98 & \begin{tabular}{|l|l|l|}
59.7 \\
\end{tabular} & 3.681 & 12.48 & & 4.47 & & & 10 \\
\hline 5 & & & & & \begin{tabular}{|l|l|}
3.47 & 5.79
\end{tabular} & 0 & & 7.11 & $\begin{array}{l}.09 \\
\end{array}$ & $\begin{array}{l}9.52 \\
\end{array}$ & 12.31 & & & & & 5.6 & & & & & & $\begin{array}{lll}5.531 \\
\end{array}$ & & & & & & 5.16 & 20.51 & & & 3.63 & 37.99 & $1.73 / 2$ & 24.0 & & 4 & & & \\
\hline 6 & & & & & \begin{tabular}{|l|l|l|l} 
& \\
\end{tabular} & & & & 20.81 & \begin{tabular}{|l|l|}
4.1 & 1 \\
\end{tabular} & 16.6 & & & & \begin{tabular}{|l|}
46.06 \\
\end{tabular} & 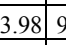 & & & & 7 & 55 & 5.761 & 13 & & & & .09 & 4.691 & 11.29 & & & 2.07 & \begin{tabular}{|c|}
19 \\
\end{tabular} & 1.783 & 32.2 & & 4.5 & & & \\
\hline 7 & & & & & \begin{tabular}{|l|l|}
4.37 & 6.66
\end{tabular} & 5 & & & & $\left.5.26\right|_{2}$ & 22.14 & & & & & 2.37 & & & & \begin{tabular}{|l|}
7.45 \\
\end{tabular} & \begin{tabular}{|l|l|}
48.58 \\
\end{tabular} & \begin{tabular}{|l|l|l|}
5.8 & 1
\end{tabular} & 11 & & & 8 & 37.51 & 3.92 & 4.43 & & & 33.0 & 0 & $1.59 \sqrt{3}$ & & & 94.77 & 67 & & \\
\hline 8 & & & & & \begin{tabular}{|l|l}
4.48 & 5. \\
\end{tabular} & 0 & & & 0 & \begin{tabular}{l|l|l}
4.85 & \\
\end{tabular} & 18. & & & & 52 & 2.16 & & & & & & 5.051 & & & & & & & & & & 33. & & 1.423 & & & & & & \\
\hline 9 & & & & & \begin{tabular}{|l|l}
3 & 5.25 \\
\end{tabular} & 0 & & & & \begin{tabular}{|l|}
4.43 \\
\end{tabular} & 9. & & & & \begin{tabular}{|l|}
8.64 \\
\end{tabular} & 4.04 & & & & & & 2.08 & 4.3 & & & 10 & & 29 & 7.73 & & & 13.2 & 0 & 1.593 & 38.45 & & & & & \\
\hline & & & & & 145. & & & & & \begin{tabular}{|l|}
4.35 \\
\end{tabular} & & & & & & 0.74 & & & & & & 1.26 & & & & & & & & & & & & & & & & & & \\
\hline & & & & & $\begin{array}{ll}41 & 1.7 \\
\end{array}$ & & & & & 20.0 & & & & & & 1.2 & & & & & & \begin{tabular}{|l|}
1.64 \\
\end{tabular} & 1.6 & & & & & 0.8 & 7.4 & & & 1.9 & & 2.292 & 2.23 & & & & & \\
\hline & & & & & $\begin{array}{l}10.55 \\
\end{array}$ & 0 & & & & & & & & & & 0.24 & & & & & & 3.25 & & & & & & & & & & & & & & & & & & \\
\hline & & & & & \begin{tabular}{l|l}
3 & 0. \\
\end{tabular} & & & & & \begin{tabular}{l|l|}
.79 \\
\end{tabular} & & & & & & & & & & & & 0.48 & & & & & & & & & & & & & & & & & & \\
\hline & & & & & \begin{tabular}{|l|l|l|}
8 & 2.41 \\
\end{tabular} & 0 & & & & .1 & & & & & & 0.44 & & & & & & 4.58 & 3. & & & & & & & & & & & & & & & & & \\
\hline & e-7 & & & \begin{tabular}{l|l|l}
0 & 2 \\
\end{tabular} & \begin{tabular}{|l|l|l|}
2.03 \\
\end{tabular} & 0 & & & 0 & \begin{tabular}{|l|}
4.69 \\
\end{tabular} & 1.41 & 0 & & 1.11 & 0 & \begin{tabular}{ll|}
0.68 \\
\end{tabular} & 1.6 & & & 48.46 & \begin{tabular}{|l|l|} 
\\
\end{tabular} & \begin{tabular}{|l|l|}
5.64 \\
\end{tabular} & 4.7 & & & & 0 & \begin{tabular}{|l|l|}
11.3 \\
\end{tabular} & 3.59 & & & \begin{tabular}{|l}
5.09 \\
\end{tabular} & 0 & \begin{tabular}{ll|}
6.9996 \\
\end{tabular} & 6.89 & & 0 & 19.44 & & 10 \\
\hline & & & & Am2 & 241 & & & & Am24 & $42 \mathrm{~m}$ & & & & & Am2 & & & & & & $\mathrm{Cm} 2$ & 242 & & & & & $\mathrm{Cm} 2$ & 2243 & & & & & $\mathrm{Cm} 2$ & & & & & 2245 & & 246 \\
\hline & & & & & & & & & & $\left|\sigma_{\mathrm{el}}\right|$ & & & & & & & & & & & & & & & & & & & & & & & & & & & & & & \\
\hline 1 & & & $\mid 12.74$ & & 3.5128 .8 & \begin{tabular}{|l|l}
3 & 10.03 \\
\end{tabular} & & 21.37 & 55 & $8.36 / 8$ & 84.913 & 31 & 88 & 14.44 & \begin{tabular}{|l|}
61.97 \\
\end{tabular} & 7.516 & 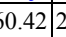 & \begin{tabular}{|l|l|l|}
26.63 &
\end{tabular} & & \begin{tabular}{|l|}
31.49 \\
\end{tabular} & & 3.015 & 52.785 & & 64 & & 75 & 5.65 & 77.57 & 52.75 & 55 & 17.86 & 38.26 & & 89.194 & 40.91 & 1.21 & 22.43 & & \\
\hline & & & & & \begin{tabular}{l|l|l}
3.77 .3 \\
\end{tabular} & \begin{tabular}{|l|l|}
8 & 0 \\
\end{tabular} & & & & & 63.01 & & & 11.03 & & $4.64 \sqrt{4}$ & & \begin{tabular}{|l|}
0 \\
\end{tabular} & & & & 5.273 & 37.41 & & & & 2 & 9.12 & 44.12 & & & 31.25 & & 10.25 & \begin{tabular}{|l|l}
53.78 \\
\end{tabular} & & & 993.53 & & \\
\hline 3 & & & & & \begin{tabular}{l|l}
5.12 & 9.
\end{tabular} & & & & & & & & & & & 7.492 & & & & & & $2.85 \sqrt{2}$ & 23 & & & & & & & & & & & & & & & & & 0 \\
\hline 4 & & 0. & & & \begin{tabular}{|l|l}
4.52 & 6.9 \\
\end{tabular} & & & & & \begin{tabular}{|l|l|}
12.03 \\
\end{tabular} & 39.4 & & & & 42.15 & 4.111 & & & & 39 & & 1.661 & 19 & & & & & & & & & & & \begin{tabular}{|l|}
10.7 \\
\end{tabular} & & & & & & \\
\hline 5 & & & & & \begin{tabular}{|l|l}
5.5 & 5 \\
\end{tabular} & & & & & 13.6 & 2 & & & & & \begin{tabular}{l|l|}
5.9 & 8 \\
\end{tabular} & & & & & & 1.711 & & & & & & & & & & .53 & & & & & & & & 0 \\
\hline 6 & & & & & \begin{tabular}{|l|l}
5.2 & 6.79 \\
\end{tabular} & & & & 33.65 & \begin{tabular}{|l|l|} 
\\
\end{tabular} & 19.3 & & & & \begin{tabular}{|l|l|}
79.53 \\
\end{tabular} & 7.84 & & & & & 53.15 & 2.042 & 20 & & & & 20.24 & \begin{tabular}{|l|l|}
12.7 \\
\end{tabular} & 23.36 & & & 7.56 & 63.31 & 8.3811 & & & & & & \\
\hline & & & & & & & & & & & & & & & 80.77 & & & & & & 31.73 & & & & & & & & & & & & 507 & & & & & & & \\
\hline 8 & & & & & \begin{tabular}{l|l}
11.5 & 6.
\end{tabular} & & & & \begin{tabular}{|l|}
50 \\
\end{tabular} & & & & & & \begin{tabular}{|l|}
0 \\
\end{tabular} & 13 & & & & & & 2.112 & 21 & & & & & & & & & & 0 & & & & & & & 0 \\
\hline & & & & & \begin{tabular}{|l|l}
12.3 & 6.6 \\
\end{tabular} & & & & 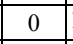 & & & & & & & & & & & & & & & & & & & & & & & & & 140 & & & & & & \\
\hline & & & & & & & & & & & & & & & 0 & & & & & & & & & & & & & & & & & & & & & & & & & 0 \\
\hline 1 & & & & & \begin{tabular}{l|l|l}
14.5 & 3.67
\end{tabular} & 0 & & & 0 & & 11. & & & & 0 & 8.962 & & & & & & \begin{tabular}{|l|l|}
12.6 & \\
\end{tabular} & 4. & & & & & 5.5 & & & & & 0 & 3.61 & & & & & & \\
\hline & & & & & & 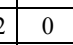 & & & 0 & & & & & & 0 & \begin{tabular}{l|l}
8.22 & 1 \\
\end{tabular} & & & & & & \begin{tabular}{|l|}
18.1 \\
\end{tabular} & & & & & & & & & & & & & & & & & & \\
\hline 1 & & & & 0 & 14.25 .54 & 0 & & & 0 & 1 & 13 & & & & 0 & \begin{tabular}{l|l}
7 & 3 \\
\end{tabular} & & 7 & 6 & & & $\overline{19.83}$ & 32 & & & & & 8.5 & & & 5.6 & 12 & 0 & \begin{tabular}{ll|l}
62 & 1 \\
2
\end{tabular} & & & & & & 0 \\
\hline & & & & & & & & & ( & & & & & & & & & & & & & & & & & & & & & & & & & & & & & & & \\
\hline & & & 3.02 & 0 & \begin{tabular}{l|l|l}
13.0 & 1.8 \\
\end{tabular} & & & 8.06 & 0 & \begin{tabular}{|l|}
21.7 \\
\end{tabular} & 19.6 & & & 2.12 & 0 & $11.4 \mid 3$ & 3.58 & & & & & $19.6 \mid 4$ & 40.7 & & & & & & & & 5.6 & 27.18 & 0 & $|0.12|$ & 12.5 & & & & & \\
\hline
\end{tabular}


Table 52. BOLNA Variance Matrix (Structural Isotopes): Only Pb204, Pb206, Pb207, Pb208 from NRG; C, B10 and He4 from ANL. Values in \%

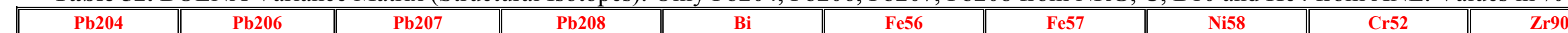

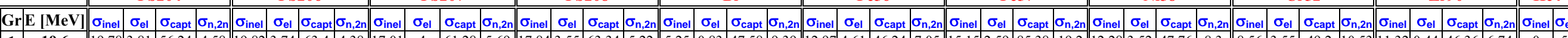

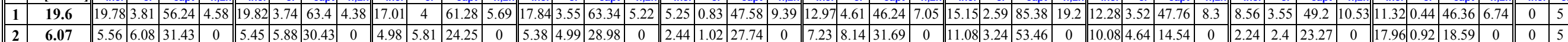
\begin{tabular}{|l|l|l|l|l|l|l|l|l|l|l|l|l|l|l|l|l|l|l|l}
$\mathbf{3}$ & $\mathbf{2 . 2 3}$ & 14.2 & 5.12 & 27.61 & 0 & 14.17 & 4.7 & 24.54 & 0 & 13.77 & 4.43 & 21.56 & 0 & 0 & 6.3 & 22.56 & 0 \\
\hline
\end{tabular}

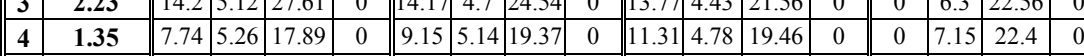

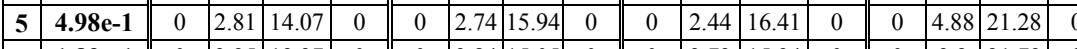

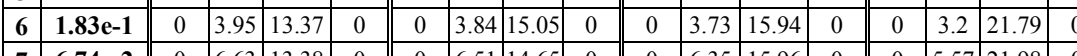

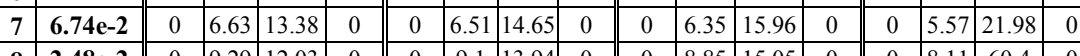

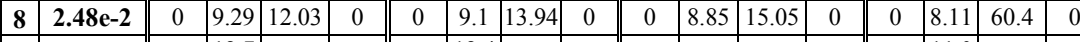
\begin{tabular}{||c||c|c|c|c|c|c|c|c|c|c|c|c|c|c|c|c|c|}
\hline $\mathbf{9}$ & $\mathbf{9 . 1 2 e}-\mathbf{3}$ & 0 & 12.7 & 12.47 & 0 & 0 & 12.4 & 12.8 & 0 & 0 & 12 & 14.27 & 0 & 0 & 11.0 & 182.3 & 0 \\
\hline $\mathbf{1 0}$ & $\mathbf{2 . 0 4 e - 3}$ & 0 & 17.7 & 13.57 & 0 & 0 & 17.2 & 276.5 & 0 & 0 & 16.6 & 20.01 & 0 & 0 & 15.0 & 317.0 & 0 \\
\hline
\end{tabular} \begin{tabular}{l|l||c|c|c|c|c|c|c|c|c|c|c|c|c|c|c|c|c|}
\hline $11.54 \mathrm{e}-4$ & 0 & 11.4 & 8.31 & 0 & 0 & 11.0 & 8.66 & 0 & 0 & 10.69 & 8.6 & 0 & 0 & 9.61 & 13.94 & 0 \\
\hline
\end{tabular} \begin{tabular}{|l||c|c|c|c|c|c|c|c|c|c|c|c||c|c|c|c|c|}
12 & $\mathbf{2 . 2 6 e - 5}$ & 0 & 0 & 0 & 0 & 0 & 0 & 0 & 0 & 0 & 0 & 0 & 0 & 0 & 0 & 0 & 0 \\
\hline
\end{tabular} \begin{tabular}{|l|l||c|c|c|c|c|c|c|c|c|c|c|c|c|c|c|c|c|}
\hline 13 & $\mathbf{4 . 0 0 e}-\mathbf{6}$ & 0 & 0 & 0 & 0 & 0 & 0 & 0 & 0 & 0 & 0 & 0 & 0 & 0 & 0 & 0 & 0 \\
$\mathbf{1 4}$ & $\mathbf{5 . 4 0 \mathrm { e } - 7}$ & 0 & 0 & 0 & 0 & 0 & 0 & 0 & 0 & 0 & 0 & 0 & 0 & 0 & 0 & 0 & 0 \\
\hline
\end{tabular} \begin{tabular}{l|l|l|l|l|l}
14 & $5.40 \mathrm{e}-7$ & 0 \\
\hline 15 & $1.00 \mathrm{e}-7$ & 0 & \\
\hline
\end{tabular}

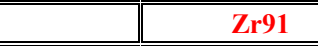
\begin{tabular}{|lllll|llllll}
0 & 0 & 0 & 0 & 0 & 0 & 0 & 0 \\
\hline
\end{tabular} \begin{tabular}{|lllll|llllll}
0 & 0 & 0 & 0 & 0 & 0 & 0 & 0 \\
\hline
\end{tabular} \begin{tabular}{|l|l|l|l|l|l}
\hline 34.07 & 2.06 & 17.56 & 0 \\
\hline
\end{tabular}

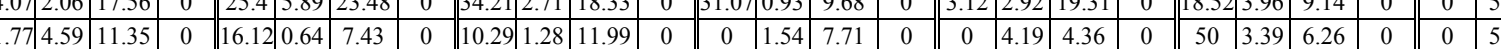

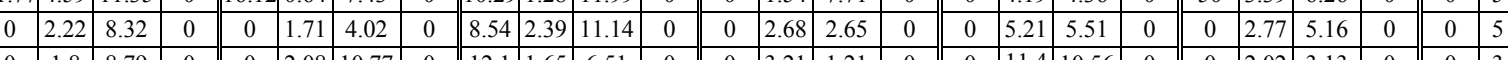

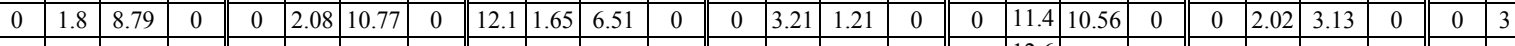

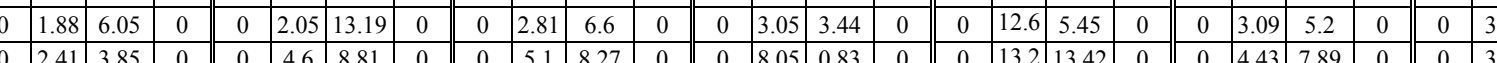

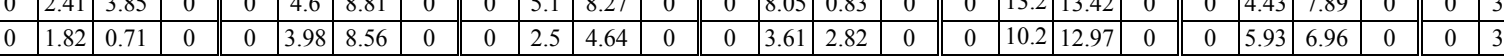
\begin{tabular}{llll||c|c|c|c|c|c|c|c|c|c|c|c|c|c|c|c|c|c|c|c|c|c|}
0 & 1.82 & 0.71 & 0 & 0 & 3.98 & 8.56 & 0 & 0 & 2.5 & 4.64 & 0 & 0 & 3.61 & 2.82 & 0 & 0 & 10.2 & 12.97 & 0 & 0 & 5.93 & 6.96 & 0 & 0 & 3 \\
0 & 1.93 & 0.43 & 0 & 0 & 4.16 & 11.23 & 0 & 0 & 16.1 & 29.24 & 0 & 0 & 2.96 & 2.41 & 0 & 0 & 7.79 & 2.75 & 0 & 0 & 6.83 & 10.55 & 0 & 0 & 3 \\
\hline
\end{tabular} \begin{tabular}{|l|l|l||ll|l|l|l|l|l|l|l|l|l|l|l|l|l|l|l|l|l|l|l|l|l|}
\hline & 1.85 & 1.47 & 0 & 0 & 4.28 & 11.25 & 0 & 0 & 8.48 & 10.69 & 0 & 0 & 2.77 & 2.4 & 0 & 0 & 7.37 & 2.7 & 0 & 0 & 6.73 & 5.95 & 0 & 0 & 3 \\
\hline
\end{tabular}

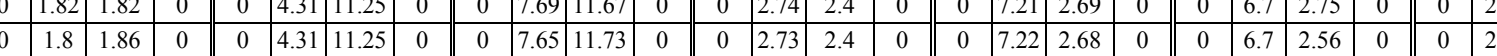

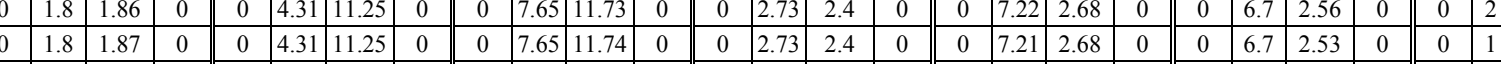
$\mathrm{Si}$ \begin{tabular}{|c|c|c|c|c|c|c|}
0 & 0 \\
\hline
\end{tabular} $\mathrm{Na}$

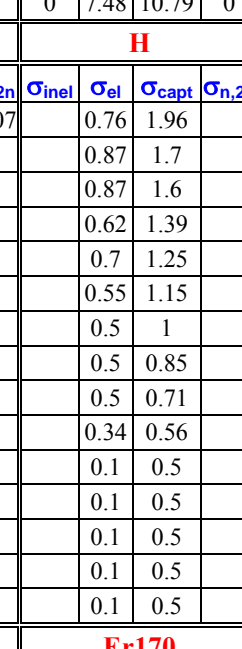
$\mathrm{Al}$ 2.24 Gd156 He4

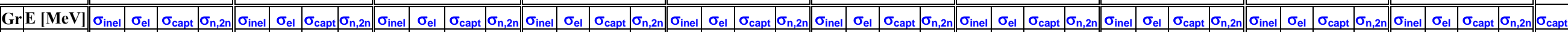

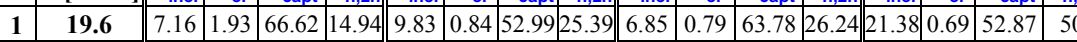

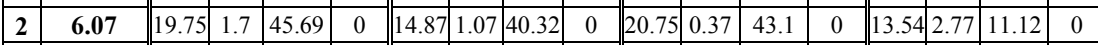
\begin{tabular}{|l|l|lll|l|l|l|l|l|l|l|l|l|l|l|l|l|l}
\hline $\mathbf{3}$ & $\mathbf{2 . 2 3}$ & 5.18 & 4.15 & 22.89 & 0 & 15.07 & 4.1 & 21.53 & 0 & 10.43 & 2.63 & 25.76 & 0 & 50 & 1.66 & 10.07 & 0 \\
\hline
\end{tabular} \begin{tabular}{|l|l||lll|l|l|l|l|l|l|l|l|l|l|l|l|l|l|l}
\hline $\mathbf{4}$ & $\mathbf{1 . 3 5}$ & 50 & 4.11 & 16.83 & 0 & 40.85 & 2.41 & 11.31 & 0 & 41.27 & 1.1 & 14.22 & 0 & 0 & 1.43 & 6.77 & 0 \\
\hline
\end{tabular}

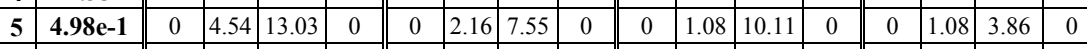

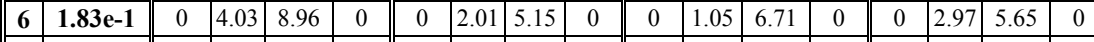

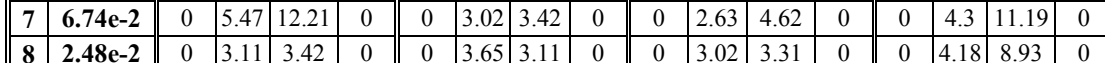

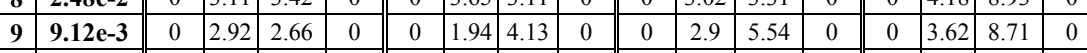

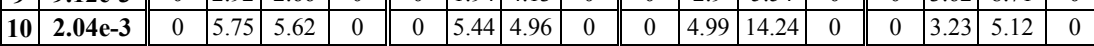

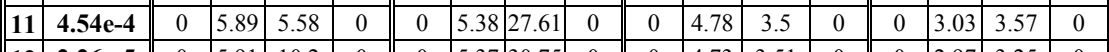

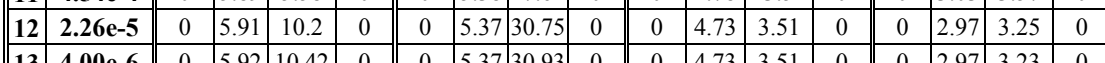

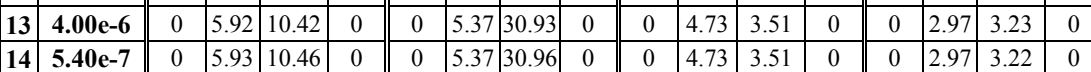

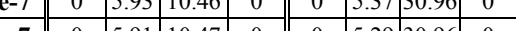
\begin{tabular}{|l|l|lll|l|l|l|l|l|l|l|l|l|l|l|l|l|l|l|l|}
\hline 15 & $\mathbf{1 . 0 0 e}-7$ & 0 & 5.91 & 10.47 & 0 & 0 & 5.29 & 30.96 & 0 & 0 & 4.73 & 3.51 & 0 & 0 & 2.9 & 2.96 & 0 \\
\hline \hline
\end{tabular} Gd157 Gd158 Er166

\begin{tabular}{|c|c|c|c|c|c|c|c|}
\hline 0 & 5 & 100 & 0 & 8.87 & 4.62 & 24.33 & 0 \\
\hline 0 & 12.1 & \begin{tabular}{|l|l|}
100 \\
\end{tabular} & 0 & 12.56 & 3.72 & 1.7 & \\
\hline 0 & 1.43 & 100 & 0 & 28 & 3.01 & \begin{tabular}{|l|l}
7.44 \\
\end{tabular} & 0 \\
\hline 0 & 1.68 & 81.81 & 0 & 50 & 3.31 & \begin{tabular}{|l|l}
6.81 \\
\end{tabular} & \\
\hline 0 & 1.68 & $\mid 69.63$ & 0 & 0 & 3.25 & 233.59 & 0 \\
\hline 0 & 2.36 & \begin{tabular}{|l|l}
44.27 \\
\end{tabular} & 0 & 0 & 2.38 & \begin{tabular}{|l}
6.79 \\
\end{tabular} & 0 \\
\hline 0 & 2.35 & 28.21 & 0 & 0 & 2.87 & \begin{tabular}{|l|l}
6.63 \\
\end{tabular} & \\
\hline 0 & 2.24 & \begin{tabular}{|l|l|}
12.1 \\
\end{tabular} & $\overline{0}$ & 0 & 3.23 & \begin{tabular}{|l}
1.18 \\
\end{tabular} & 0 \\
\hline 0 & 2.23 & \begin{tabular}{|l|l}
9.36 \\
\end{tabular} & 0 & 0 & 4.93 & 2.28 & 0 \\
\hline$\underline{0}$ & 2.22 & \begin{tabular}{|l|l}
10.42 \\
\end{tabular} & 0 & 0 & 4.76 & \begin{tabular}{|l|}
2.3 \\
\end{tabular} & \\
\hline 0 & 2.22 & \begin{tabular}{|l|l}
11.29 \\
\end{tabular} & 0 & 0 & 4.73 & 2.29 & 0 \\
\hline 0 & 2.23 & 10.62 & 0 & 0 & 4.71 & 2.29 & \\
\hline 0 & 2.23 & 11.03 & 0 & 0 & 4.7 & 2.29 & 0 \\
\hline 0 & 22 & 8 & 0 & 0 & 4.59 & 2.07 & 0 \\
\hline
\end{tabular}

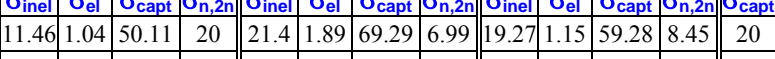
\begin{tabular}{|l|l|l|l|l|l|l|l|l|l|l|l|l|}
\hline 17.05 & 2.19 & 23.93 & 0 & 1.68 & 3.58 & 38.94 & 0 & 7.37 & 1.97 & 18.81 & 0 & 20 \\
\hline
\end{tabular} \begin{tabular}{|l|l|l|l|l|l|l|l|l|l|l|l|l|l|l|}
\hline 26.23 & 1.78 & 10.42 & 0 & 14.2 & 3.71 & 19.61 & 0 & 8.51 & 2 & 9.17 & 0 & 20 \\
\hline 17.7 & 1.55 & 5.68 & 0 & 163 & 0.93 & 11.04 & 0 & 12.64 & 5.6 & 6.48 & 0 & 20 \\
\hline
\end{tabular} \begin{tabular}{|l|l|l|l|l|l|l|l|l|l|l|l|l|}
\hline 17.71 & 1.55 & 5.68 & 0 & 16.37 & 5.93 & 11.04 & 0 & 12.64 & 5.6 & 6.48 & 0 & 20 \\
\hline
\end{tabular}

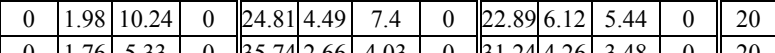
\begin{tabular}{|l|l|l|l|r|r|r|r|r|r|r|r|r|r|r|}
\hline 0 & 1.76 & 5.33 & 0 & 35.74 & 2.66 & 4.03 & 0 & 31.24 & 4.26 & 3.48 & 0 & 20 \\
\hline 0 & 2.49 & 5.48 & 0 & 0 & 3.1 & 3.99 & 0 & 0 & 2.92 & 3.7 & 0 & 20 \\
\hline 0
\end{tabular} \begin{tabular}{|l|l|l|l|l|l|l|l|l|l|l|l|l|l|l|}
\hline 0 & 2.49 & 5.48 & 0 & 0 & 3.1 & 3.99 & 0 & 0 & 2.92 & 3.7 & 0 & 20 \\
\hline 0 & 2.51 & 5.97 & 0 & 0 & 3.95 & 6.02 & 0 & 0 & 3.21 & 4.92 & 0 & 20 \\
\hline 0 & 0.9 & 5.25 & 0 & 0 & 4.65 & 7.35 & 0 & 0 & 3.94 & 6.97 & 0 & 20 \\
\hline
\end{tabular}

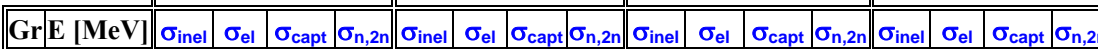

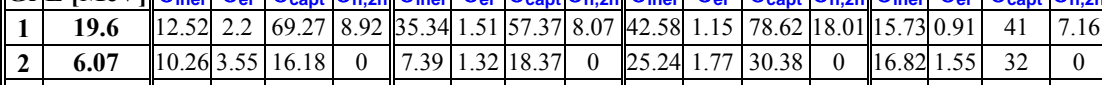

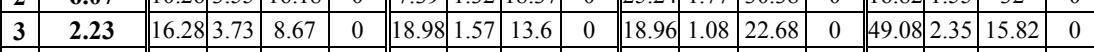

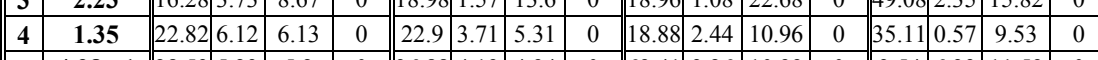

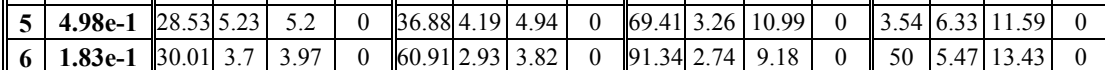
\begin{tabular}{|l|l|l|l|l|l|l|l|l|l||l|l|l|l|l|l|l|l|l}
$\mathbf{7}$ & $\mathbf{6 . 7 4 \mathrm { e } - 2}$ & 21.25 & 2.47 & 3.12 & 0 & 0 & 2.98 & 3.71 & 0 & 0 & 2.77 & 6.91 & 0 & 0 & 3.9 & 3.24 & 0 & \\
\hline
\end{tabular}

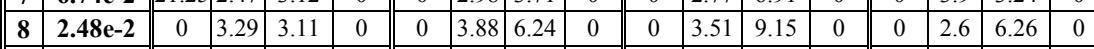

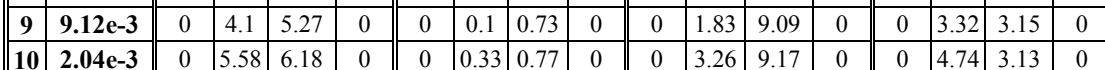
\begin{tabular}{|l|l||c|c|c|c|c|c|c|c|c|c|c|c|c|c|c|c|c|c}
\hline $\mathbf{1 0}$ & $\mathbf{2 . 0 4 e - 3}$ & 0 & 5.58 & 6.18 & 0 & 0 & 0.33 & 0.77 & 0 & 0 & 3.26 & 9.17 & 0 & 0 & 4.74 & 3.13 & 0 \\
$\mathbf{1 1}$ & $\mathbf{4 . 5 4 \mathrm { e } - 4}$ & 0 & 2.27 & 1.49 & 0 & 0 & 1.18 & 0.85 & 0 & 0 & 8.6 & 7.76 & 0 & 0 & 7.71 & 3.97 & 0 \\
\end{tabular}

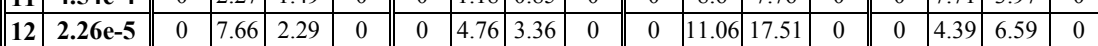

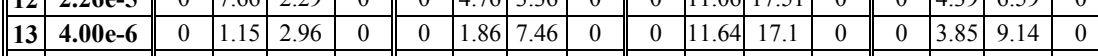

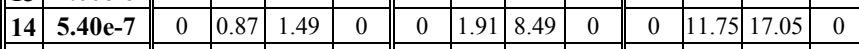
\begin{tabular}{|l|l|l|l|l|l|l|l|l|l||c|c|c|c|c|c|c|c|}
\hline 15 & $\mathbf{1 . 0 0}-7$ & 0 & 1.15 & 0.2 & 0 & 0 & 1.91 & 8.64 & 0 & 0 & 11.72 & 17.05 & 0 & 0 & 3.69 & 8.63 & 0 \\
\hline
\end{tabular} Er170

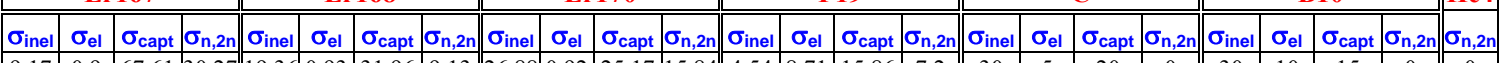

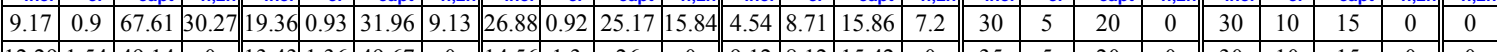
\begin{tabular}{|l|l|l|l|l|l|l|l|l|l|l|l|l|l|l|l|l|l|l|l|l|l|l|l|l|l|l|l|l|l|l|l|l|l|}
\hline 12.29 & 1.54 & 49.14 & 0 & 13.43 & 1.36 & 49.67 & 0 & 14.56 & 1.3 & 26 & 0 & 9.12 & 8.12 & 15.42 & 0 & 35 & 5 & 20 & 0 & 30 & 10 & 15 & 0 & 0 \\
\hline
\end{tabular} \begin{tabular}{|l|l|l|l|l|l|l|l|l|l|l|l|l|l|l|l|l|l|l|l|l|l|l|l||c||}
10.2 & 2.45 & 30.21 & 0 & 44.37 & 2.43 & 21.89 & 0 & 53.41 & 2.58 & 11.08 & 0 & 7.3 & 2.12 & 8.5 & 0 & 0 & 5 & 20 & 0 & 30 & 10 & 15 & 0 & 0 \\
\hline
\end{tabular} \begin{tabular}{|l|l|l|l|l|l|l|l|l|l|l|l||l|l|l|l|l||l|l|l|l|l|l|l|l|l||}
5.97 & 0.78 & 12.93 & 0 & 37.67 & 0.54 & 12.98 & 0 & 51.08 & 0.68 & 8.9 & 0 & 22.03 & 1.65 & 5.14 & 0 & 0 & 5 & 20 & 0 & 35 & 10 & 15 & 0 & 0 \\
\hline 4.22 & 6.65 & 9.33 & 0 & 7.28 & 5.96 & 14.97 & 0 & 19.18 & 5.62 & 7.47 & 0 & 15.88 & 1.02 & 6.13 & 0 & 0 & 5 & 20 & 0 & 0 & 10 & 15 & 0 & 0 \\
\hline
\end{tabular} \begin{tabular}{||c|c|c||c|c|c|c|c|c|c|c|c|c|c|c|c|c|c|c|c|c|c|c|c|c|c|c|c|c|c|}
4.22 & 6.65 & 9.33 & 0 & 7.28 & 5.96 & 14.97 & 0 & 19.18 & 5.62 & 7.47 & 0 & 15.88 & 1.02 & 6.13 & 0 & 0 & 5 & 20 & 0 & 0 & 10 & 15 & 0 & 0 \\
\hline 6.61 & 5.57 & 8.23 & 0 & 50 & 4.82 & 19.44 & 0 & 41.37 & 4.07 & 4.99 & 0 & 0 & 1.08 & 2 & 0 & 0 & 3 & 20 & 0 & 0 & 10 & 10 & 0 & 0 \\
\hline
\end{tabular} \begin{tabular}{|c|c|c||c|c|c|c|c|c|c|c|c|c|c|c|c|c|c|c|c|c|c|c|c|c|c|}
\hline & 3.82 & 3.92 & 0 & 0 & 3.09 & 9.74 & 0 & 0 & 7.65 & 6.22 & 0 & 0 & 0.97 & 2.89 & 0 & 0 & 3 & 20 & 0 & 0 & 10 & 10 & 0 & 0 \\
\hline
\end{tabular}

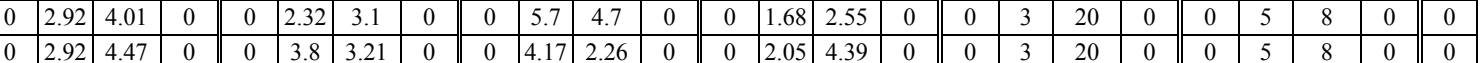
\begin{tabular}{|l|l|l|l||c|c|c|c||c|c|c|c|c|c|c|c|c||c|c|c|c||c|c|c|c||c|}
0 & 2.92 & 4.47 & 0 & 0 & 3.8 & 3.21 & 0 & 0 & 4.17 & 2.26 & 0 & 0 & 2.05 & 4.39 & 0 & 0 & 3 & 20 & 0 & 0 & 5 & 8 & 0 & 0 \\
\hline 0 & 5.12 & 2.81 & 0 & 0 & 5.34 & 6.15 & 0 & 0 & 4.82 & 3.38 & 0 & 0 & 2.05 & 6.05 & 0 & 0 & 3 & 20 & 0 & 0 & 5 & 5 & 0 & 0 \\
\hline 0 & 6.69 & 1.8 & 0 & 0 & 8.6 & 5.05 & 0 & 0 & 7.7 & 7.2 & 0 & 0 & 2.05 & 6.09 & 0 & 0 & 3 & 20 & 0 & 0 & 5 & 5 & 0 & 0 \\
\hline
\end{tabular}

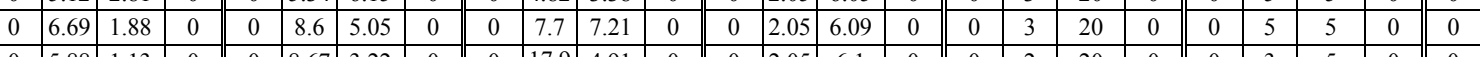

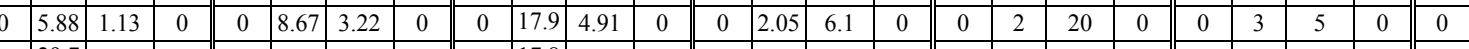
\begin{tabular}{|l|l|l|l|l|l|l|l||c|c|c|c||c|c|c|c||c|c|c|c||c|c|c|c||c|}
0 & 29.7 & 1.04 & 0 & 0 & 8.8 & 3.07 & 0 & 0 & 17.8 & 3.92 & 0 & 0 & 2.05 & 6.11 & 0 & 0 & 2 & 20 & 0 & 0 & 3 & 3 & 0 & 0 \\
\hline 0 & 9.57 & 1.02 & 0 & 0 & 8.83 & 3.05 & 0 & 0 & 17.8 & 3.7 & 0 & 0 & 2.05 & 6.11 & 0 & 0 & 1 & 2 & 0 & 0 & 2 & 1 & 0 & 0 \\
\hline
\end{tabular} \begin{tabular}{l|l|l|l|l|l|l|l|l|l|l|l|}
0 & 0.57 & 1.02 & 0 & 0 & 8.83 & 3.05 & 0 & 0 \\
\hline 0 & 57.6 & 1.2 & 0 & 0 & 8.65 & 2.8 & 0 & 0 \\
\hline
\end{tabular} 


\section{References}

1. G. Aliberti, G. Palmiotti, M. Salvatores, C. G. Stenberg, "Transmutation Dedicated Systems: An assessment of Nuclear Data Uncertainty Impact", Nucl. Sci. and Eng. 146, 13-50, (2004).

2. G. Aliberti, G. Palmiotti, M. Salvatores, T.K. Kim, T.A. Taiwo, M. Anitescu, I. Kodeli, E. Sartori, J.C. Bosq, J. Tommasi, "Nuclear Data Sensitivity, Uncertainty and Target Accuracy Assessment for Future Nuclear Systems", Ann. Nucl. Energy, 33, 700-733 (2006).

3. M. Salvatores, G. Aliberti, G. Palmiotti, D. Rochman, P. Oblozinsky, M. Hermann, P. Talou, T. Kawano, L. Leal, A. Koning, I. Kodeli, "Nuclear Data Needs for Advanced Reactor Systems. A NEA Nuclear Science Committee Initiative", ND2007, Nice (France), April 2007.

4. M. Salvatores, G. Aliberti and G. Palmiotti, "The Role of Differential and Integral Experiments to Meet Requirements for Improved Nuclear Data", ND2007, Nice (France), April 2007.

5. L.N. Usachev et al., Proc. Int. Conf. Neutron Physics and Other Applied Purposes, Harwell, September 2529, 1978, CONF-780921, p. 181, International Atomic Energy Agency (1978).

6. G. Palmiotti and M. Salvatores, "Use of Integral Experiments in the Assessment of Large Liquid-Metal Fast Breeder Reactor Basic Design Parameters". Nucl. Sci. Eng. 87, 333 (1984).

7. G. Palmiotti, R.F. Burstasll, E. Kiefhaber, W. Gebhardt, J.M. Rieunier, "New Methods Developments and Rationalization of Tools for LMFBR Design in the Frame of the European Collaboration", FR'91 International Conference on Fast Reactors and Related Fuel Cycles, Kyoto, Japan, October 28 - November 1,1991 .

8. G. Rimpault, et al., "The ERANOS Code and Data System for Fast Reactor Neutronic Analyses", Proc. PHYSOR 2002 Conference, Seoul (Korea), October 2002.

9. G. Palmiotti, J.M. Rieunier, C. Gho, M. Salvatores, "BISTRO Optimized Two Dimensional Sn Transport Code", Nucl. Sci. Eng., 104, 26 (1990).

10. G. Rimpault, "Algorithmic Features of the ECCO Cell Code for treating Heterogeneous Fast Reactor Assemblies", International Topical Meeting on Reactor Physics and Computation, Portland - Oregon, May $1-5,1995$.

11. OECD/NEA Report 17, “The JEF-2.2 Nuclear Data Library”, April 2000.

12. OECD/NEA Data Bank, JEFF Report 19, "The JEFF-3.0 Nuclear Data Library”,2005.

13.P.J. Finck, J.C. Cabrillat, M. Martini, R. Soule, G. Rimpault, R. Jacqmin, "The CIRANO Experimental Program in Support of Advanced Fast Reactor Physics", International Conference on the Physics of Reactors, PHYSOR 96, Mito, Japan, September 16-20, 1996.

14. G. Palmiotti, M. Salvatores, "Proposal for Nuclear Data Covariance Matrix”, JEFDOC 1063 Rev.1, January 2005.

15. Y. I. Chang, P. J. Finck, C. Grandy, “Advanced Burner Reactor Preconceptual Design Report”, ANL-ABR-1 (Argonne National Laboratory, September 2006).

16.NEA/NSC/DOC (95)03/I, II, VII September 2003.

17. C. Jammes, G. Perret and G. Imel, "First MUSE-4 Experimental Results Based on Time Series Analysis", International Conference PHYSOR 2002, Seoul, South Korea.

18. M. Salvatores, G. Aliberti, G. Palmiotti, "Nuclear Data Validation and Fast Reactor Design Performances Uncertainty Reduction", ANS meeting, Boston, MA (USA), June 007.

19. Takeda and A. Yoshimura, "Prediction Uncertainty Evaluation Method of Core Performance Parameters in Large Liquid Metal Fast Breeder Reactors", Nucl. Sci. Eng., 103,157 (1989).

20. T. Takeda et al. "Generalized Bias Factor Method for Accurate Prediction of Neutronics Characteristics", PHYSOR-2006, ANS Topical Meeting on Reactor Physics, Vancouver, BC, Canada, September 2006.

21. Y. Ronen et al, "Determination and Application of Generalized Bias Operators Using an Inverse Perturbation Approach”, Nucl. Sci. Eng., 77, 426 (1981).

22. A. Gandini, "Uncertainty Analysis and Experimental Data Transposition Methods" in Uncertainty Analysis, Y. Ronen Editor, CRC Press 1988.

23. A. Gandini, M. Petilli, "AMARA: A Code Using the Lagrange Multipliers Methods of Nuclear Data Adjustment”, RT/FI(73)39, Comitato Nazionale per l'Energia Nucleare (1973).

24. G. Palmiotti, G. Aliberti, M. Salvatores, J. Tommasi, "Integral Experiments Analysis for Validation and Improvement of Minor Actinide Data for Transmutation Needs", Int. Conf. on Nuclear Data, ND2004, Santa Fe', NM (USA), September 2004. 
25. G. Aliberti, G. Palmiotti, M. Salvatores, "New Covariance Data and their Impact on ADS Designs", AccApp2007, Pocatello, ID (USA), July-August, 2007.

26. D. Rochman, M. Herman, P. Oblozinsky, and S. F. Mughabghab, "Preliminary Cross-Section Covariances for WPEC Subgroup 26", Tech. Rep. BNL-77407-2007-IR (Brookhaven National Laboratory, 2007).

27. D. Rochman, M. Herman, P. Oblozinsky, and S. F. Mughabghab, "Preliminary nu-bar Covariances for 238; $242 \mathrm{Pu}$ and 242; 243; 244; 245Cm", Tech. Rep. BNL-77407-2007-IR-Suppl.1 (Brookhaven National Laboratory, 2007).

28. M. Chadwick, P. Oblozinsky, et al., "ENDF/B-VII.0: Next Generation Evaluated Nuclear Data Library for Nuclear Science and Technology", Nuclear Data Sheets, 107, pp. 2931 (December 2006).

29. S. F. Mughabghab, Atlas of Neutron Resonances: Resonance Parameters and Thermal Cross-Sections (Amsterdam: Elsevier, 2006).

30. M. Herman, R. Capote, B. Carlson, P. Oblozinsky, M. Sin, A. Trkov, and V. Zerkin, "EMPIRE Nuclear Reaction Model Code", version 2.19 (Lodi). www.nndc.bnl.gov/empire219/ (March 2005).

31. T. Kawano Tech. Rep. JAERI-Research 99-009, (JAERI, 1999).

32. N. M. Larson, “Updated Users' Guide for SAMMY: Multilevel R-Matrix Fits to Neutron Data Using Bayes' Equations", ORNL/TM-9179/R7 (2007).

33. L. Leal, H. Derrien, N. Larson, G. Arbanas, and Royce Sayer, "ORNL Methodology for Covariance Generation for Sensitivity/Uncertainty Analysis", International Conference on Nuclear Criticality Safety (St. Petersburg, Russia, May 2007).

34. A.J. Koning, "Generating Covariance Data with Nuclear Models", in Proceedings of the International Workshop on Nuclear data Needs for Generation IV Nuclear energy systems (Antwerpen, April 5-7, 2005), ed. P. Rullhusen, World Scientific (2006), p. 153.

35. A.J. Koning, S. Hilaire and M.C. Duijvestijn, "TALYS: Comprehensive Nuclear Reaction Modeling", in Proceedings of the International Conference on Nuclear Data for Science and Technology - ND2004, AIP vol. 769, eds. R.C. Haight, M.B. Chadwick, T. Kawano, and P. Talou, (Santa Fe, USA, Sep. 26 - Oct. 1, 2004), p. 1154 (2005).

36. P.E. Gill, W. Murray and M.A. Saunders, "SNOPT: An SQP algorithm for Large-Scale constrained programming", Technical Report SOL 97-3, Systems Optimization Laboratory, Department of Operations Research, Stanford University, Stanford, California 94305-4022, 1997. 


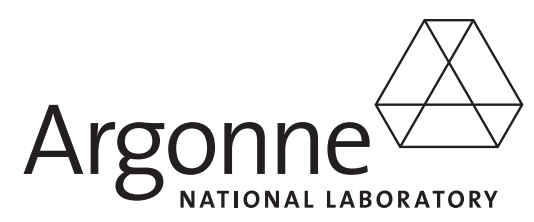

Nuclear Engineering Division

Argonne National Laboratory

9700 South Cass Avenue, Bldg. 208

Argonne, IL 60439-4842

www.anl.gov 